\title{
Determination of "Hoffmann Analytes" in Cigarette Mainstream Smoke. The Coresta 2006 Joint Experiment
}

\author{
by \\ Michael Intorp ${ }^{l}$, Steve Purkis ${ }^{2}$, Martin Whittaker ${ }^{3}$, and Wendy Wright ${ }^{4}$ \\ ${ }^{1}$ Imperial Tobacco Limited,P.O. Box 525, Southville, Bristol BS99 1LQ, UK \\ ${ }^{2}$ Imperial Tobacco Limited,P.O. Box 525, Southville, Bristol BS99 1LQ, UK \\ ${ }^{3}$ Statistical Consultant, 2 Station Road, Bristol BS48 4PD, UK \\ ${ }^{4}$ Labstat Inc, 262 Manitou Drive, Kitchener, Ontario N2C1L3, Canada
}

\section{SUMMARY}

Regulatory authorities are currently discussing the measurement of and imposition of ceilings on certain smoke analytes, the so called "Hoffmann analytes". However, as a prerequisite, the measurement methods and the tolerances around the measurements first need to be established.

In 1999, the Cooperation Centre for Scientific Research Relative to Tobacco (CORESTA) set up a Task Force "Special Analytes" to deal with analytical methodology for measuring "Hoffmann analytes" under International Standard (ISO) smoking and to work towards the standardisation of methods. This paper describes the output and conclusions from a 2005-2006 joint experiment made within the Task Force representing laboratories currently able to analyse these compounds. Data were obtained on most "Hoffmann analytes" from reference cigarettes (2R4F and 1R5F), collecting data according to the existing methods used by the nineteen participating laboratories, in order to describe the within and among laboratory variability and to see which methods could most benefit from more rigorous standardisation work.

In some cases, the applied statistical analysis found that methods could not well differentiate the $1 \mathrm{R} 5 \mathrm{~F}$ and $2 \mathrm{R} 4 \mathrm{~F}$ cigarettes of differing 'tar' yield. This was explained, in part, by the broad range of methods used by the participating laboratories but also indicated that there were significant inadequacies in the choice of some methods or weaknesses in their application.

Results indicate that "Hoffmann Analyte" data are generally more variable both within and among laboratories than nicotine free dry particulate matter (NFDPM); nicotine and carbon monoxide due to their lower smoke yields. Accordingly, tolerances around methods adopted for regulatory purposes will need to be proportionately higher.
Methods for benzo $[a]$ pyrene $(\mathrm{B}[a] \mathrm{P})$ and tobacco-specific nitrosamines (TSNAs), already taken to CORESTA recommended methods or ISO standardised methods through the efforts of this Task Force, give some of the most reproducible results, showing the value of this process. However, these data strongly suggest that even these analytes have much higher among-laboratory variability than for NFDPM, nicotine and $\mathrm{CO}$ and, based on the only two available one point in time studies, may need tolerances in the range of $35-45 \%$ for $\mathrm{B}[a] \mathrm{P}$ and $26-55 \%$ for TSNAs, if they are to be measured for regulatory purposes.

The collected data is useful to participating laboratories for internal method validation and laboratory accreditation, and data comparisons with others allow laboratories to identify strengths and weaknesses in their current methods.

However, much work still needs to be carried out to take most of the methods towards standardisation. Although some fundamental differences or areas of concern around the methodology are discussed herein, they are not comprehensive and there may be others that need to be addressed before methods can be considered ready to take to a Recommended Method and/or to an ISO Standard. These methodological issues are being addressed in further CORESTA work within this Task Force. Smoke analytes with the highest variability found in this study and those analytes that are currently of highest regulatory interest are being prioritised and after further joint experiments, the results are intended to be published. [Beitr. Tabakforsch. Int. 24 (2009) 161-202]

\section{ZUSAMMENFASSUNG}

In einigen Staaten werden von Seiten der Überwachungsbehörden seit einiger Zeit die Messung und damit ver- 
bunden Höchstmengen für eine Gruppe von Substanzen, den so genannten Hoffmann-Analyten (HA), die im Hauptstromrauch von Zigaretten enthalten sind, diskutiert. Aus diesem Grund ist eine Überprüfung der zur Zeit genutzten Analysemethoden zur Bestimmung der HA wie auch die damit verbundenen Messtoleranzen dringend angeraten. Seit 1999 befaßt sich die Arbeitsgruppe der CORESTA „Special Analytes” mit der Entwicklung von standardisierten Methoden zur Messung der HA unter den Abrauchbedingungen der Internationalen Organisation für Normung (ISO). Die vorliegende Arbeit beschreibt die Ergebnisse einer Studie, die von November 2005 bis Juni 2006 innerhalb dieser Arbeitsgruppe durchgeführt wurde und umfasst die Bestimmung von 34 der $40 \mathrm{HA}$ an den zwei Referenzcigaretten Kentucky 2R4F und Kentucky 1R5F. Daten von 19 Labors wurden ausgewertet, wobei jedes Labor seine eigene Methode zur Bestimmung der HA verwendete. Mit Hilfe der Studie sollte die Variabilität innerhalb und zwischen den Laboratorien untersucht werden und weiterhin die Frage, ob auf der Basis des jeweils angewandten Analyseverfahrens ein statistisch gesicherter Unterschied zwischen den Referenzzigaretten ermittelt werden kann.

Die Ergebnisse der Studie zeigten, dass für die gemessenen HA die Daten sowohl innerhalb der Labors als auch zwischen den Labors generell stärker streuen als Messdaten, die für nikotinfreies Trockenkondensat (NFDPM), Nikotin oder Kohlenmonoxid (CO) bestimmt werden. Sollten Höchstmengen für diese Analyten von Seiten der staatlichen Überwachung erwogen werden, sind entsprechende Toleranzen zu berücksichtigen.

Bei der Auswertung der Ergebnisse zeigte sich weiterhin, dass für die Methoden zur Bestimmung von Benz $[a]$ pyren $(\mathrm{B}[a] \mathrm{P})$ und den tabakspezifischen Nitrosaminen (TSNA) die besten Reproduzierbarkeiten ermittelt werden konnten, was sicherlich auf die schon durch ISO vorgenommene Standardisierung dieser Methoden zurückzuführen ist.

Dennoch liegen auch für diese Methoden die Varianzen zwischen den Labors wesentlich höher als die Varianzen für NFDPM, Nikotin oder CO. Dieses Ergebnis wird durch verschiedene CORESTA Ringversuche bestätigt. Für B[a]P wurden dabei Toleranzbereiche von $\pm 45 \%$ bzw. $\pm 35 \%$ bei der Referenzzigarette $2 \mathrm{R} 4 \mathrm{~F}$ ermittelt, während für die vier TSNAs die Toleranzen zwischen $\pm 26 \%$ und $55 \%$ liegen. Die beteiligten Labors können die Daten aus der Studie sowohl zur Methodenvalidierung nutzen als auch zur Bewertung von Stärken oder Schwächen ihrer derzeit verwendeten Methoden heranziehen.

Um die verschiedenen Methoden für die Hoffmann-Analyten zu standardisieren, bedarf es sicherlich noch einiger Anstrengungen. In der Auswertung der Studie wurden u.a. die Aspekte der methodischen Unterschiede näher beleuchtet und diskutiert. Dennoch konnten nicht alle Gesichtspunkte der einzelnen individuellen Methoden in dieser Studie umfassend behandelt werden, so dass man davon ausgehen kann, dass der Weg zur Erstellung einer CORESTA „Recommended Method” oder einer ISO Methode noch weiterer Arbeit bedarf. Rauchanalyten mit der höchsten Variabilität und solche, die gegenwärtig von hohem regulativen Interesse sind, sollten in zukünftiger Arbeit vorrangig behandelt werden. [Beitr. Tabakforsch. Int. 23 (2009) 161-202]

\section{RESUME}

Les autorités de normalisation discutent actuellement de la mesure et de l'imposition des plafonds sur certaines analytes de la fumée, connues comme " la liste Hoffmann ». Cependant, ce qui constitue une condition préalable, les méthodes de mesure et les tolérances des mesures doivent être établies.

En 1999, le Centre de Coopération pour les Recherches Scientifiques Relatives au Tabac (CORESTA) a installé un groupe de travail pour examiner la méthodologie analytique pour la mesure des composants de tabac de la liste Hoffmann, selon le régime de fumage de l'ISO avec le but d'une normalisation des méthodes. Cet article décrit les résultats et les conclusions d'une étude effectuée dans les années 2005 à 2006 par le groupe de travail, représentant des laboratoires actuellement capable d'analyser ces composants.

Les dix-neuf laboratoires qui ont participé à l'étude ont mesuré les teneurs de 34 des 40 analytes de la « liste Hoffmann » dans les cigarettes de référence $2 \mathrm{R} 4 \mathrm{~F}$ et $1 \mathrm{R} 5 \mathrm{~F}$, selon les méthodes généralement utilisées. Le but de l'étude était de savoir si les différentes méthodes d'analyses permettent de faire une différentiation statistique entre les cigarettes $1 \mathrm{R} 5 \mathrm{~F}$ et $2 \mathrm{R} 4 \mathrm{~F}$.

Les résultats indiquent que les données obtenues des analytes de la « liste Hoffmann » sont généralement plus variables inter- et intra-laboratoire que le goudron, la nicotine et l'oxyde de carbone à cause de leur rendement plus bas de la fumée. En conséquence, si les rendements de ces composants dans la fumée devraient être plafonnés en vue d'une normalisation, les marges de tolérances devraient être plus variable.

L'examination des résultats de l'étude montre également, que les méthodes d'analyse pour le benzo[a]pyrene $(\mathrm{B}[a] \mathrm{P})$ et les nitrosamines spécifiques du tabac (TSNAs), pour lesquelles des méthodes normalisées ont déjà été élaborées, permettent d'obtenir des résultats les plus reproductibles.

Cependant, ces données indiquent fortement que la variabilité inter-laboratoire $(r)$ soit beaucoup plus haute pour $\mathrm{B} a \mathrm{P}$ et TSNAs que pour goudron, nicotine et CO. Basé sur les seules deux études ponctuelles disponibles, les indications sont que les valeurs de tolérance de $\mathrm{BaP}$ même pour la cigarette $2 \mathrm{R} 4 \mathrm{~F}$ à plus haut rendement devraient être au moins en moyenne le $\pm 35 \%$ des 2003 données de collaboration de CORESTA et en moyenne le $\pm 45 \%$ de l'étude courante. De même, pour quatre TSNAs individuels, les tolérances devraient être au moins dans la gamme moyenne de \pm 35 à $55 \%$ des 2005 données de collaboration de CORESTA et le \pm moyen 26 à $42 \%$ de l'étude courante. Les données rassemblées sont utiles aux laboratoires participants pour la validation interne de la méthode et les comparaisons de buts et de données d'accréditation avec d'autres permettent à des laboratoires d'identifier les points de force et de faiblesse dans leurs méthodes courantes.

Beaucoup de travail doit encore être accomplit pour avancer la plupart des diverses méthodes vers la normalisation. Bien que quelques différences ou soucis fondamentaux à l'égard de la méthodologie soient discutés ci-dessus, elles ne sont pas complètes et il peut y en avoir 
d'autres qui doivent être adressées avant que les méthodes puissent être considérées au niveau de méthode recommandée et/ou de norme de l'OIN. [Beitr. Tabakforsch. Int. 23 (2009) 161-202]

\section{PARTICIPATING LABORATORIES}

The authors wish to acknowledge the excellent contributions of each principal investigator without which this work would not have been completed.

Participating laboratories Principal investigators and Institutions

\begin{tabular}{|c|c|}
\hline Altadis (France) & Valerie Troude \\
\hline Arista (USA) & $\begin{array}{l}\text { Richard Higby, Alexandra } \\
\text { Martin, Brad Norwood }\end{array}$ \\
\hline Arista Europe (UK) & $\begin{array}{l}\text { Tatiana Humphries, Helen } \\
\text { Taylor }\end{array}$ \\
\hline British American & Helen Backshell, Claire \\
\hline Tobacco (UK) & Ranby, Tina Mead \\
\hline CNTC Beijing (China) & Jun Zhou \\
\hline $\begin{array}{l}\text { CNTC ZhengZhou } \\
\text { (China) }\end{array}$ & Fuwei Xie, Hongwei Hou \\
\hline $\begin{array}{l}\text { Filtrona Technology } \\
\text { Centre (UK) }\end{array}$ & Joanne Walker \\
\hline $\begin{array}{l}\text { Imperial Tobacco Group } \\
\text { (Germany) }\end{array}$ & $\begin{array}{l}\text { Michael Intorp (Task Force } \\
\text { Chairman), } \\
\text { Steve Purkis (Task Force } \\
\text { Secretary) }\end{array}$ \\
\hline Japan Tobacco (Japan) & Takatsugu Hyodo \\
\hline $\begin{array}{l}\text { Japan Tobacco } \\
\text { International (Germany) }\end{array}$ & $\begin{array}{l}\text { Thomas Schmidt, Stefan } \\
\text { Mittermüller }\end{array}$ \\
\hline Philip Morris (Germany) & $\begin{array}{l}\text { Joerg Diekmann, Klaus } \\
\text { Rustemeier }\end{array}$ \\
\hline $\begin{array}{l}\text { Philip Morris } \\
\text { (Switzerland) }\end{array}$ & Michel Rotach \\
\hline $\begin{array}{l}\text { Austria Tabak / Gallaher } \\
\text { (Austria) }\end{array}$ & Jutta Müller \\
\hline $\begin{array}{l}\text { Food Consumer Product } \\
\text { Safety (Netherlands) }\end{array}$ & Walther Klerx \\
\hline Labstat (Canada) & $\begin{array}{l}\text { Mehran Sharifi, Pete Joza, } \\
\text { Wendy Wright (statistical } \\
\text { interpretation) }\end{array}$ \\
\hline KT\&G (Korea) & Hyo-Keun Kim \\
\hline Reynolds Tobacco (USA) & Linda Crumpler \\
\hline $\begin{array}{l}\text { Rothmans Benson and } \\
\text { Hedges (Canada) }\end{array}$ & $\begin{array}{l}\text { Jennifer DeGraaf, Ian } \\
\text { Jenkins }\end{array}$ \\
\hline Sampoerna (Indonesia) & $\begin{array}{l}\text { Bimo Haryo Progo, } \\
\text { Mochammad Sholichin }\end{array}$ \\
\hline $\begin{array}{l}\text { Verband der Cigaretten- } \\
\text { industrie, (Germany) }\end{array}$ & $\begin{array}{l}\text { Wolf-Dieter Heller } \\
\text { (statistical advice) }\end{array}$ \\
\hline Consultant & $\begin{array}{l}\text { Martin Whittaker (statistical } \\
\text { interpretation) }\end{array}$ \\
\hline
\end{tabular}

\section{INTRODUCTION}

Certain smoke constituents have been measured for many years in 'one point in time' studies and such data have been described, for example, in UK Governmental sponsored reports in the 1980s and 1990s (1-4). More recently, Health Canada have mandated the measurement of 44 smoke emissions, the so-called "Hoffmann analytes", on an annual basis, for brands sold in Canada using methods posted on their website (5). The term "Hoffmann analytes" has been adopted by many industry and regulatory scientists as an acknowledgement of the work carried out by Dietrich Hoffmann and co-workers at the American Health Foundation. He identified, catalogued and published lists of biologically active substances in cigarette smoke, for example, as given in the reference (6).

Various 'one point in time' benchmark studies have also been requested by regulatory authorities (7-10) to compare commercial products in a specific market. There are also a limited number of small-scale within- and amonglaboratory studies on "Hoffmann analytes" that can also be found in the literature describing both short-term and longterm variability (11-15) within reference or commercial cigarettes.

Recently, TobReg (16), a part of the World Health Organisation, have been discussing the regular measurement of certain analytes on a global basis and proposals for the imposition of ceilings on certain analytes on a per milligram 'tar' or per milligram smoke nicotine basis. However, the measurement methods and the tolerances around the measurements first need to be established within a rigorous standardisation process before this is practically feasible.

In 1999, CORESTA responded to the greater interest in "Hoffmann analytes" in the regulatory environment by working to standardise the methods for the measurement of benzo[apyrene $(\mathrm{B}[a] \mathrm{P})$ and tobacco-specific nitrosamines (TSNAs). These analytes were chosen as a priority because of assumed regulatory interest and also because it was felt that their analytical methods would be reasonably straightforward to take to standardisation. However, this work took a considerably longer time than expected in order to achieve reasonable agreement in yields across all the participating laboratories when applying the same methodology. It was also taken into consideration, when the standard methodology was chosen, that the instrumentation should be available to most competent laboratories without incurring prohibitive costs. The recommended CORESTA methods are now available for $\mathrm{B}[a] \mathrm{P}$ and TSNAs (17-18) and $\mathrm{B}[a] \mathrm{P}$ has gone through the ISO standardisation process (19).

Although it is clear that the learning that has been achieved during these standardisation processes can be applied to other analytes, CORESTA felt that in the light of the probable length of time taken to bring further methods forward to Recommended Methods and/or to ISO standardisation it would be more useful to approach the issue in the manner described below as an initial step before embarking on further method standardisation.

It was agreed by CORESTA in 2005 that a broad survey of methodology used by participating laboratories should be undertaken and that data should be compared on a range of "Hoffmann analyte" smoke constituents obtained from 
reference cigarettes according to existing methods used by participants. The objective of this joint experiment was to describe the within- and among-laboratory variability across a large number of "Hoffmann analytes" in order to see which methods already gave comparable data and were thus more suitable to proceed towards standardisation and which methods would most benefit from rigorous investigative work before embarking on standardisation. This work was carried out in laboratories with current expertise in these analytes.

Although it was recognised that a more intense regime may be introduced into the regulatory arena in the future (16), it was decided that the current ISO smoking regime (20) should be used in this joint experiment.

This paper describes the output from this joint experiment. Although some fundamental differences or areas of concern around the methodology are discussed herein, they are not comprehensive and there will be others that need to be addressed before methods can be considered ready to take to a Recommended Method and/or to an ISO Standard. These issues are being addressed in further work of the Task force.

\section{EXPERIMENTAL}

\section{Overview of the protocol}

The following work was organized within the CORESTA Special Analytes Task Force in the 2006 Joint Experiment. Proficiency testing using, for example, the Food Analysis Performance Assessment Scheme (FAPAS) allows participating laboratories to use their own methodologies for testing a reference material. This approach seemed inappropriate for cigarette smoke methods where the reference material was smoke and for smoke analytes that were generated in situ. Therefore, it was decided to obtain guidance from statistical experts on an appropriate experimental design and protocol for this joint experiment. The term "Hoffmann analytes" has been used to describe the list of smoke components that Health Canada has mandated for annual testing on Canadian cigarette brands. The chosen "Hoffmann analytes" for this study were ammonia, four aromatic amines, $\mathrm{B}[a] \mathrm{P}$, eight carbonyls, hydrogen cyanide (HCN), nitric oxide (NO), four tobaccospecific nitrosamines (TSNAs), three semi-volatiles, seven phenols and five selected volatiles ${ }^{\mathrm{a}}$. These are described in more detail in Appendix 1.

Toxic metals were omitted from the study because few laboratories were set up to carry out these analyses and even those that could undertake the analyses often found levels below the limits of quantification for many of the metals. The participants also decided, rightly or wrongly in hindsight, that it was inappropriate to include NFDPM, nicotine and $\mathrm{CO}$ in this study as these are covered within other CORESTA working groups.

\footnotetext{
a Some of the "Hoffmann analytes" on the Canadian smoke emissions list have never or have not been consistently listed as important biologically active smoke constituents by DIETRICH HOFFMANN (6). For example, the following compounds are not included in the given reference e.g., 1-aminonaphthalene, 3-aminobiphenyl, propionaldehyde, butyraldehyde, MEK, acetone hydroquinone, resorcinol and the three cresols It should be noted that $m$-cresol and $p$-cresol are measured together and given as a combined yield in this and many other studies.
}

A draft protocol was agreed with the objective to describe the variability of "Hoffmann analytes" as analysed over a range of laboratories. Each laboratory was requested to use its own in-house methods and agreed to share their methodologies. There was no rule given that the laboratories either had to have a certain level of accreditation or any other auditing of their methodology and suitability to partake in the study.

The 2R4F and 1R5F Kentucky reference cigarettes were the products chosen for testing and were sourced from a single batch isolated by the University of Kentucky to try to minimise product variability. Five replicates for each analyte in three independent experiments were required, providing a total of 15 results for each analyte. Participants were asked to follow the given smoking plans for rotary and linear machines.

It was requested that the five replicates should be run over one or two consecutive days and the three experiments should be run with a minimum of one week or longer in between each experiment. A full description of the protocol is given in Appendix 1.

An excellent response was given to this work by participants and results were obtained from 19 laboratories. The numbers of data sets received from laboratories, for individual analytes, ranged from 12 to 18 for the $2 \mathrm{R} 4 \mathrm{~F}$ cigarette and from 9 to 16 for the 1R5F cigarette. Some laboratories found levels below their limits of quantification when analysing $1 \mathrm{R} 5 \mathrm{~F}$ and so the number of data sets available for further analysis on the $1 \mathrm{R} 5 \mathrm{~F}$ cigarette is lower than for the $2 \mathrm{R} 4 \mathrm{~F}$ cigarette.

\section{Overview of data}

Some weight data was provided by 16 laboratories. The $1 \mathrm{R} 5 \mathrm{~F}$ cigarette had a mean weight of $0.845 \mathrm{~g}$ and the $2 \mathrm{R} 4 \mathrm{~F}$ cigarette had a mean weight of $1.058 \mathrm{~g}$ after standard ISO conditioning (21). For each cigarette type, the coefficient of variation $(\mathrm{CoV})$ in measured mean weights across these laboratories was only $2 \%$ indicating that for this parameter at least, the product was fairly uniform.

Over 18,000 data points were obtained across all analytes. Mean values for each analyte were obtained across all laboratories and are shown in Appendices 2 and 3 for the 2R4F and 1R5F cigarette types respectively.

From analysis of these results, Appendices 4 and 5 show mean data for each analyte across all laboratories for each cigarette type along with standard deviations (SDs), CoVs, maximum (Max) and minimum (Min) mean values from participating laboratories, the ratio of maximum to minimum ( $\mathrm{max} / \mathrm{min})$ values and the number of data sets for both $2 \mathrm{R} 4 \mathrm{~F}$ and $1 \mathrm{R} 5 \mathrm{~F}$. This information gives an overview of all collected data prior to any data removal.

It can be observed from CoV values in Appendix 4 that for $2 \mathrm{R} 4 \mathrm{~F}$ cigarettes, the least variable data was observed for catechol and $\mathrm{N}$-nitroso-nornicotine (NNN) whereas the most variable data was observed for quinoline and resorcinol possibly because these were being measured near to their limits of quantification (LOQ). The most extreme differences between the laboratory means were seen for acrolein, toluene, pyridine and styrene (from $\mathrm{max} / \mathrm{min}$ data). This might be caused by methodological problems, poor calibration, or data transcription problems 
at the laboratory before results were sent for statistical analysis. In some cases, a high or low value resulted from just one laboratory performing markedly differently than the rest, creating a false impression of higher variability. For 1R5F, the least variable data was seen for catechol and acetaldehyde and the most variable data seen for pyridine and formaldehyde as depicted in Appendix 5. The most extreme differences (max/min) were found for 1naphthylamine, toluene, pyridine and styrene, again this might have been due to methodological or data transcription problems.

\section{Statistical analysis}

The statistical functions ' $r$ ' and ' $R$ ' are properly applied within collaborative studies using the same methodology across all laboratories to provide estimates of the repeatability within-laboratory and the reproducibility among-laboratories respectively. However, data in this joint experiment was obtained at one point in time by laboratories each using their own chosen method.

Data analysis in this report cannot provide estimates of reproducibility and repeatability. However, an analysis was carried out to describe statistically the within-laboratory variability of analytes, to identify analytes that give similar average yields irrespective of the laboratory method used, and to describe those analytes which show a higher variability among laboratories thereby indicating those methods that are less specific or in greater need of standardisation.

An attempt was also made to identify any inherent parameters in the methodology that might lead to marked yield differences among laboratories (i.e. effects of smoking machines and number of cigarettes per replicate). Evaluations were made by the various statisticians, based on ISO Standard 5725 (22), and the differences in their approaches are set out in Appendix 7.

Data removal: It was agreed that it would be difficult to make a judgement on whether any particular data were really outliers and so it was decided that all data should be retained wherever possible. However, certain data were removed on the following basis.

a) Analytes where fewer than 10 results of the possible 15 were obtained from a laboratory. This ensured that each laboratory's mean was based on data from at least two experiments to give reasonable precision.

b) Some data had certain irregularities or did not strictly follow protocol. For example, laboratory 11 was excluded because it did not separate out its data into the three different experiments required in the protocol.

c) Some $1 \mathrm{R} 5 \mathrm{~F}$ datasets were reported with all values less than the LOQ and so the $2 \mathrm{R} 4 \mathrm{~F}$ values had to be excluded for these datasets when doing certain comparisons between $2 \mathrm{R} 4 \mathrm{~F}$ and $1 \mathrm{R} 5 \mathrm{~F}$ (see below).

Details of the data removed prior to statistical analysis are shown in Appendix 6.

Within-laboratory variability: The statistical analysis estimated within-laboratory variability values $(r)$ among replicates and experiments found within the various participating laboratories. Although it used the same statistical equations, this approach could not properly estimate repeatability within-laboratory because each laboratory did not use a standardised methodology. The equations defining $r$ and its $\mathrm{CoV}$, and $r$ values obtained for both the 1R5F and $2 \mathrm{R} 4 \mathrm{~F}$ for each of the studied analytes are given in Appendix 7 and are based on statistical equations described in ISO 5725 (22).

From Appendix 8 it was observed that $\mathrm{CoV}(r)$ values were generally lower for $2 \mathrm{R} 4 \mathrm{~F}$ than for $1 \mathrm{R} 5 \mathrm{~F}$ across all analytes and that $\mathrm{CoV}(r)$ was generally higher for "Hoffmann analytes" than for nicotine free dry particulate matter (NFDPM). There was no statistical evidence in this study that compounds measured in $\mu \mathrm{g} / \mathrm{cig}$ were any less variable within-laboratories than those in ng/cig.

Typical data on NFDPM variability are included in Appendix 8 for comparative purposes and are taken from another recent CORESTA study (23). As expected, the value for within-laboratory variability for NFDPM was lower than for most of the 35 "Hoffmann analytes" under study.

Among-laboratory variability: Similarly, the statistical analysis used the same method to estimate among-laboratory variability values $(R)$ as used to more properly estimate reproducibility among-laboratory in collaborative studies using the same methodology across laboratories. Although it used the same statistical equations, this approach could not properly estimate reproducibility among-laboratory because each laboratory did not use a standardised methodology. The equations defining $R$ and its $\mathrm{CoV}$ and $R$ values obtained for both the $1 \mathrm{R} 5 \mathrm{~F}$ and $2 \mathrm{R} 4 \mathrm{~F}$ for each of the studied analytes are given in Appendix 7 and are based on ISO 5725 (22).

From Appendix 9, it was observed that among-laboratory variability is higher for $1 \mathrm{R} 5 \mathrm{~F}$ than $2 \mathrm{R} 4 \mathrm{~F}$ but these differences were not as distinct as those in Appendix 8 depicting within-laboratory variability. It was also observed that $\mathrm{CoV}$ $(R)$ values were much higher for the 35 "Hoffmann analytes" under study than for NFDPM derived from the previous CORESTA study (23) using the ISO standardised smoking method (20).

Well established tolerance values within $95 \%$ confidence limits are given in ISO 8243 (24) for NFDPM, nicotine and carbon monoxide when measuring over a period of time and at one point-in-time. Differences in yield measurements up to the tolerance values can be expected from any two laboratories on similar samples. These tolerances are $\pm 15 \%$ (period of time) and $\pm 20 \%$ (point of time) for NFDPM and nicotine and $\pm 20 \%$ (period of time) and $\pm 25 \%$ (point of time) for carbon monoxide. For lower yielding products these tolerance figures are transformed to absolute numbers for minimum tolerances, that is $\pm 1.0 \mathrm{mg}$ for NFDPM, $\pm 0.1 \mathrm{mg}$ for nicotine and $\pm 1.5 \mathrm{mg}$ for carbon monoxide.

It was therefore not unexpected that some very high values for $\% \mathrm{CoV}$ were noted for the low yielding analytes (Appendix 10) particularly for the 1R5F cigarette when comparing data among-laboratory. This is in contrast to findings for the within-laboratory variability.

Differentiation between $2 R 4 F$ and $1 R 5 F$ reference cigarettes: It is clear that all the "Hoffmann analytes" will need to be standardised if they are to be used for regulatory 
purposes. However, as a first step, one of the main objectives of this study was to identify which analytes give similar results irrespective of the laboratory method used, and those analytes which show a higher variability among laboratories thereby highlighting the greater need for a more detailed evaluation before they progress to full standardisation.

The assessment of both the method stability and the expertise applied in the different laboratories used in this study is based on the similarity / dissimilarity of the data among laboratories. The statistical analysis of the effectiveness with which the array of laboratory methods used in the study for each analyte was able to differentiate between the $1 \mathrm{R} 5 \mathrm{~F}$ and $2 \mathrm{R} 4 \mathrm{~F}$ cigarettes is the means that was used to reach this objective. The statistical assessment is made on the basis that each of the two reference cigarettes would be tested by two different laboratories, together with the assumptions that each analyte is roughly correlated with NFDPM for these two reference cigarettes. Here, it is noted that on the NFDPM scale these two samples are distinctly different, with average yields of approximately 1.7 and $9 \mathrm{mg} /$ cigarette, respectively.

Figures 1-11 show the ability to discriminate between the two types of cigarette (1R5F and 2R4F). This is given as an estimate of the within laboratory variability $(r)$ on the left side of the graphs and as an estimate of the among laboratory variability $(R)$ on the right side of the graphs. If data for the $r$ intervals is shown to overlap then it is not possible to discriminate even within at least one of the laboratories between these two cigarettes. However, most of the laboratories could differentiate between the two cigarette types in this way as also shown in Appendix 11.

$1 \mathrm{R} 5 \mathrm{~F}$ yields of certain analytes may be measured at high levels in one laboratory and these yields may be in the same yield range as relatively low $2 \mathrm{R} 4 \mathrm{~F}$ yields measured in another laboratory. This leads to overlapping $R$ values from which it can be concluded that the methods applied in at least two laboratories cannot differentiate between 1R5F and $2 \mathrm{R} 4 \mathrm{~F}$. A summary of the statistical approach used is given in more detail in Appendix 11. A summary of the extent to which each analyte was able to distinguish between $1 \mathrm{R} 5 \mathrm{~F}$ and $2 \mathrm{R} 4 \mathrm{~F}$ cigarettes is illustrated graphically in Appendix 12. The vertical axis defines the smallest difference between the mean yields for $2 \mathrm{R} 4 \mathrm{~F}$ and $1 \mathrm{R} 5 \mathrm{~F}$ (samples A and B) that can be differentiated, with $95 \%$ confidence, when each sample has been tested by separate laboratories. Axes have been normalised to $\% \mathrm{CoV}$ of $R$ (Mean 2R4F - 1R5F) to allow plots of all analytes on one graph.

Points on the $y$-axis which are $\leq 100$ indicate that for these analytes it would be possible to differentiate, with $95 \%$ confidence, between $1 \mathrm{R} 5 \mathrm{~F}$ and $2 \mathrm{R} 4 \mathrm{~F}$ cigarettes among laboratories using their current methods. However, there is still a variability around the data and there is still a need for rigorous method standardisation.

For analytes where the points on the $y$-axis are $\geq 100$, it would not be possible to differentiate between $1 \mathrm{R} 5 \mathrm{~F}$ and 2R4F cigarettes using their current methods. For 9 of the 34 analytes there would appear to be a greater need to investigate in the most detail some of the factors involved in this variability before moving on to standardise a method and also to obtain proper repeatability and reproducibility data in properly conducted collaborative studies.
- $\mathrm{B}[a] \mathrm{P}$ and the TSNAs, which have recently been subjected to laboratory method standardisation, gave some of the best yield differentiation. All individual phenolics, also gave good differentiation, except resorcinol.

- Carbonyls, HCN and NO yields differentiated well or moderately.

- Analyte groups for which most individual analyte yields were poorly differentiated were ammonia, semivolatiles, aromatic amines and selected volatiles.

Possible effects on variability of various methodological features: a) Number of cigarettes per replicate - For most methods, at least 5 cigarettes were smoked per replicate. However, there are some in-house established methods where a lesser number were smoked such as for the carbonyl group. There was a statistically significant relationship between the standard deviation (SD) and the number of cigarettes smoked per replicate as seen in the graphical plot for acetone in Appendix 13.

Increasing the minimum number of cigarettes per replicate for each analyte may minimise the variability between replicates for some analytes. There would seem to be a case for recommending a minimum number of cigarettes smoked per replicate for each analyte in order to help to minimise the variability between replicates.

b) Smoking machines and other methodological features The possible effects on yields of different smoking machine types and other methodological features were investigated. Due to the number of interacting factors, the effects, if any, of smoking machine type could not be detected. Total particulate matter (TPM) yields relating to specific analytes were not supplied by the participants in every case or could not be supplied due to methodology restrictions and so were not analysed statistically. TPM generation may be affected by different methods and may be a contributing factor to variability. Puff count is often a good indicator of good smoking practice and the correct conditioning of cigarettes. The mean TPM and puff count data, provided by participating laboratories, are summarised in Appendices 14 and 15. It was observed that some of the highest or lowest analyte yields within datasets were associated with some of the highest or lowest TPM yields respectively.

Other than the specific observations discussed under the following section, it was noted that within the current study it was not possible to identify any general features having a statistically significant effect on yields. It was not the intention of this work to evaluate methodologies in detail although some observations have nonetheless been described in the following section. More detailed investigation of specific aspects of methodologies will need to be carried out and reported in further Task Force work.

\section{INDIVIDUAL METHODOLOGY DISCUSSION AND STATISTICAL EVALUATION}

\section{Overview of statistical handling of data}

A brief overview description of the methodology employed at each laboratory is provided below and the related Appendices for each of the groups of analytes. As the basis 


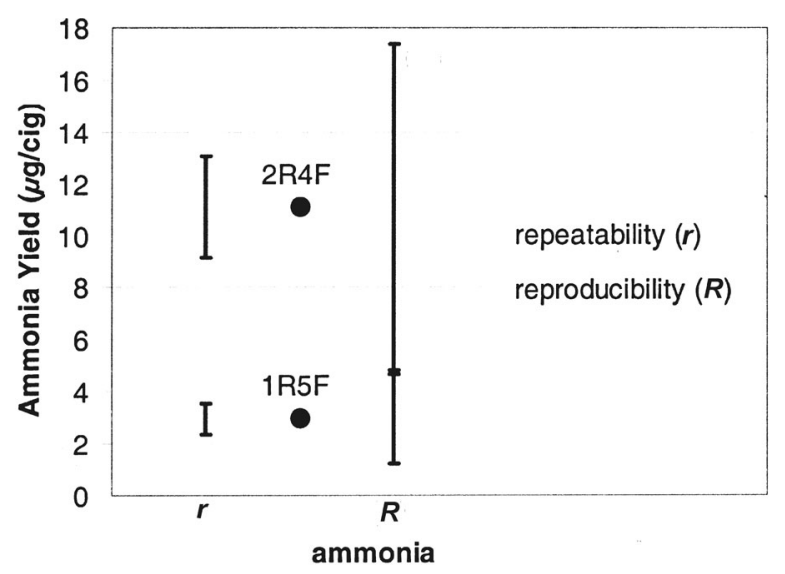

Figure 1. Summary of ammonia yields and their variability

for continual method improvement at each laboratory and to move towards better standardisation of methodology, detailed information was shared between participants and is discussed briefly.

As mentioned earlier, Appendix 12 indicates the relative status of all the analytes with respect to the capability of current methods differentiating between the two reference cigarettes. In the following subsections more details are given for each analyte group including pictorial representations of the estimated variability ( $r$ and $R$ values). Where the lines representing $r$ and/or $R$ for the two reference cigarettes overlap, all participating laboratories were requested to investigate whether their yields were among the most extreme and, if so, to consider future modifications to their methodologies.

The estimated statistical $r$ and $R$ values in this section were obtained in a slightly modified way to those shown in the Experimental section but any differences still lead to the same conclusions by both methods. This was simply because of the slightly different statistical approach used by two different statisticians. The equations are also given in Appendix 7 and are based on ISO 5725 (22). Analyte groupings are considered simply in alphabetical order.

\section{Ammonia methodology}

Twelve laboratories provided ammonia data and their choice of methodology is shown in Appendix 16. A summary of mean yields and range of maximum and minimum yields for each laboratory is shown graphically in Appendix 17.

Participants raised questions on the effect on yields of certain methodology features such as linear versus quadratic calibration; the time and temperature dependency between smoke collection and analysis: because data indicate that ammonia levels may increase with time, and the influence of the volume of the impinger solution.

Eleven laboratories applied ion chromatography (IC) and one laboratory (Number 3) used photometric methodology. The latter method could possibly overestimate the yield because the method is not specific. This hypothesis is supported by the observed higher yields from this laboratory. The mean yield for 2R4F was $11.5 \mu \mathrm{g} / \mathrm{cig}$, (excluding Laboratory $3=$ $10.2 \mu \mathrm{g} / \mathrm{cig}$ ) and the mean for $1 \mathrm{R} 5 \mathrm{~F}$ was $3.1 \mu \mathrm{g} / \mathrm{cig}$ (excluding Laboratory $3=2.8 \mu \mathrm{g} / \mathrm{cig}$ ).
Figure 1 shows the mean yields and $r$ and $R$ values for each cigarette type. Because $R$ overlapped, it was concluded that it may prove difficult to always detect differences between samples among participating laboratories, if both of the different methodologies continue to be employed. It should be noted that no methods were excluded in any initial evaluation and the reason for the overlapping in this case may be that the photometric determination is less specific and less suitable methodology.

\section{Aromatic amines methodology}

Appendix 18 summarises the methodology used in the 13 contributing laboratories. The trapping systems incorporated the use of either Cambridge filter pads (CFPs) for 11 of the 13 laboratories or impingers for Laboratories 3 and 12 . The amines were mainly reacted to form pentafluoropropionic acid (PFPA) derivatives although Laboratories 5 and 6 formed the heptaflurobutyric acid (HFBA) derivatives. The clean-up was mainly based on liquid-liquid partition, followed by derivatisation and solid-phase extraction on florisil. The detection and quantification was carried out by gas chromatography-mass spectrometry (GC-MS) with single ion monitoring (SIM).

The mean, maximum and minimum yields for each of the four individual amines are given in Appendices 19 and 20. Their relative yield patterns were very similar across most laboratories. However, a different pattern was observed for the 4 individual amines from Laboratories 3, 5 and 18 for the 1 R5F cigarettes.

It was noted from the information provided by participants that some laboratories are running at LOQs that are quite near to the measured smoke yields, especially from the 1R5F cigarette.

There was variation of $2 \mathrm{R} 4 \mathrm{~F}$ yields among laboratories, but no indication that differences in results were caused by the variations in methods described previously. Laboratory 3 had significantly lower 1R5F yields for all amines, and although not supported by Laboratory 12 data, it raised the question of the relative effect of impinger vs. CFP traps. In Figure 2, the $R$ values were overlapping or were close to overlapping for each of the four aromatic amines. Thus, it may prove difficult to always detect differences between samples among the participating laboratories. In the case of 4-aminobiphenyl, some individual laboratories could not even discriminate between $1 \mathrm{R} 5 \mathrm{~F}$ and $2 \mathrm{R} 4 \mathrm{~F}$ as shown by the overlapping $r$ values.

\section{Benzo[a]pyrene methodology}

Appendix 21 provides information on the methodology from the 17 laboratories that provided data for this analyte. Twelve laboratories used the CORESTA Recommended / ISO Method $(17,19)$, with GC-MS as the analytical tool. A further five laboratories used high performance liquid chromatography (HPLC) with fluorescence detection similar to the methodology initially investigated by the Special Snalytes Task Force.

Mean yield data and the range of minimum and maximum yields across laboratories are shown in Appendix 22 alongside the main methodological differences observed. Variability of results for both reference cigarettes was in 


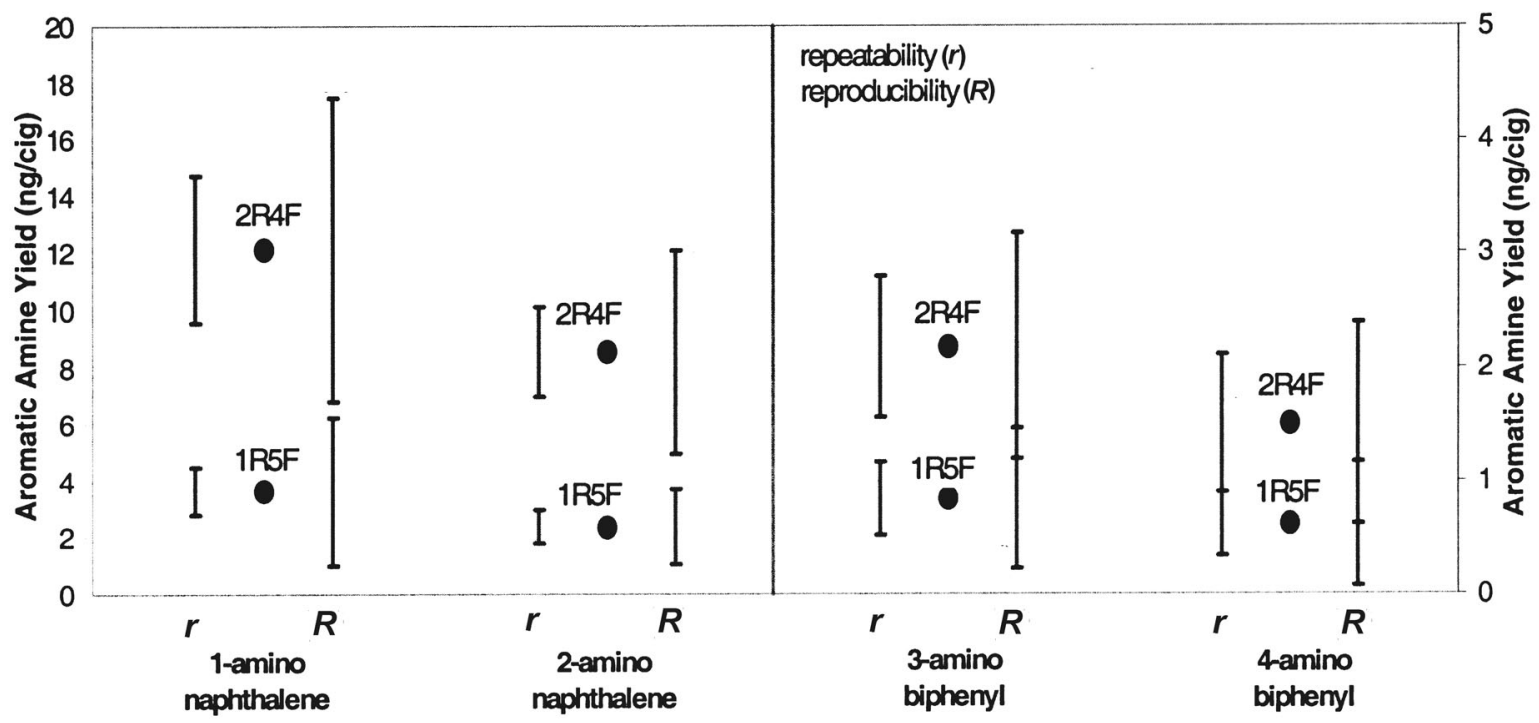

Figure 2. Summary of aromatic amine yields and their variability

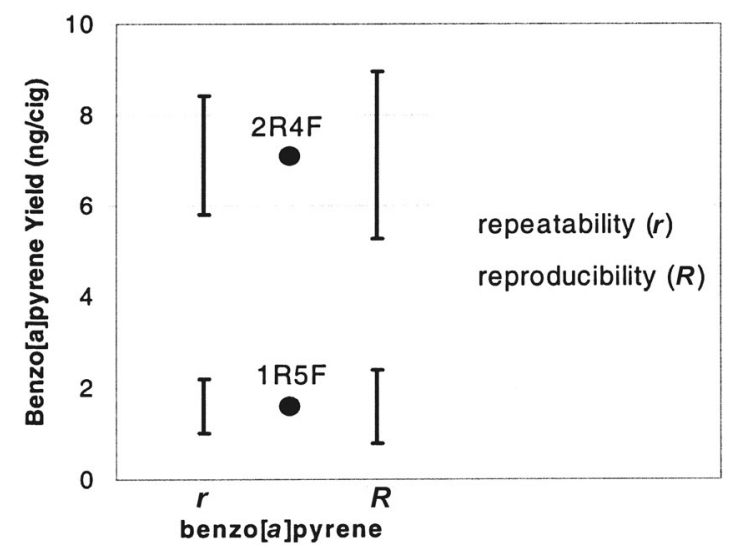

Figure 3. Summary of B[a]P yields and their variability

line with results previously obtained from joint Special Analytes Task Force experiments. The CORESTA method (17) with mean yield taken from the 2003 collaborative study for Kentucky 2R4F was 7.28 ng/cig with $r=1.27 \mathrm{ng}$ and $R=2.52 \mathrm{ng}$. This compared extremely well with the mean value of $7.1 \mathrm{ng} / \mathrm{cig}$ with $R=3.2 \mathrm{ng}$ obtained in the current study.

In Figure 3, good separation was found between the $R$ values for the cigarettes of different 'tar' yields and $R$ and $r$ values were not too dissimilar.

This result clearly demonstrates the value of standardisation and the level of variation using standardised methods that might be expected from other smoke analytes if they were taken through a similar rigorous standardisation process.

\section{Carbonyls methodology}

A summary of the different methodologies used across laboratories is given in Appendix 23.

Twelve laboratories trapped smoke using only impingers. Two laboratories (Numbers 2 and 7) additionally trapped on CFPs. Two others (Numbers 18 and 19) trapped smoke on 2-4-dinitrophenylhydrazine (DNPH)-impregnated CFPs and a further laboratory (Number 14) trapped smoke on activated silica after the CFP.

Fifteen out of the 17 laboratories carried out the derivatisation of carbonyls with 2,4-dinitrophenylhydrazine. One laboratory (Number 6) derivatised with 2-diphenylacetyl-1,3-indandione-1-hydrazone (DPAIH). Fifteen laboratories measured with high performance liquid chromatography-ultraviolet (HPLC-UV) or HPLC-DAD (diode arry detection) and Laboratory 10 with liquid chromatography-mass spectrometry-mass spectrometry (LC-MSMS). Laboratory 14 applied colorimetric measurement using an auto analyser for formaldehyde and did not measure the other carbonyls for this collaborative study. Mean, maximum and minimum yields and ratio patterns of the major carbonyls (acetaldehyde and acetone) are given in Appendices 24 and 25 and for the minor carbonyls (formaldehyde, acrolein, methyl ethyl ketone (MEK), propionaldehyde, butyraldehyde and crotonaldehyde) are given in Appendices 26 and 27. Major carbonyls compared well for both aspects. Laboratory numbers 11, 12 and 18 showed different yield patterns of minor carbonyls for the $1 \mathrm{R} 5 \mathrm{~F}$ cigarette. The highest yields for MEK were observed for Laboratory 12.

Although Laboratory 6 measured the yields of most carbonyls in line with most other laboratories, formaldehyde yields were lower with the DPAIH derivative used. An understanding of which hydrazone derivative is measuring formaldehyde correctly would seem particularly needed during method standardisation because the printing of formaldehyde yields is already mandated (25) on packets of Canadian cigarettes using Health Canada methods (5).

It can be noted that investigations (26) have suggested that the results for formaldehyde with DPAIH tended to be lower than some literature values for the Kentucky reference cigarettes obtained from laboratories using a DNPH solution made with unrecrystallised DNPH. Water is known to react with HMTA (hexamethylenetetramine) formed from the reaction of ammonia and formaldehyde in the vapor phase of smoke to form formaldehyde and ammonia. Thus, this referenced work found that to obtain accurate formaldehyde results every attempt must be made 


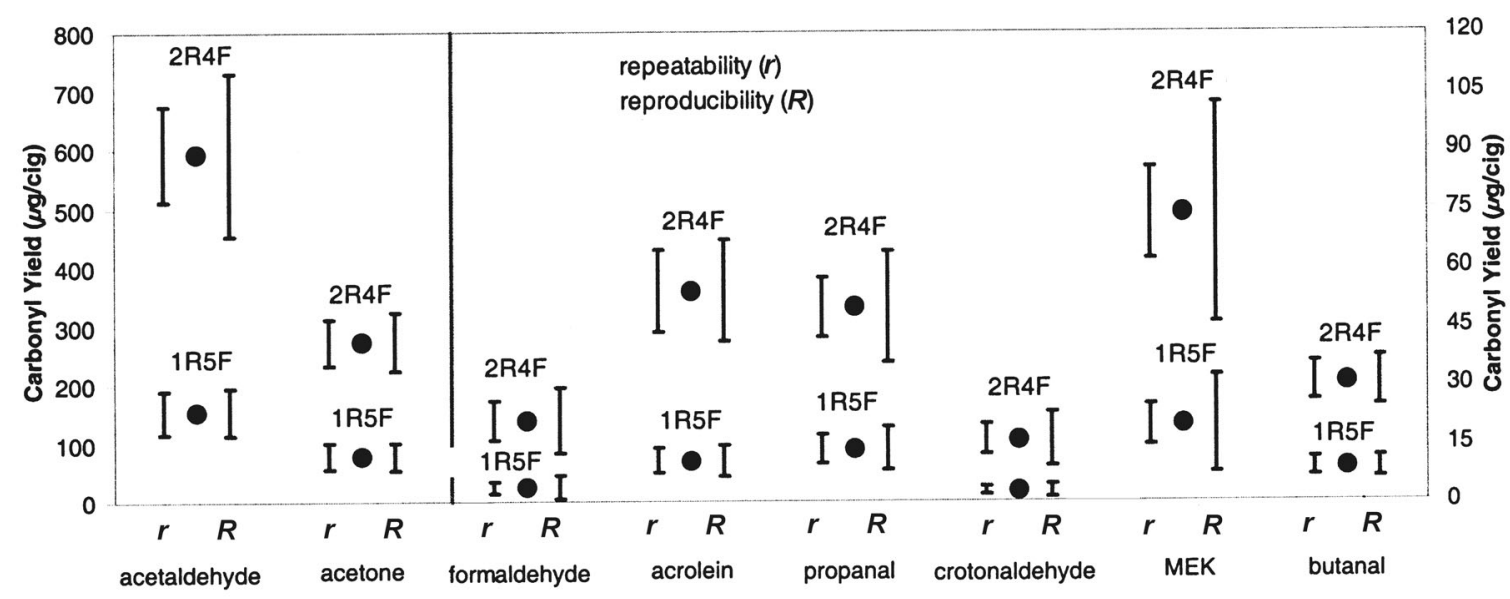

Figure 4. Summary of carbonyl yields and their variability

to reduce the water content of the trapping solution. The water content of unrecrystallised DNPH is approximately $30 \%$ by weight and, if used, will yield much higher formaldehyde results for the same cigarette when compared with recrystallised DNPH. Results obtained with recrystallised DNPH and DPAIH, the latter with no water added and with molecular sieves, are virtually identical for the same cigarettes.

It was also suggested that smoking more cigarettes will give a longer period before stopping derivatisation and has led to higher yields and a need for investigation and control of reaction time during method standardisation. Some participants noted that acetone yields may also be affected by the presence of water.

Some participants noted that crotonaldehyde is not well separated from other analytes in the chromatographic separation. It was discussed that resolution by $\mathrm{C}_{18}$ columns may depend on column suppliers and manufacturing lots, and has been found to be one of the factors affecting differences among laboratories.

In Figure 4, good separation was found between $R$ values for the cigarettes of different 'tar' yields for all carbonyls. For formaldehyde, crotonaldehyde and MEK some improvements are still needed to enhance their method performance.

\section{Hydrogen cyanide methodology}

A summary of the different methodologies used across laboratories is given in Appendix 28. The methods of determination for this analyte were the most diverse of the ones considered.

A range of systems were used by the various laboratories to trap the smoke and the following observations were made.

- Eight laboratories used a CFP in combination with either 1 or 2 impingers.

- One laboratory collected smoke on the CFP and combined it with the contents of an Ascarite trap, containing sodium hydroxide-coated silica.

- One laboratory collected smoke not only on the CFP but also in a trapping unit with activated silica gel.

- Three laboratories simply collected smoke in two consecutive impingers.
- One laboratory collected smoke in a glass syringe after the CFP with individual puffs being sampled.

- One laboratory collected smoke in a glass tube containing sodium hydroxide solution.

Where it was used, the derivatisation step mainly involved $\mathrm{HCN}$ and chloramine T reacting with pyridine-pyrazolone or pyridine-barbituric acid to form a polymethine dye although in one case HCN was reacted with naphthalene2,3-dicarboxaldehyde (NDA) and taurine.

Detection and quantification was undertaken by several different methods, such as colour reaction products with photometric detection in continuous flow analysis (CFA) in the majority of cases but also was quantified by

- Liquid chromatography - mass spectrometry (LC-MS) of the derivative or

- Headspace gas chromatography or

- Gas chromatography - flame ionisation detection (GCFID) or

- Ion chromatography (IC) or

- Ion-selective electrode (ISE) determination.

Mean, maximum and minimum yield data obtained across the laboratories is shown graphically in Appendix 29 alongside major methodological differences. They show that there are no clear method-specific differences, although a relatively higher yield was obtained from both LC-MS/MS with NDA and taurine (Laboratory 10) and from trapping on activated silica gel (Laboratory 14). There is some indication that TPM yields might contribute to some extent to the relatively lower $1 \mathrm{R} 5 \mathrm{~F}$ yields for Laboratory 13 and higher 1R5F yields for Laboratory 14 .

It can be noted that the printing of hydrogen cyanide yields has been already mandated on Canadian cigarette packets (25) by Health Canada methods (5) and a rigorously standardised method is required.

From Figure 5, it can be seen that it is possible to discriminate between cigarette types in the participating laboratories according to the statistical observations on $r$ and $R$ variability seen below.

\section{Nitric oxide methodology}

A summary of the different methodologies used across laboratories is given in Appendix 30. Mean, maximum and minimum yield results are summarised graphically in 


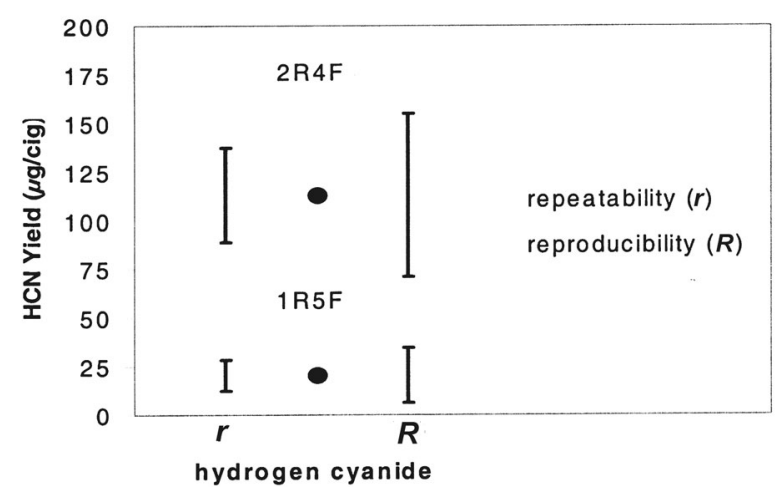

Figure 5. Summary of hydrogen cyanide yields and their variability

Appendix 31. Some factors were identified as having the potential to cause among-laboratory variability such as the effect of the

- Analysis of 'fresh' smoke on a puff by puff basis compared to analysis of 'aged' smoke from all puffs mixed together at the end of the smoking run.

- Analysis of only whole puffs or the inclusion of partial (last) puffs.

- Analysis of $\mathrm{NO}$ versus total nitrogen oxides $\left(\mathrm{NO}_{\mathrm{X}}\right)$.

- Smoke dilution within the collection chamber.

There is some indication that the relatively high $2 \mathrm{R} 4 \mathrm{~F}$ yield for Laboratory 4 is associated with a relatively high TPM yield.

From Figure 6 it can be seen that although $R$ values were rather close to overlapping, it was possible to discriminate between cigarette types among the participating laboratories.

\section{Phenolics methodology}

A summary of the different methodologies used across laboratories is given in Appendix 32.

Two different methods were applied; one involved direct measurement of phenolics by HPLC-Fluorescence from CFP extracts and the other method involved BSTFA $(N, N$ bis(trimethylsilyl)trifluoroacetamide) derivatisation of the pad extract and GC-MS determination of derivatives.

Mean, maximum and minimum yield results are summarised graphically in Appendix 33. Yields and ratio of

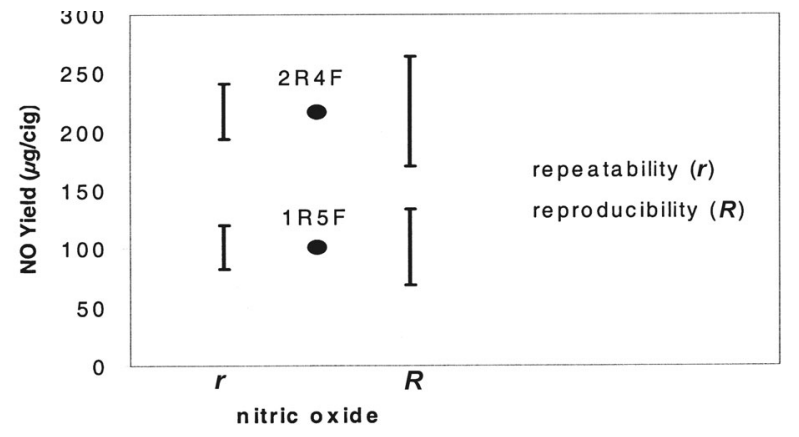

Figure 6. Summary of nitric oxide yields and their variability

patterns for all phenolics are given in Appendix 34. There is some indication that the relatively high $1 \mathrm{R} 5 \mathrm{~F}$ yield for laboratory 10 is associated with a relatively high TPM yield.

Yields and patterns of minor phenolics are shown in Appendices 35 and 36 and demonstrate that minor phenolics obtained from 2R4F by Laboratories 2 and 19 were different even though they used similar methodology. There was an inconsistent pattern of phenolics observed across laboratories from $1 \mathrm{R} 5 \mathrm{~F}$ for minor phenolics but no indication of method influence.

In Figure 7, $R$ values overlapped for resorcinol. For other phenolics, it was possible to discriminate between cigarette types among the participating laboratories.

\section{Selected volatiles methodology}

A summary of the different methodologies used across 16 laboratories is given in Appendix 37. Laboratory 6 provided data using two different trapping systems. It was observed that the methodology was very similar.

Fourteen laboratories trapped smoke by impingers and CFPs. Of these, six laboratories smoked into one impinger trap; another fove into two consecutive traps and the other three had a set-up consisting of three or even four consecutive traps. The total volume of impingers ranged from $20 \mathrm{~mL}$ to $50 \mathrm{~mL}$, with most applying $20 \mathrm{~mL}$.

A further three laboratories $(3,5$ and $6 \mathrm{~B})$ trapped vapour phase smoke in a Tedlar bag or a glass syringe. The participants highlighted the need to deactivate sites in the collection bag in this method.

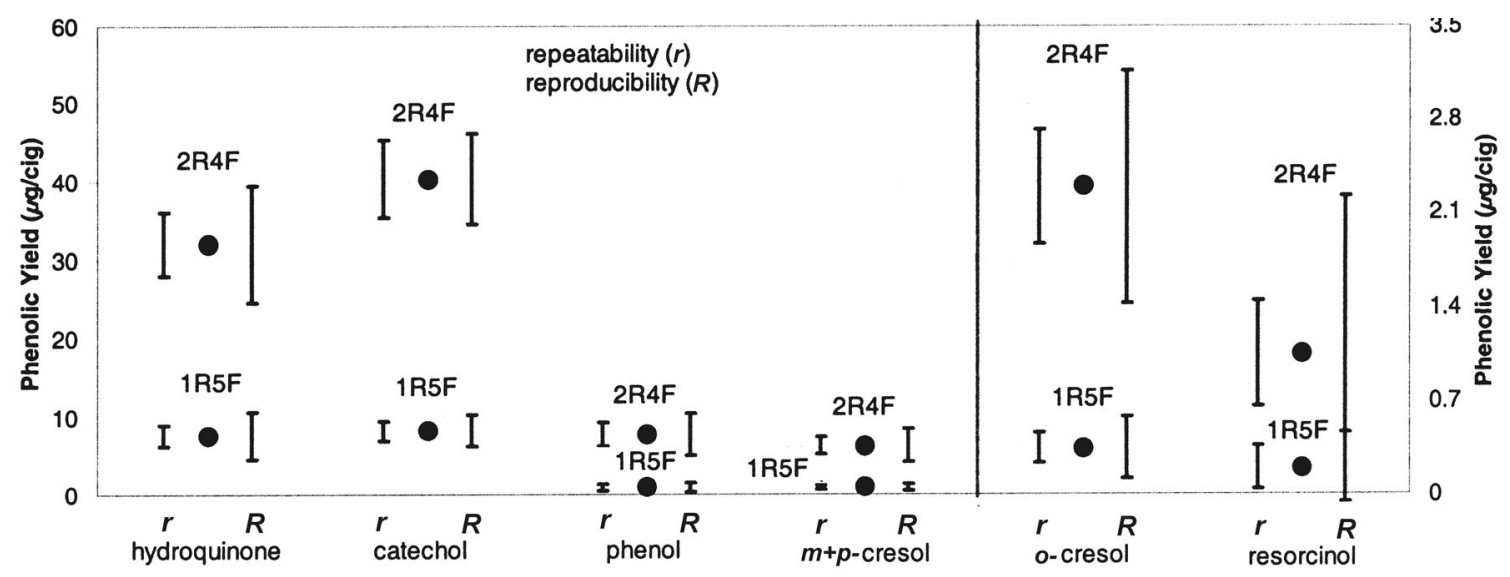

Figure 7. Summary of phenolic yields and their variability 


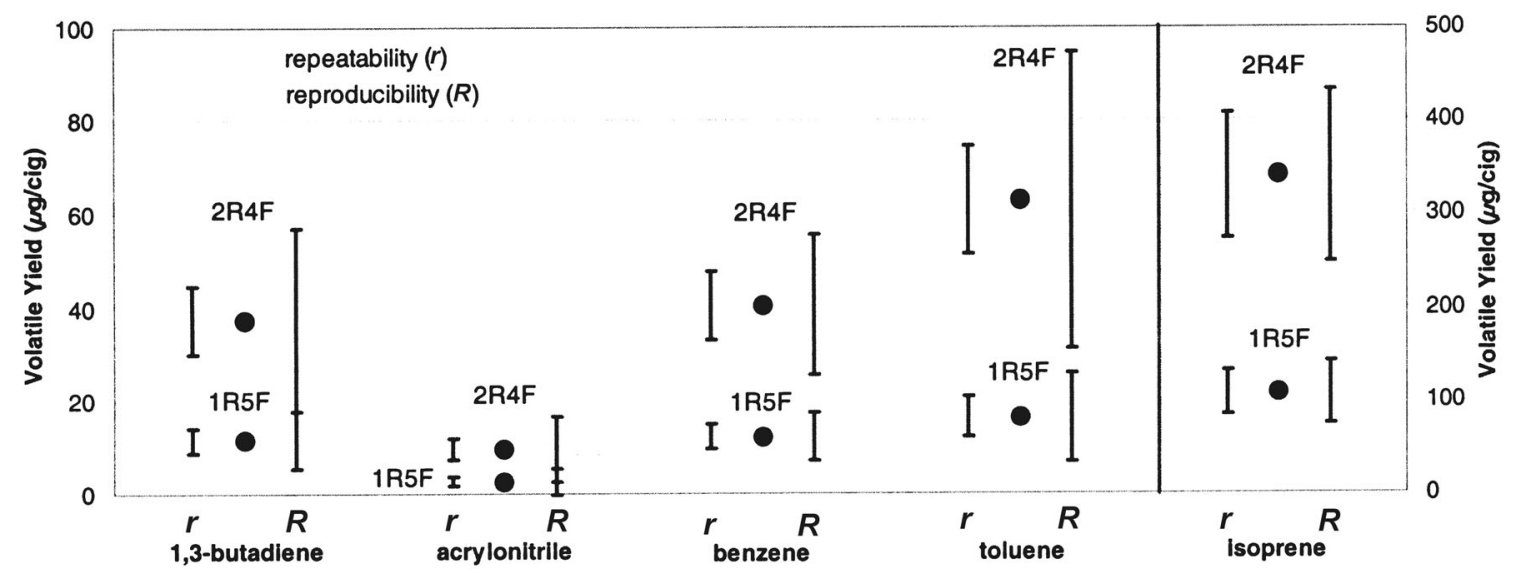

Figure 8. Summary of selected volatile yields and their variability

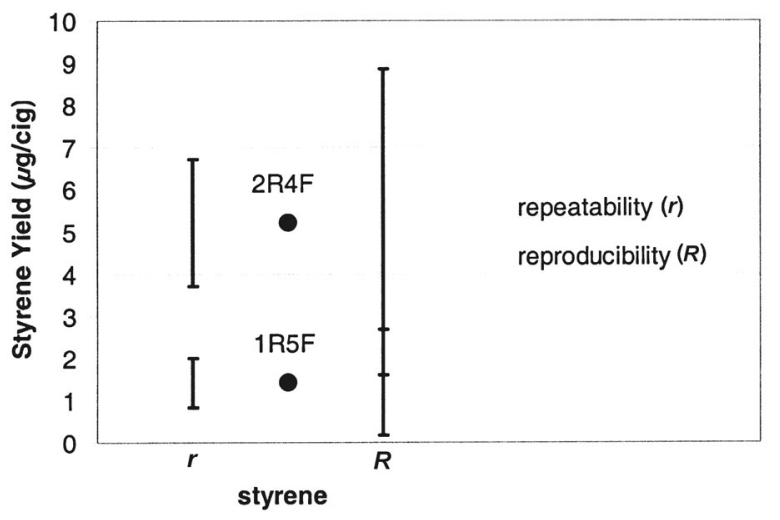

Figure 9. Summary of styrene yields and their variability

Fourteen laboratories measured selected volatiles by GC-MS with SIM and the other three laboratories applied GC-FID (flame ionisation detection) (laboratories 3,11 and 17). Other experimental factors such as choice and quality of calibration standards were not considered in this study. The mean, maximum and minimum yields are shown graphically in Appendix 38. It is noteworthy that Laboratories 3 (direct trapping) and 19 found markedly more butadiene than the others. Laboratory 9 measured the highest yields for acrylonitrile. There is some indication that the relatively high $2 \mathrm{R} 4 \mathrm{~F}$ yield for Laboratory 17 is associated with a relatively high TPM yield.

The pattern of selected volatiles from Laboratory 19 was different to all the others (see Appendix 39) ${ }^{\mathrm{b}}$.

From the $r$ and $R$ data given in Figure 8 it can be seen that butadiene, acrylonitrile and toluene give variable data and it is not possible to always differentiate samples among the participating laboratories whereas benzene and isoprene are better differentiated.

It can be noted that the printing of benzene yields, one of the selected volatiles, is already mandated on Canadian cigarette packets (25) by Health Canada methods (5) and a rigorously standardised method would be beneficial.

\footnotetext{
${ }^{\mathrm{b}}$ Subsequent to all the statistical analyses for this report, laboratory 19 identified errors in yield calculations for these analytes that would put their data in better line with data from other laboratories. However, these changes do not affect the overall conclusions made about this group of analytes in this report.
}

Semi-volatiles methodology

Appendices 40 and 42 show a summary of the methodology employed to measure styrene, pyridine and quinoline in cigarette smoke by the contributing laboratories. The semi-volatiles can trap to some extent on CFPs whilst a proportion will filter through and still need to be trapped by other means. The separation into "semi-volatiles" and "selected volatiles" is therefore somewhat arbitrary. Eleven laboratories trapped smoke by a combination of impingers and CFPs. Four laboratories smoked into one impinger and another 5 smoked into two traps. A further two laboratories had a trapping device consisting of three or even four liquid traps. The total volume of the impingers ranged from $20 \mathrm{~mL}$ to $50 \mathrm{~mL}$. Three laboratories (numbers 5, 14 and 18) trapped smoke onto XAD-4 and CFP while one used acid impregnated CFPs.

Thirteen laboratories measured semi-volatiles by GC-MS coupled with SIM. Two laboratories (11 and 17) applied GC-FID.

Appendices 41 and 43 show graphically the mean, maximum and minimum yields obtained for the semivolatiles. There is some indication that the relatively high $2 \mathrm{R} 4 \mathrm{~F}$ and $1 \mathrm{R} 5 \mathrm{~F}$ yields for Laboratory 6 are associated with relatively high TPM yields.

Laboratory 14 measured the highest yields for pyridine and styrene. Laboratory 3 sampled only styrene in the vapour phase. The pattern of semi-volatiles from Laboratory 19 was different to all others ${ }^{\text {b) }}$.

For styrene in Figure 9, the $R$ values significantly overlapped and so it may not be possible to always differentiate samples among the participating laboratories.

For pyridine and quinoline in Figure 10, $R$ values also overlapped and again it may not be possible to always differentiate samples among the participating laboratories.

\section{Tobacco-specific nitrosamines (TSNAs) methodology}

The methodology is summarised in Appendix 44. Six laboratories applied the more modern LC-MS-MS method without any sample clean up whereas seven laboratories carried out TSNA determinations according to the CORESTA recommended method (19) by GC-TEA and clean up. One of the latter laboratories provided two sets of data after collecting smoke on both linear and rotary 


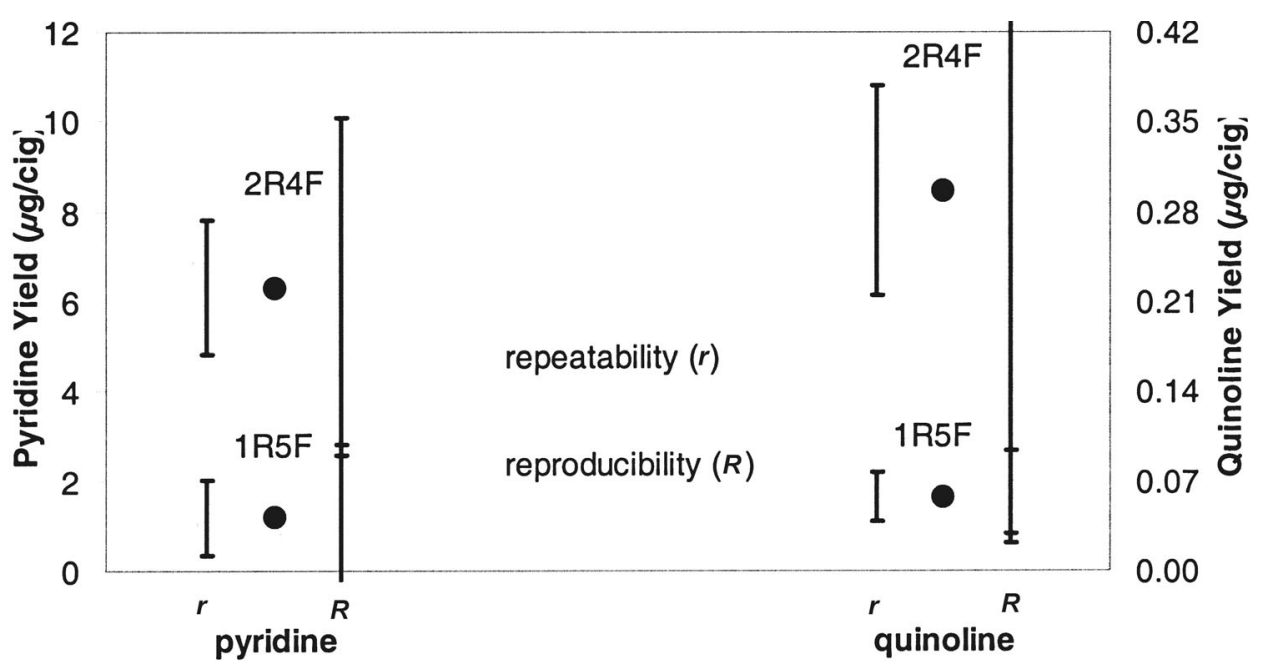

Figure 10. Summary of pyridine and quinoline yields and their variability

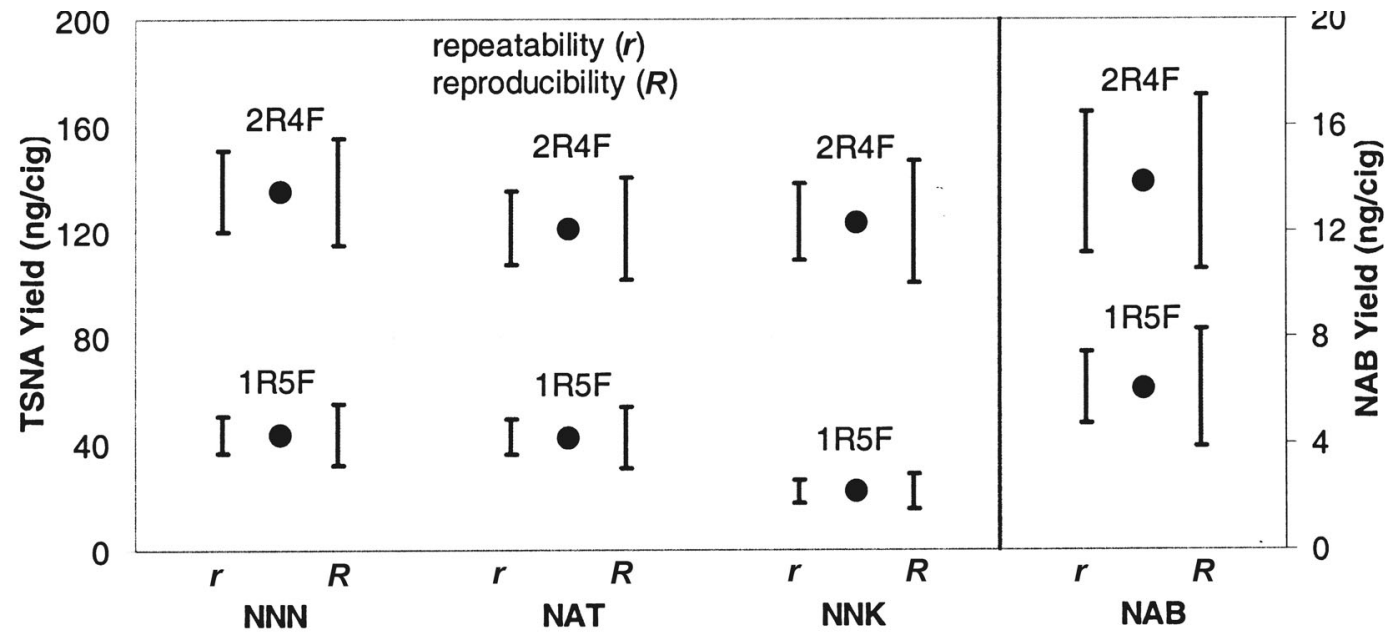

Figure 11. Summary of TSNA yields and their variability

smoking machines. There were no obvious differences from results obtained either with GC-TEA and LC-MSMS.

Good differentiation was found between products among all participating laboratories with similar values for $r$ and $R$ as shown in Figure 11.

The mean, maximum and minimum yield data for the TSNAs are shown graphically in Appendix 45.

The mean yield data and reproducibility values $R$ were obtained for the 2R4F cigarette as part of the collaborative study on TSNAs in 2005 where all participating laboratories used the same method. This is shown alongside mean yield and variability data $(R)$ from this joint experiment for the $2 \mathrm{R} 4 \mathrm{~F}$ cigarette as given below:

\begin{tabular}{ll} 
Mean 2005 & Mean 2006 \\
\hline NNN: $146.01 \mathrm{ng} / \mathrm{cig}(R=51.06)$ & $135.2 \mathrm{ng} / \mathrm{cig}(R=35.1)$ \\
NAB: $16.60 \mathrm{ng} / \mathrm{cig}(R=9.16)$ & $13.8 \mathrm{ng} / \mathrm{cig}(R=5.8)$ \\
NAT: $143.38 \mathrm{ng} / \mathrm{cig}(R=76.95)$ & $121.1 \mathrm{ng} / \mathrm{cig}(R=32.7)$ \\
NNK: $141.39 \mathrm{ng} / \mathrm{cig}(R=73.44)$ & $123.7 \mathrm{ng} / \mathrm{cig}(R=40.8)$
\end{tabular}

Results are fairly comparable and demonstrate the value of standardisation in reducing data variability. Data variability may even have improved since the collaborative study as many laboratories are measuring the TSNAs on a fairly regular basis. Even so, the data also demonstrates the relatively high level of variation obtained even using standardised methods and the high variability expected from other similar smoke analytes even after standardisation.

\section{CONCLUSIONS}

The collected data should be useful to individual laboratories for their internal method validation and accreditation purposes. As a means of continuous improvement, the data comparisons with others allow laboratories to identify the strengths and flaws or weaknesses in their current methods. As a general overview of the current situation, the preferred methodologies across a wide range of laboratories have been identified and demonstrate quite well the current worldwide expertise in this field.

For most analyses, the participating laboratories obtained quite different yields from the $1 \mathrm{R} 5 \mathrm{~F}$ and $2 \mathrm{R} 4 \mathrm{~F}$ cigarettes. However, the approach used to determine the current method performance was to investigate the level of statistical differentiation that could be achieved between 
$1 \mathrm{R} 5 \mathrm{~F}$ and 2R4F among laboratories when different laboratories were applying their different methodologies. It was felt that if the methods could not well differentiate these products then there were significant weaknesses in the application of at least some of these methods and in the future this could have wider regulatory implications. Even for the methods with the least among-laboratory variability there was still a need for rigorous standardisation and for properly conducted collaborative studies to obtain good estimates of repeatability within-laboratories and reproducibility among-laboratories.

Results indicate that "Hoffmann analyte" data are generally more variable both within- and among-laboratories than NFDPM; nicotine and carbon monoxide. Accordingly, tolerances around methods adopted for regulatory purposes will need to be proportionately higher.

It should be noted that ISO standardised $\mathrm{B}[a] \mathrm{P}$ and the CORESTA recommended TSNA methods give some of the most reproducible results, showing the value of the standardisation process.

However, this data strongly suggests that the amonglaboratory variability $(R)$ is much higher for $\mathrm{B}[a] \mathrm{P}$ and TSNAs than for NFDPM, nicotine and CO.

Based only on the two available one point in time studies, the indications are that tolerance values for the $9 \mathrm{mg} 2 \mathrm{R} 4 \mathrm{~F}$ cigarette should be at least

- Mean $\pm 35 \%$ from the 2003 data and mean $\pm 45 \%$ from the current study for $\mathrm{B}[a] \mathrm{P}$, that is, mean $\pm R$.

- Mean ranging $\pm 35-55 \%$ from the 2005 data and mean $\pm 26-42 \%$ from the current study under the ISO smoking regime for the individual TSNAs, that is, mean $\pm R$.

Much work still needs to be carried out to take most of the various methods towards standardisation and CORESTA work is focusing on methods that are not currently differentiating well between reference cigarettes.

\section{REFERENCES}

1. DHSS: Fourth Report of the Independent Scientific Committee on Smoking and Healt;. HMSO, London, 1988.

2. Darrall, K., J. Figgins, R. Brown, and G. Phillips: Determination of benzene and associated volatile compounds in mainstream cigarette smoke; Analyst 123 (1998) 1095-1101.

3. Phillips, G and R. Waller: Yields of tar and other smoke components from UK cigarettes; Food Chem. Toxicol. 29 (1991) 469-474.

4. LGC and Arista reports to the UK Department of Health (accessed November 2006); http://www. advisorybodies.doh.gov.uk/scoth/research.htm.

5. Health Canada methods (accessed November 2006); http://www.hc-sc.gc.ca/hl-vs/tobac-tabac/ legislation/reg/indust/method/index_e.html.

6. Hoffmann D. and I. Hoffmann: The changing cigarette: Chemical studies and bioassays; in: Risks associated with smoking cigarettes with low machine-measured yields of tar and nicotine; edited by DHSS, smoking and Tobacco Control Monograph 13, NCI, NIH, Bethesda 2001, Chapter 5.
7. Borgerding, M.F., J.A. Bodnar, D.E. Wingate (Compilers), C.R.Taylor, J.R. Reid, M.A. Sudholt, K.F. Podraza, F.S. Hsu, M.F. Borgerding, J.A. Bodnar, and J.F. Whidby (Principal Investigators): The 1999 Massachusetts Benchmark Study. Final Report; [A research study conducted after consultation with the Massachusetts Department of Public Health (MDPH)], 2000.

8. Borgerding, M.F., N. Cohen, S.R., Massey, D.R.E. Thomas in consultation with M.J. Kaiserman and W.S. Rickert: The 1999 Canadian Benchmark Study, 2000.

9. Department of Health and Ageing: Australian cigarette emissions data (2001); (accessed November 2006) http://www.health.gov.au/internet/wcms/publishing.n sf/Content/health-pubhlth-strateg-drugs-tobaccoemis_data.htm.

10. Gregg, E., C. Hill, M. Hollywood, M. Kearney, K. McAdam, D. McLaughlin, S. Purkis, and M. Williams: The UK Smoke Constituents Testing Study. Summary of results and comparison with other studies; Beitr. Tabakforsch. Int. 21 (2004) 117-138.

11. Rickert, W.S. and W.G. Wright: Stability of yields of Canadian mandated analytes from the Kentucky Reference Cigarette; 2000 CORESTA Conference, paper ST26.

12. Hsu, F., J.F. Whidby, B.D. McVeety, N.H. Moore, R.B. Westerberg, H.T. Karnes, and S. Bolton: Interlaboratory analytical methods comparison; 53 ${ }^{\text {rd }}$ Tobacco Science Research Conference Paper No. 33 1999.

13. Purkis, S.W., C.A. Hill, and I.A. Bailey: Current Measurement reliability of selected smoke analytes; Beitrage Tabakforsch. Int. 20 (2003) 314-324.

14. Chen, P.X. and S.C. Moldoveanu: Mainstream smoke chemical analyses for 2R4F Kentucky reference cigarette; Beitr. Tabakforch. Int. 20 (2003) 448-458.

15. Hyodo T., O. Inoue, H. Katagiri, A. Mikita, and M. Fujiwara: Long-term inter-laboratory comparisons of selected smoke analytes in 2R4F mainstream smoke; 2006 CORESTA Conference Paper SS7.

16. World Health Organisation: TobReg Recommendation: Guiding principles for the development of tobacco product research and testing capacity and proposed protocols for the initiation of tobacco product testing; 2004, (accessed November 2006) http://www.who. int/tobacco/sactob/recommendations/en/iso_ftc_en.pdf

17. CORESTA Recommended Method No. 58: Determination of benzo $[a]$ pyrene in cigarette mainstream smoke - gas chromatography-mass spectrometry method; February 2004, CORESTA CD 18, Cooperation Centre for Scientific Research Relative to Tobacco, Paris, France.

18. CORESTA Recommended Method No. 63: Determination of tobacco-specific nitrosamines in cigarette mainstream smoke - GC-TEA method; June 2005, CORESTA CD 20, Cooperation Centre for Scientific Research Relative to Tobacco, Paris, France.

19. ISO 22634: Determination of benzo[a]pyrene in cigarette mainstream smoke - method using gas chromatography / mass spectrometry; International Organisation for Standardization, Geneva, Switzerland, 2007.

20. ISO Standard 3308: Routine analytical cigarette 
smoking machine - Definitions and standard conditions; International Organisation for Standardization, Geneva, Switzerland, 2000.

21. ISO 3402: Tobacco and tobacco products - Atmosphere for conditioning and testing; International Organisation for Standardization, Geneva, Switzerland, 1999.

22. ISO 5725: Accuracy (trueness and precision) of measurement me2009-23-04-190hods and results, Part 2: Basic method for the determination of repeatability and reproducibility of a standard measurement method; and Part 6: Use in practice of accuracy values; International Organisation for Standardization, Geneva, Switzerland, 1994.

23. Saint-Jalm, Y., M.F. Borgerding, S.G. Chapman, and W.T. Morgan (Co-ordinators): CORESTA Task Force report on Alternative Smoking Regimes; Cooperation Centre for Scientific Research Relative to Tobacco, Paris, France, 2006.
24. ISO 8243: Cigarettes - Sampling; International Organisation for Standardization, Geneva, Switzerland, 2006.

25. Tobacco Products Information Regulations SOR/2000272, Canada Gazette Part II Volume 134 No. 15, 2000.

26. Dominguez, L. and C. Rouse: Unpublished work at R.J. Reynolds and Brown and Williamson Tobacco companies; communicated to the CORESTA Special Analytes Task Force, 2006.

Address for correspondence

Steve Purkis

Imperial Tobacco Limited

P.O. Box 525, Southville,

Bristol BS99 1LQ

E-mail: Steve.Purkis@uk.imptob.com 


\section{OBJECTIVE}

The main objective of this study was to describe the variability of individual analyte yields obtained by various laboratories using various methodologies and attempt to model the variability as far as possible.

\section{ANALYTES AND METHODS}

The analytes to be included in the study were:

Table A1: Analytes investigated in the study

\begin{tabular}{|c|c|c|c|}
\hline No. & Class and Analyte(s) & No. & Class and Analyte(s) \\
\hline 1 & Ammonia & 7 & $\begin{array}{c}\text { Tobacco-specific } N \text {-nitrosamines } \\
\mathrm{N} \text {-nitrosonornicotine (NNN) }\end{array}$ \\
\hline \multirow[t]{5}{*}{2} & Aromatic amines & & $\begin{array}{l}\text { 4-(N-nitrosomethylamino)-1-(3- } \\
\text { l)-1-butanone (NNK) }\end{array}$ \\
\hline & 1- aminonaphthalene & & $N$-nitrosoanatabine (NAT) \\
\hline & 2- aminonaphthalene & & $\mathrm{N}$-nitrosoanabasine (NAB) \\
\hline & 3- aminobiphenyl & 8 & Semi-volatiles \\
\hline & 4- aminobiphenyl & & Pyridine \\
\hline \multirow[t]{2}{*}{3} & Benzo[a]pyrene & & Quinoline \\
\hline & & & Styrene \\
\hline \multirow[t]{9}{*}{4} & Volatile carbonyls & 9 & Phenolic compounds \\
\hline & Formaldehyde & & Hydroquinone \\
\hline & Acetaldehyde & & Resorcinol \\
\hline & Acetone & & Catechol \\
\hline & Acrolein & & Phenol \\
\hline & Propionaldehyde & & $\mathrm{m}+p$-Cresol \\
\hline & Crotonaldehyde & & o-Cresol \\
\hline & $\begin{array}{l}\text { MEK (methyl ethyl } \\
\text { ketone) }\end{array}$ & 10 & Selected volatiles \\
\hline & Butyraldehyde & & 1,3 Butadiene \\
\hline \multirow[t]{2}{*}{5} & Hydrogen cyanide & & Isoprene \\
\hline & & & Acrylonitrile \\
\hline \multirow[t]{2}{*}{6} & NO & & Benzene \\
\hline & & & Toluene \\
\hline
\end{tabular}

The method(s) applied in determining the yields of the analytes listed in the above table was the in-house method currently being used by each participating laboratory. It was not required that each participating laboratory make determinations for all of the analytes listed, but rather as many as are possible given the constraints of the laboratory.

Since no single test method was required to be followed for any of the analyte determinations, the specifics of each method utilized by a laboratory were documented in the laboratory report.

\section{STUDY PROTOCOL}

Cigarette samples smoked were Kentucky reference 2R4F (A) and Kentucky reference $1 \mathrm{R} 5 \mathrm{~F}$ (B).

\section{Smoking plans}

Five replicates for each test sample should be generated in 3 independent experiments. Products should be smoked randomly and smoking plans allowing this should be used.

Fully orthogonal random smoking plans cannot be generated, but random smoking plans may be obtained with the help of a random number generator (random permutation of 5 replicates of 2 brands).
Each experiment must be smoked on a different day, separated by minimum of one week, in order to incorporate day-to-day variation into the resulting data. If it is not possible to generate the 10 samples required for each experiment in a single day, the sample generation can be carried over to consecutive days.

Table A2. Example for rotary smoking machines

\begin{tabular}{c|c|c}
\hline Experiment No. 1 & Experiment No. 2 & Experiment No. 3 \\
\hline A & B & B \\
B & B & A \\
B & A & A \\
A & B & A \\
B & A & B \\
A & B & A \\
A & A & B \\
B & A & A \\
A & B & B \\
B & A & B \\
\hline
\end{tabular}

In each experiment, 10 ports will be used and 10 "blank" ports will remain unused, Table A3:

Table A3. Example for 20 port linear smoking machines

\begin{tabular}{|c|c|c|c|c|c|c|c|c|c|c|}
\hline \multirow[b]{2}{*}{ Exp. No. } & \multicolumn{10}{|c|}{ Port } \\
\hline & 1 & 2 & 3 & 4 & 5 & 6 & 7 & 8 & 9 & 10 \\
\hline 1 & & B & $A$ & & A & & & B & & \\
\hline 2 & & A & & B & & A & $A$ & & A & \\
\hline 3 & B & A & $A$ & B & & & $A$ & & & B \\
\hline Exp. No. & 11 & 12 & 13 & 14 & 15 & 16 & 17 & 18 & 19 & 20 \\
\hline 1 & A & B & $A$ & & & B & A & & B & \\
\hline 2 & B & & & B & & & & B & A & B \\
\hline 3 & B & $A$ & & & $A$ & & & & & B \\
\hline
\end{tabular}

In each experiment, 10 ports will be used and 6 "blank" ports will remain unused, Table A4:

Table A4. Example for 16 port linear smoking machines

\begin{tabular}{l|c|c|c|c|c|c|c|c}
\hline Exp. No. & 1 & 2 & 3 & 4 & 5 & 6 & 7 & 8 \\
\hline 1 & B & A & & B & A & A & & B \\
2 & & B & A & B & A & A & B & \\
3 & B & B & A & B & B & & A & \\
\hline Exp. No. & 9 & 10 & 11 & 12 & 13 & 14 & 15 & 16 \\
\hline 1 & & B & & B & A & A & & \\
2 & A & B & & A & & & & B \\
3 & A & & & B & A & & & A \\
\hline
\end{tabular}

In each experiment, all 10 ports will be used, Table A5:

Table A5. Example for 10 port linear smoking machines

\begin{tabular}{l|l|l|l|l|l|l|l|l|l|l}
\hline Exp. No & 1 & 2 & 3 & 4 & 5 & 6 & 7 & 8 & 9 & 10 \\
\hline 1 & B & B & B & B & A & A & A & B & A & A \\
2 & A & A & A & B & B & A & A & B & B & B \\
3 & A & A & B & A & B & B & A & A & B & B \\
\hline
\end{tabular}


In each experiment, the 10 samples will be split into two runs of 5 samples, Table A6:

Table A6. Example for 5 port linear smoking machines

\begin{tabular}{l|l|l|l|l|l|l}
\hline Exp. No. & Run No. & 1 & 2 & 3 & 4 & 5 \\
\hline 1 & 1 & B & B & B & B & A \\
& 2 & A & A & B & A & A \\
2 & 1 & A & A & A & B & B \\
& 2 & A & A & B & B & B \\
3 & 1 & A & A & B & A & B \\
& 2 & B & A & A & B & B \\
\hline
\end{tabular}

\section{DATA SUBMISSION AND ANALYSIS}

A template was used for data submission and test methods used for each analyte or groups were submitted along with the data. The data was analysed independently by 3 statisticians to ensure that as much data interpretation was made as possible. The laboratories mainly performed the study from November 2005 to July 2006 and results were sent to the data coordinators and then on to the statisticians by August 2006.

Appendix 2. Summary of all received mean data on Kentucky Reference 2R4F cigarettes

Table A7. Summary of all received mean data on 2R4F cigarettes in laboratories 1-19

\begin{tabular}{|c|c|c|c|c|c|c|c|c|c|c|c|c|c|c|c|c|c|c|c|c|}
\hline Smoke analyte & 1 & 2 & 3 & 4 & 5 & $6 \mathrm{~A}$ & $6 \mathrm{~B}$ & 7 & 8 & 9 & 10 & 11 & 12 & 13 & 14 & 15 & 16 & 17 & 18 & 19 \\
\hline Ammonia & 10.1 & ND & 25.4 & 10.1 & 10.6 & 12.8 & & 10.3 & ND & ND & ND & 10.6 & 10.2 & ND & 6.6 & ND & 12.0 & 9.1 & 10.2 & ND \\
\hline 1-Naphthyl amine & 12.8 & ND & 7.0 & 13.6 & 14.9 & 10.3 & & 9.0 & ND & ND & ND & ND & 11.0 & 11.3 & ND & ND & 16.3 & 12.0 & 18.1 & 8.1 \\
\hline 2-Naphthyl amine & 9.8 & ND & 7.4 & 9,6 & 10.1 & 7.8 & & 5.7 & ND & 6.1 & ND & ND & 8.9 & 7.6 & ND & ND & 10.5 & 8.1 & 13.2 & 4.7 \\
\hline 3-Amino biphenyl & 2.2 & ND & 1.6 & 2.1 & 2.2 & 2.1 & & 2.0 & ND & ND & ND & ND & 2.0 & 2.3 & ND & ND & 2.3 & 2.0 & 3.9 & 1.6 \\
\hline 4-Amino biphenyl & 1.7 & ND & 1.3 & 1.5 & 1.5 & 1.3 & & 1.3 & ND & 1.1 & ND & ND & 1.5 & 1.1 & ND & ND & 1.9 & 1.4 & 3.0 & 1.0 \\
\hline $\mathrm{B}[\mathrm{a}] \mathrm{P}$ & 6.0 & ND & 7.5 & 6.2 & 7.3 & 5.6 & & 5.9 & ND & 7.2 & 8.5 & 7.0 & 8.3 & 8.9 & 7.5 & 7.7 & 6.4 & 6.2 & 6.4 & 8.5 \\
\hline Formaldehyde & 25.3 & 20.2 & 24.2 & 23.3 & 29.8 & 8.6 & & 22.2 & 23.3 & 18.2 & 13.4 & 14.5 & 24.1 & ND & 22.3 & ND & 23.3 & 17.1 & 18.8 & 21.3 \\
\hline Acetaldehyde & 629.8 & 435.9 & 481.8 & 628.8 & 546.4 & 655.1 & & 655.1 & 732.8 & 546.9 & 546.2 & 562.0 & 649.8 & ND & ND & ND & 452.9 & 673.0 & 616.9 & 585.7 \\
\hline Acrolein & 60.6 & 48.9 & 55.2 & 61.7 & 56.9 & 54.5 & & 60.4 & 61.3 & 52.1 & 49.2 & 4.9 & 60.7 & ND & ND & ND & 50.1 & 53.3 & 46.6 & 37.9 \\
\hline Acetone & 297.2 & 238.3 & 227.1 & 242.3 & 292.6 & 261.9 & & 296.1 & 300.6 & ND & 251.8 & 244.9 & 267.0 & ND & ND & ND & 265.3 & 329.9 & 284.8 & 256.6 \\
\hline MEK & 76.5 & 57.8 & 45.8 & 61.6 & 69.2 & 79.5 & & 92.7 & 94.2 & ND & 64.9 & 64.6 & 114.9 & ND & ND & ND & 63.3 & 76.7 & 56.9 & 69.1 \\
\hline Butyraldehyde & 31.3 & 28.3 & 23.7 & 30.1 & 32.0 & 29.8 & & 30.5 & 34.2 & ND & 29.8 & 63.3 & 38.1 & ND & ND & ND & 30.0 & 27.3 & 32.2 & 32.2 \\
\hline Propionaldehyde & 46.0 & 39.8 & 42.5 & 44.7 & 48.0 & 56.6 & & 53.9 & 60.9 & 45.0 & 44.3 & 41.3 & 53.0 & ND & ND & ND & 43.7 & 51.2 & 72.2 & 41.2 \\
\hline Crotonaldehyde & 14.6 & 18.6 & 11.1 & 23.8 & 13.9 & 12.2 & & 17.0 & 20.1 & ND & 17.5 & 47.7 & 17.1 & ND & ND & ND & 11.9 & 11.2 & 20.2 & 12.7 \\
\hline $\mathrm{HCN}$ & 101.9 & 94.0 & 94.8 & 119.2 & 113.3 & 133.0 & & 122.5 & ND & 82.0 & 164.1 & 53.1 & 123.4 & 74.3 & 149.3 & ND & 106.9 & ND & 92.0 & ND \\
\hline NO & 218.6 & 236.6 & 225.1 & 248.1 & 195.2 & 181.7 & & 159.7 & ND & 252.0 & ND & 228.7 & 237.3 & ND & 190.9 & ND & 233.8 & ND & 228.2 & ND \\
\hline Phenol & 11.0 & 7.7 & 5.1 & 10.2 & 6.4 & 5.8 & & 7.2 & 8.0 & 6.8 & 7.5 & 5.7 & 10.0 & 6.1 & 8.7 & ND & 7.8 & 7.9 & 9.0 & 7.2 \\
\hline o-Cresol & 3.1 & 2.3 & 1.3 & 3.2 & 2.2 & 1.8 & & 2.2 & 2.1 & ND & 2.0 & 1.2 & 2.1 & 2.7 & 2.1 & ND & 2.3 & 2.9 & 3.0 & 1.6 \\
\hline$m / p$-Cresol & 8.1 & 6.4 & 3.5 & 8.2 & 6.6 & 5.8 & & 5.9 & 5.7 & ND & 5.3 & 3.6 & 6.0 & 7.5 & 5.0 & ND & 6,4 & 7.5 & 8.1 & 4.8 \\
\hline Hydroquinone & 33.9 & 33.8 & 28.6 & 33.5 & 32.6 & 31.9 & & 31.0 & 30.9 & ND & 36.0 & 30.2 & 43.7 & 26.5 & 34.2 & ND & 30.1 & 32.5 & 31.4 & 22.2 \\
\hline Catechol & 44.4 & 43.7 & 34.1 & 40.5 & 41.1 & 41.2 & & 40.0 & 40.2 & & 39.5 & 36.1 & 41.3 & 44.4 & 38.8 & ND & 39.7 & 40.6 & 44.3 & 33.8 \\
\hline Resorchinol & 0.7 & 2.7 & 0.7 & 1.0 & 0.8 & 0.7 & & 0.7 & 0.7 & & NN & 1.3 & 0.8 & 0.6 & 2.0 & ND & 0.6 & 0.6 & 0.7 & 2.7 \\
\hline 1,3-Butadiene & 32.1 & 24.6 & 68.7 & 38.7 & 32.5 & ND & 30.1 & 35.2 & ND & & 22.4 & ND & 36.7 & ND & ND & ND & 37.0 & 39.5 & 39.4 & 61.9 \\
\hline Isoprene & 342.0 & 364.4 & 304.8 & 404.3 & 276.7 & 303.0 & 312.5 & 412.7 & ND & & 284.4 & 381.1 & 368.5 & 293.3 & ND & ND & 316.5 & 449.5 & 315.7 & 300.0 \\
\hline Acrylonitrile & 7.7 & 7.5 & 16.1 & 7.0 & 8.8 & 10.1 & 10.2 & 8.6 & ND & & 8.4 & 14.0 & 9.2 & 5.6 & ND & ND & 8.1 & 9.5 & 12.0 & 4.9 \\
\hline Benzene & 34.7 & 39.2 & 43.3 & 35.0 & 46.5 & 38.0 & 47.2 & 46.6 & ND & & 45.3 & 54.9 & 46.4 & 40.8 & ND & ND & 35.7 & 45.3 & 47.4 & 12.9 \\
\hline Toluene & 57.9 & 58.2 & 66.7 & 44.0 & 66.3 & 61.9 & & 79.9 & ND & & 82.8 & 85.4 & 76.9 & 69.1 & ND & ND & 56.9 & 73.4 & 70.8 & 5.6 \\
\hline NNN & 137.6 & ND & 154.3 & 126.1 & 120.0 & 119.3 & 119.1 & 142.2 & ND & & 144.9 & ND & 143.8 & ND & ND & ND & 144.7 & 127.9 & 133.8 & $144-8$ \\
\hline NAT & 117.9 & ND & 136.2 & 119.5 & 112.7 & 112.3 & 110.0 & 118.6 & ND & & 115.0 & ND & 125.6 & ND & ND & ND & 138.2 & 107.4 & 119.6 & 141.1 \\
\hline NNK & 119.9 & ND & 151.6 & 118.9 & 109.7 & 115.0 & 112.2 & 131.2 & ND & & 140.9 & ND & 122.7 & ND & ND & ND & 134.3 & 103.0 & 117.5 & 135.8 \\
\hline NAB & 13.1 & ND & 16.0 & 14.6 & 13.5 & 12.2 & 12.4 & 12.7 & ND & & 14.2 & ND & 13.5 & ND & ND & ND & 16.4 & 12.2 & 11.2 & 17.2 \\
\hline Pyridine & 5.0 & ND & ND & 5.8 & 5.7 & 9.7 & & 5.2 & 4.2 & & 6.2 & 5.3 & 5.8 & 6.0 & 10.6 & ND & 8.7 & 6.8 & 7.8 & 1.1 \\
\hline Quinoline & 1.18 & ND & ND & 0.24 & 0.35 & 0.25 & & 0.20 & 0.21 & & 0.26 & 0.20 & 0.3 & 0.21 & 0.23 & ND & 0.23 & ND & 0.33 & 0.85 \\
\hline Styrene & 3.8 & ND & 3.4 & 3.7 & 6.6 & $n / p$ & & 5.8 & $n / p$ & & 5.9 & 2.4 & 6.3 & 3.3 & 10.6 & ND & 6.8 & 5.3 & 5.0 & 0.7 \\
\hline
\end{tabular}

Note: Each mean value in this table is the simple average of all individual replicates across 3 experiments 
Appendix 3. Summary of all received mean data on Kentucky Reference 1R5F cigarettes

Table A8. Summary of all received mean data on 1R5F cigarettes in laboratories 1-19

\begin{tabular}{|c|c|c|c|c|c|c|c|c|c|c|c|c|c|c|c|c|c|c|c|c|}
\hline Smoke analyte & 1 & 2 & 3 & 4 & 5 & $6 \mathrm{~A}$ & $6 \mathrm{~B}$ & 7 & 8 & 9 & 10 & 11 & 12 & 13 & 14 & 15 & 16 & 17 & 18 & 19 \\
\hline Ammonia & 2.7 & ND & 5.5 & 2.8 & 2.8 & 2.2 & & 3.2 & ND & ND & ND & 2.9 & 4.9 & ND & 1.4 & ND & 3.3 & 2.0 & 3.0 & ND \\
\hline 1-Naphthyl amine & 3.1 & ND & 0.3 & 4.5 & 6.9 & 3.4 & & 2.9 & ND & ND & ND & ND & 2.5 & 5.4 & ND & ND & 4.1 & 3.2 & 2.7 & 4.9 \\
\hline 2-Naphthyl amine & 2.3 & ND & 0.7 & 3.1 & $<3.4$ & 2.8 & & 1.9 & ND & 1.7 & ND & ND & 2.0 & 4.2 & ND & ND & 2.7 & 2.0 & 2.8 & 2.6 \\
\hline 3-Amino biphenyl & 0.7 & ND & 0.2 & 0.8 & $<1.1$ & 0.8 & & 0.8 & ND & ND & ND & ND & 0.9 & 1.5 & ND & ND & 0.7 & 0.6 & 1.4 & 1.6 \\
\hline 4-Amino biphenyl & 0.5 & ND & 0.2 & 0.6 & 0.6 & 0.6 & & 0.5 & ND & 0.3 & ND & ND & 0.7 & 1.6 & ND & ND & 0.6 & 0.4 & 0.9 & 0.7 \\
\hline $\mathrm{B}[\mathrm{a}] \mathrm{P}$ & 1.1 & ND & 1.7 & 1.3 & 2.4 & 1.0 & & 1.3 & ND & 1.7 & 1.8 & 1.8 & 1.6 & 1.8 & 1.6 & 1.5 & 1.2 & 1.8 & 1.4 & 2.6 \\
\hline Formaldehyde & 3.6 & 3.7 & 4.2 & 3.4 & 8.8 & 1.5 & & 2.7 & 3.8 & 2.8 & 2.1 & 17.7 & 3.0 & ND & 5.1 & ND & 4.5 & 1.8 & 5.0 & 2.3 \\
\hline Acetaldehyde & 147.2 & 110.5 & 136.3 & 161.7 & 154.5 & 176.7 & & 164.4 & 189.5 & 160.5 & 148.3 & 167.3 & 130.8 & ND & ND & ND & 131.3 & 150.8 & 174.4 & 168.4 \\
\hline Acrolein & 10.7 & 9.6 & 12.7 & 12.9 & 11.6 & 11.2 & & 12.0 & 11.9 & 12.5 & 9.7 & 3.1 & 11.2 & ND & ND & ND & 11.8 & 7.7 & 6.2 & 6.9 \\
\hline Acetone & 89.5 & 70.4 & 69.1 & 65.3 & 94.7 & 68.8 & & 82.8 & 68.7 & ND & 64.8 & 68.5 & 62.4 & ND & ND & ND & 87.5 & 81.7 & 95.2 & 83.4 \\
\hline MEK & 17.8 & 15.6 & 13.0 & 14.7 & 18.9 & 19.7 & & 22.6 & 22.3 & ND & 14.4 & 12.9 & 44.7 & ND & ND & ND & 17.2 & 15.7 & 15.1 & 22.7 \\
\hline Butyraldehyde & 8.3 & 8.5 & 7.5 & 8.8 & 9.4 & 8.1 & & 8.6 & 10.0 & ND & 8.0 & 20.1 & 6.2 & ND & ND & ND & 9.8 & 6.9 & 10.5 & 11.3 \\
\hline Propionaldehyde & 11.6 & 10.6 & 13.1 & 11.6 & 14.1 & 13.9 & & 14.5 & 17.0 & 14.4 & 11.3 & 12.5 & 9.5 & ND & ND & ND & 13.3 & 12.2 & 23.2 & 12.5 \\
\hline Crotonaldehyde & 2.0 & 3.7 & 2.2 & 4.3 & 1.9 & 0.6 & & 2.2 & 3.1 & ND & 3.2 & 2.3 & 3.6 & ND & ND & ND & 2.3 & 1.3 & 4.4 & 2.4 \\
\hline $\mathrm{HCN}$ & 19.3 & 18.4 & 17.5 & 14.3 & 21.5 & 20.7 & & 21.5 & ND & 17.5 & 39.8 & 13.8 & 19.4 & 5.7 & 36.3 & ND & 20.1 & ND & 14.1 & ND \\
\hline NO & 126.0 & 123.0 & 94.1 & 113.8 & 85.7 & 89.6 & & 62.7 & ND & 122.9 & ND & 103.2 & 78.5 & ND & 103.3 & ND & 114.7 & ND & 100.2 & ND \\
\hline Phenol & 1.4 & 0.7 & 0.6 & 1.4 & 0.8 & 0.6 & & 1.0 & 0.9 & 1.2 & 1.6 & 0.7 & 1.3 & 0.5 & 0.9 & ND & 0.9 & 0.6 & 0.3 & 1.1 \\
\hline o-Cresol & 0.5 & 0.2 & 0.3 & 0.5 & 0.4 & 0.2 & & 0.5 & 0.4 & ND & 0.5 & 0.2 & 0.7 & 0.3 & 0.2 & ND & 0.3 & 0.4 & 0.2 & 0.1 \\
\hline$m / p$-Cresol & 1.4 & 0.5 & 0.7 & 1.4 & 1.1 & 0.8 & & 1.2 & 0.7 & ND & 1.3 & 0.6 & 0.9 & 1.0 & 0.6 & ND & 1.0 & 1.0 & 1.0 & 0.6 \\
\hline Hydroquinone & 8.6 & 9.2 & 9.0 & 8.8 & 8.4 & 5.9 & & 8.3 & 7.1 & ND & 12.9 & 7.9 & 6.1 & 6.1 & 7.9 & ND & 7.7 & 6.8 & 5.0 & 5.0 \\
\hline Catechol & 0.2 & 9.1 & 8.2 & 8.7 & 8.5 & 8.1 & & 9.2 & 7.9 & 8.6 & 11.6 & 7.7 & 8.1 & 8.2 & 7.1 & ND & 8.1 & 7.2 & 6.8 & 6.0 \\
\hline Resorchinol & 8.3 & 0.6 & 0.2 & 0.2 & 0.2 & 0.1 & & $<L O Q$ & 0.1 & ND & ND & 0.3 & $<0.1$ & 0.1 & $\begin{array}{c}<\mathrm{LOQ} \\
0.5\end{array}$ & ND & 0.2 & 0.1 & 0.1 & 0.5 \\
\hline 1,3-Butadiene & 96.0 & 7.9 & 22.0 & 11.5 & 9.5 & ND & 8.8 & 11.1 & ND & 13.5 & 7.2 & ND & 11.0 & ND & ND & ND & 11.3 & 11.0 & 10.5 & 18.1 \\
\hline Isoprene & 1.9 & 123.2 & 103.6 & 132.0 & 102.2 & 89.0 & 107.2 & 131.7 & $n / p$ & 137.4 & 80.2 & 121.5 & 102.9 & 87.3 & ND & ND & 102.6 & 134.8 & 113.8 & 92.0 \\
\hline Acrylonitrile & 9.0 & 1.6 & 3.7 & 1.9 & 2.5 & 2.4 & 3.3 & 1.9 & $n / p$ & 8.5 & 2.3 & 3.3 & 3.1 & 1.8 & ND & ND & 2.0 & 1.7 & 2.0 & 1.1 \\
\hline Benzene & 13.0 & 12.2 & 13.2 & 11.7 & 14.5 & 9.6 & 14.5 & 14.5 & $n / p$ & 17.9 & 13.2 & 15.0 & 12.9 & 12.5 & ND & ND & 11.2 & 12.8 & 13.5 & 3.6 \\
\hline Toluene & 41.0 & 14.3 & 17.3 & 12.2 & 23.8 & 14.3 & & 20.9 & $n / p$ & 24.4 & 21.3 & 27.4 & 16.0 & 22.2 & ND & ND & 16.8 & 19.7 & 20.6 & 1.4 \\
\hline NNN & 39.1 & ND & 52.9 & 43.4 & 43.9 & 32.2 & 35.5 & 50.5 & ND & 46.0 & 48.0 & ND & 53.4 & ND & ND & ND & 48.4 & 37.9 & 36.4 & 41.1 \\
\hline NAT & 20.2 & ND & 52.0 & 45.7 & 46.1 & 34.2 & 37.5 & 48.6 & ND & ND & 39.0 & ND & 43.4 & ND & ND & ND & 51.7 & 35.7 & 31.9 & 47.0 \\
\hline NNK & 5.1 & ND & 30.2 & 20.4 & 22.5 & 17.5 & 18.9 & 25.5 & ND & 21.2 & 23.8 & ND & 25.8 & ND & ND & ND & 24.0 & 17.1 & 17.5 & 25.4 \\
\hline NAB & 0.8 & ND & 7.7 & 6.5 & 6.1 & $\begin{array}{c}<\mathrm{LOQ} \\
10\end{array}$ & $\begin{array}{c}<\mathrm{LOQ} \\
10\end{array}$ & 6.2 & ND & ND & 5.8 & ND & $<\mathrm{LOQ}$ & ND & ND & ND & 7.5 & 4.8 & 3.6 & 7.2 \\
\hline Pyridine & 0.04 & ND & ND & 0.6 & 0.9 & 1.6 & & 0.6 & 0.6 & ND & 1.2 & 1.6 & 0.6 & 1.1 & 4.3 & ND & 1.8 & 1.6 & 0.9 & 0.2 \\
\hline Quinoline & 0.6 & ND & ND & 0.06 & 0.06 & 0.05 & & 0.07 & 0.04 & ND & 0.06 & $<L O Q$ & 0.04 & 0.04 & $\begin{array}{c}<\mathrm{LOQ} \\
0.1\end{array}$ & ND & 0.05 & ND & 0.06 & 0.12 \\
\hline Styrene & & ND & 1.1 & 0.8 & 1.6 & $n / p$ & & 1.3 & $n / p$ & 1.7 & 1.5 & 1.3 & $<2.0$ & 1.4 & 1.9 & ND & 2.3 & 3.2 & 1.2 & 0.1 \\
\hline
\end{tabular}

Note: Each mean value in this table is the simple average of all individual replicates across 3 experiments

Appendix 4. Summary of all received mean data on Kentucky Reference 2R4F cigarettes

Table A9. Summary of mean data, standard deviation (SD), coefficient of variation \% (CoV), maximum yield (Max), minimum yield (Min) and Max/Min on 2R4F cigarettes The mean and SD were calculated directly from the individual laboratory mean values shown in Appendix 2.

\begin{tabular}{|c|c|c|c|c|c|c|c|}
\hline Smoke analyte & Mean & SD & CoV\% & $\operatorname{Max}$ & Min & Min/Max & Data Sets \\
\hline Catachol & 40.1 & 3.2 & 7.9 & 44.4 & 33.8 & 1.3 & 18 \\
\hline NNN & 135.2 & 11.3 & 8.3 & 154.3 & 119.1 & 1.3 & 14 \\
\hline NAT & 121.1 & 11.0 & 9.1 & 141.1 & 107.4 & 1.3 & 13 \\
\hline Acetone & 270.4 & 28.7 & 10.6 & 329.9 & 227.1 & 1.5 & 15 \\
\hline NNK & 123.7 & 13.4 & 10.6 & 151.6 & 103.0 & 1.5 & 14 \\
\hline NO & 218.1 & 27.8 & 12.7 & 252.0 & 159.7 & 1.6 & 13 \\
\hline NAB & 13.8 & 1.8 & 13.2 & 17.2 & 11.2 & 1.5 & 13 \\
\hline Hydroquinone & 31.9 & 4.4 & 13.9 & 43.7 & 22.2 & 2.0 & 17 \\
\hline Acetaldehyde & 587.4 & 83.2 & 14.2 & 732.8 & 435.9 & 1.7 & 16 \\
\hline $\mathrm{B}[\mathrm{a}] \mathrm{P}$ & 7.1 & 1.0 & 14.3 & 8.9 & 5.6 & 1.6 & 17 \\
\hline Isoprene & 341.2 & 50.5 & 14.8 & 449.5 & 276.7 & 1.6 & 17 \\
\hline Propionaldehyde & 49.0 & 8,7 & 17.7 & 72.2 & 39.8 & 1.8 & 16 \\
\hline Phenol & 7.7 & 1.6 & 21.3 & 11.0 & 5.1 & 2.2 & 18 \\
\hline Benzene & 41.8 & 9.4 & 22.5 & 54.9 & 12.9 & 4.2 & 17 \\
\hline$m / p$-Cresol & 6.2 & 1.4 & 23.3 & 8.2 & 3.5 & 2.3 & 17 \\
\hline MEK & 72.5 & 17.5 & 24.1 & 114.9 & 45.8 & 2.5 & 15 \\
\hline Formaldehyde & 20.6 & 5.1 & 24.8 & 29.8 & 8.6 & 3.5 & 17 \\
\hline o-Cresol & 2.2 & 0.6 & 26.0 & 3.2 & 1.2 & 2.5 & 17 \\
\hline
\end{tabular}




\begin{tabular}{|c|c|c|c|c|c|c|c|}
\hline Smoke analyte & Mean & SD & CoV\% & Max & Min & Min/Max & Data Sets \\
\hline $\mathrm{HCN}$ & 108.2 & 28.7 & 26.6 & 164.1 & 53.1 & 3.1 & 15 \\
\hline 3-Amino biphenyl & 2.2 & 0.6 & 26.6 & 3.9 & 1.6 & 2.5 & 12 \\
\hline 2-Naphthyl amine & 8.4 & 2.3 & 27.0 & 13.2 & 4.7 & 2.8 & 13 \\
\hline Acrolein & 50.8 & 13.9 & 27.3 & 61.7 & 4.9 & 12.6 & 16 \\
\hline Butyraldehyde & 32.8 & 9.0 & 27.4 & 63.3 & 23.7 & 2.7 & 15 \\
\hline 1-Naphthyl amine & 12.0 & 3.3 & 27.6 & 18.1 & 7.0 & 2.6 & 12 \\
\hline Toluene & 65.0 & 19.6 & 30.1 & 85.4 & 5.6 & 15.2 & 16 \\
\hline 1.3-Butadiene & 38.2 & 12.7 & 33.2 & 68.7 & 22.4 & 3.1 & 14 \\
\hline 4-Amino Biphenyl & 1.5 & 0.5 & 33.7 & 3.0 & 1.0 & 3.0 & 13 \\
\hline Pyridine & 6.3 & 2.3 & 36.9 & 10.6 & 1.1 & 10.0 & 15 \\
\hline Ammonia & 11.5 & 4.6 & 40.3 & 25.4 & 6.6 & 3.9 & 12 \\
\hline Acrylonitrile & 10.1 & 4.5 & 44.7 & 23.9 & 4.9 & 4.9 & 17 \\
\hline Styrene & 5.0 & 2.3 & 46.1 & 10.6 & 0.7 & 14.4 & 15 \\
\hline Crotonaldehyde & 18.0 & 9.1 & 50.4 & 47.7 & 11.1 & 4.3 & 15 \\
\hline Quinoline & 0.3 & 0.2 & 58.8 & 0.9 & 0.2 & 4.7 & 14 \\
\hline Resorcinol & 1.1 & 0.7 & 68.6 & 2.7 & 0.6 & 4.5 & 16 \\
\hline
\end{tabular}

Appendix 5. Summary of all received mean data on Kentucky Reference 1R5F cigarettes

Table A10. Summary of mean data, standard deviation (SD), coefficient of variation \% (CoV), maximum yield (Max), minimum yield (Min) and Max/Min on 1 R5F cigarettes The mean and SD were calculated directly from the individual laboratory mean values shown in Appendix 3 .

\begin{tabular}{|c|c|c|c|c|c|c|c|}
\hline Smoke analyte & Mean & SD & CoV\% & Max & Min & Min/Max & Data Sets \\
\hline Acetaldehyde & 158.2 & 17.4 & 11.0 & 189.5 & 130.8 & 1.4 & 14 \\
\hline Catechol & 8.1 & 1.2 & 15.1 & 11.6 & 6.0 & 1.9 & 16 \\
\hline Acetone & 76.4 & 11.6 & 15.2 & 95.2 & 62.4 & 1.5 & 13 \\
\hline NNN & 43.8 & 6.9 & 15.7 & 53.4 & 32.2 & 1.7 & 13 \\
\hline NAT & 42.7 & 6.9 & 16.1 & 52.0 & 31.9 & 1.6 & 12 \\
\hline Isoprene & 109.2 & 18.6 & 17.0 & 137.4 & 80.2 & 1.7 & 15 \\
\hline NNK & 22.3 & 4.0 & 17.8 & 30.2 & 17.1 & 1.8 & 13 \\
\hline NO & 97.2 & 17.5 & 18.0 & 122.9 & 62.7 & 2.0 & 11 \\
\hline NAB & 6.2 & 1.3 & 21.5 & 7.7 & 3.6 & 2.1 & 9 \\
\hline Propionaldehyde & 13.8 & 3.2 & 23.4 & 23.2 & 9.5 & 2.4 & 14 \\
\hline Benzene & 12.7 & 3.1 & 24.8 & 17.9 & 3.6 & 5.0 & 15 \\
\hline $\mathrm{B}[\mathrm{a}] \mathrm{P}$ & 1.6 & 0.4 & 25.2 & 2.6 & 1.0 & 2.6 & 16 \\
\hline Hydrtoquinone & 7.5 & 2.0 & 26.1 & 12.9 & 5.0 & 2.6 & 15 \\
\hline$m / p$-Cresol & 0.9 & 0.3 & 28.5 & 1.4 & 0.6 & 2.5 & 15 \\
\hline Acrolein & 10.1 & 3.0 & 29.4 & 12.9 & 3.1 & 4.1 & 14 \\
\hline 1,3-Butadiene & 12.1 & 4.1 & 33.8 & 22.0 & 7.2 & 3.0 & 12 \\
\hline Toluene & 18.5 & 6.4 & 34.8 & 27.4 & 1.4 & 19.4 & 14 \\
\hline Butyraldehyde & 9.6 & 3.5 & 36.0 & 20.1 & 6.2 & 3.2 & 13 \\
\hline 2-Naphthyl amine & 2.4 & 0.9 & 37.3 & 4.2 & 0.7 & 5.9 & 11 \\
\hline Phenol & 0.9 & 0.3 & 37.5 & 1.6 & 0.3 & 4.7 & 16 \\
\hline Quinoline & 0.1 & 0.0 & 38.2 & 0.1 & 0.0 & 3.0 & 11 \\
\hline Ammonia & 3.1 & 1.2 & 39.0 & 5.5 & 1.4 & 4.0 & 11 \\
\hline o-Cresol & 0.3 & 0.1 & 42.0 & 0.7 & 0.1 & 4.6 & 15 \\
\hline Crotonaldehyde & 2.6 & 1.1 & 42.1 & 4.4 & 0.6 & 7.3 & 13 \\
\hline MEK & 19.5 & 8.4 & 42.8 & 44.7 & 12.9 & 3.5 & 13 \\
\hline $\mathrm{HCN}$ & 20.2 & 9.1 & 45.0 & 39.8 & 5.7 & 7.0 & 13 \\
\hline 1-Naphthylamine & 3.7 & 1.7 & 47.1 & 6.9 & 0.3 & 23.0 & 11 \\
\hline 3-Amino biphenyl & 0.9 & 0.4 & 47.2 & 1.6 & 0.2 & 7.9 & 10 \\
\hline Styrene & 1.5 & 0.7 & 50.0 & 3.2 & 0.1 & 35.6 & 13 \\
\hline 4-Amino biphenyl & 0.6 & 0.4 & 56.8 & 1.6 & 0.2 & 8.1 & 12 \\
\hline Resorcinol & 0.2 & 0.1 & 61.3 & 0.5 & 0.1 & 5.3 & 11 \\
\hline Acrylonitrile & 2.8 & 1.7 & 63.1 & 8.5 & 1.1 & 7.5 & 15 \\
\hline Pyridine & 1.2 & 1.0 & 80.6 & 4.3 & 0.2 & 22.6 & 14 \\
\hline Formaldehyde & 4.6 & 4.1 & 88.7 & 17.7 & 1.5 & 11.8 & 15 \\
\hline
\end{tabular}


Appendix 6. Statistical analysis - removed data

Table A11. Statistical analysis - removed data $(L O Q=$ limit of quantification)

\begin{tabular}{|c|c|c|c|c|}
\hline Smoke analyte & Lab no. & Data removed from statistical analyses & Lab no. & $\begin{array}{c}\text { Data excluded in comparison of } 2 \mathrm{R} 4 \mathrm{~F} \\
\text { vs } 1 \mathrm{R} 5 \mathrm{~F} \text { within a laboratory }\end{array}$ \\
\hline Quinoline & 10 & Removed - LOQ related & $\begin{array}{l}6 \mathrm{~B} \\
14\end{array}$ & \multirow{10}{*}{$\begin{array}{l}\text { Some or all values were below the } \\
\text { LOQ giving unbalanced comparisons } \\
\text { between } 1 \mathrm{R} 5 \mathrm{~F} \text { and } 2 \mathrm{R} 4 \mathrm{~F} \text { cigarettes } \\
\text { Data was only excluded for } \\
\text { differentiations between } 2 \mathrm{R} 4 \mathrm{~F} \text { and } \\
\text { 1R5F in section } 4.3 .4\end{array}$} \\
\hline Acrylonitrile & 10 & Removed - LOQ related & & \\
\hline Toluene & $6 \mathrm{~B}$ & 1 value removed - transcription error? & & \\
\hline Toluene & 5 & Removed - LOQ related & & \\
\hline 2-Amino naphthalene & 5 & Removed - LOQ related & & \\
\hline 3-Amino biphenyl & 13 & Less than 10 data points & 5 & \\
\hline Resorcinol & & & $\begin{array}{c}7 \\
12 \\
14\end{array}$ & \\
\hline o-Cresol & & & 7 & \\
\hline Styrene & & & 12 & \\
\hline NAB & & & $\begin{array}{l}6 \mathrm{~A} \\
6 \mathrm{~B} \\
12\end{array}$ & \\
\hline
\end{tabular}

Appendix 7. Statistical analysis - Estimation of values of within-laboratory $(r)$ and among laboratory $(R)$ variability

The statistical analysis (as used in the Experimental section) is based in principle on the recommended International Standard ISO 5725 method (22) as described in part 2 and part 6, section 4 of the standard.

The following mathematical equations were used to calculate the values of $r$ and $R$ for sample A. Values for sample B are obtained in a similar way.

$$
\begin{aligned}
& r=2\left\{2\left[\operatorname{SD}\left(r_{\mathrm{A}}\right)^{2} / 5\right]\right\}^{1 / 2} \\
& R=2\left\{2\left[\operatorname{SD}\left(L_{\mathrm{A}}\right)^{2}+\left(\operatorname{SD}\left(r_{\mathrm{A}}\right)^{2} / 5\right)\right]\right\}^{1 / 2} \\
& \% \operatorname{CoV}(r)=100 r / \text { Mean A } \\
& \% \operatorname{CoV}(R)=100 \mathrm{R} / \text { Mean A }
\end{aligned}
$$

where

- $\operatorname{SD}\left(L_{\mathrm{A}}\right)$ and $\operatorname{SD}\left(L_{\mathrm{B}}\right)$ are the standard deviations among laboratories for samples A (2R4F) and B (1R5F)

- $\mathrm{SD}\left(r_{\mathrm{A}}\right)$ and $\mathrm{SD}\left(r_{\mathrm{B}}\right)$ are the standard deviations between replicates, pooled over laboratories and experiments. The denominator 5 in the equation is included to define $r$ for differences under within-laboratory variability conditions between the average of 5 replicates for each analyte.

- Mean A-B is the mean difference between samples A (2R4F) and $\mathrm{B}(1 \mathrm{R} 5 \mathrm{~F})$, averaged across laboratories.

- $\mathrm{CoV}$ is the coefficient of variation

- Sample A = 2R4F Kentucky reference cigarette

- Sample B $=1$ R5F Kentucky reference cigarette

The statistical analysis (as used in the Individual Methodology discussion section) is again based in principle on the recommend International Standard ISO method (22) but in this case the variation among all 15 replicates from each laboratory was used to define the 'within lab' variance.

$$
s_{r}^{2}=\frac{\sum_{i=1}^{p}\left(n_{i}-1\right) s_{i}^{2}}{\sum_{i=1}^{p}\left(n_{i}-1\right)}
$$

is the within-laboratory variance for an analyte,

where

$p=$ total number of laboratories whose data is being used,

$n_{i}=$ the number of data points reported for lab $i$ (generally 15 , replicates pooled for all experiments),

$s_{i}=$ the standard deviation among replicates and experiments for lab $i$,

$s_{R}^{2}=s_{L}^{2}+s_{r}^{2}$ is the among-laboratory variability variance for an analyte,

$$
\begin{gathered}
s_{R}^{2}=\frac{s_{d}^{2}-s_{r}^{2}}{\bar{n}} \text { where } s_{d}^{2}=\frac{1}{p-1} \sum_{i=1}^{p} n_{i}\left(\overline{y_{i}}-\overline{\bar{y}}\right)^{2} \\
\text { and } \bar{n}=\frac{1}{p-1} \cdot \sum_{i=1}^{p} n_{i}-\frac{\sum_{i=1}^{p} n_{i}^{2}}{\sum_{i=1}^{p} n_{i}},
\end{gathered}
$$

$\overline{y_{i}}=$ is the mean analyte yield for laboratory $i$ and

$\overline{\overline{y_{i}}}=$ the analyte yield grand mean over all laboratories and replicates,

$r=2\left(2 \times S_{\mathrm{r}}^{2}\right)^{1 / 2}$,

$R=2\left(2 \times S_{\mathrm{R}}^{2}\right)^{1 / 2}$. 
Table A12. Within-laboratory $(r)$ and among laboratory $(R)$ variability values

\begin{tabular}{|c|c|c|c|c|c|c|c|}
\hline Smoke analyte & No. of labs & $\begin{array}{l}\text { Mean } \\
\text { 2R4F }\end{array}$ & $\stackrel{r}{r} 2 \mathrm{R} 4 \mathrm{~F}$ & $\begin{array}{c}R \\
2 \mathrm{R} 4 \mathrm{~F}\end{array}$ & $\begin{array}{c}\text { Mean } \\
\text { 1R5F }\end{array}$ & $\stackrel{r}{r}$ & $\underset{1 \mathrm{R} 5 \mathrm{~F}}{R}$ \\
\hline Ammonia & 11 & 11.58 & 0.94 & 13.85 & 3.06 & 0.32 & 3.51 \\
\hline Formaldehyde & 16 & 20.96 & 2.46 & 14.76 & 3.64 & 0.68 & 5.20 \\
\hline Acetaldehyde & 15 & 589.1 & 41.82 & 250.4 & 153.7 & 20.9 & 63.2 \\
\hline Acetone & 14 & 272.3 & 20.48 & 86.74 & 77.46 & 10.28 & 38.53 \\
\hline Acrolein & 15 & 53.90 & 4.67 & 21.24 & 10.56 & 1.72 & 6.49 \\
\hline Propionaldehyde & 15 & 49.53 & 3.60 & 25.50 & 13.50 & 1.84 & 9.63 \\
\hline Crotonaldehyde & 14 & 15.84 & 1.85 & 11.62 & 2.64 & 0.50 & 3.19 \\
\hline MEK & 14 & 73.08 & 5.95 & 51.66 & 19.59 & 2.66 & 22.71 \\
\hline Butyraldehyde & 14 & 30.67 & 2.43 & 10.09 & 8.70 & 1.16 & 4.47 \\
\hline $\mathrm{HCN}$ & 14 & 112.19 & 12.24 & 73.24 & 22.42 & 3.57 & 25.24 \\
\hline NO & 12 & 217.26 & 11.87 & 83.67 & 101.21 & 8.87 & 58.41 \\
\hline Pyridine & 14 & 6.32 & 0.70 & 6.86 & 1.19 & 0.28 & 3.00 \\
\hline Quinoline & 11 & 0.31 & 0.04 & 0.53 & 0.06 & 0.01 & 0.07 \\
\hline Hydroquinone & 16 & 32.06 & 1.67 & 13.41 & 7.62 & 0.70 & 5.54 \\
\hline Resorcinol & 12 & 1.03 & 0.10 & 2.23 & 0.20 & 0.08 & 0.45 \\
\hline Catechol & 17 & 40.33 & 2.31 & 9.74 & 8.24 & 0.66 & 3.55 \\
\hline Phenol & 17 & 7.78 & 0.69 & 4.77 & 0.93 & 0.20 & 1.04 \\
\hline$m / p$-Cresol & 16 & 6.30 & 0.53 & 3.84 & 0.94 & 0.15 & 0.84 \\
\hline o-Cresiol & 16 & 2.30 & 0.20 & 1.57 & 0.35 & 0.05 & 0.42 \\
\hline 1,3-Butadiene & 14 & 36.17 & 3.67 & 36.23 & 11.55 & 1.13 & 11.67 \\
\hline Isoprene & 16 & 338.57 & 32.75 & 154.10 & 108.48 & 10.70 & 56.28 \\
\hline Acrylonitrile & 15 & 9.94 & 0.90 & 13.44 & 2.62 & 0.35 & 5.08 \\
\hline Benzene & 16 & 41.02 & 3.49 & 26.47 & 12.29 & 1.26 & 9.07 \\
\hline Toluene & 14 & 63.46 & 4.99 & 58.07 & 18.73 & 2.14 & 16.66 \\
\hline Styrene & 13 & 5.12 & 0.73 & 6.75 & 1.42 & 0.28 & 2.23 \\
\hline 1-Naphthyl amine & 12 & 12.04 & 1.10 & 9.75 & 3.66 & 0.32 & 4.76 \\
\hline 2-Naphthyl amine & 12 & 8.31 & 0.70 & 6.66 & 2.40 & 0.24 & 2.41 \\
\hline 3-Amino biphenyl & 10 & 2.16 & 0.22 & 1.90 & 0.84 & 0.13 & 1.12 \\
\hline 4-Amino biphenyl & 13 & 1.50 & 0.31 & 1.53 & 0.63 & 0.14 & 0.98 \\
\hline Benzo[a]pyrene & 16 & 7.12 & 0.55 & 3.23 & 1.60 & 0.27 & 1.36 \\
\hline NNN & 14 & 135.46 & 7.20 & 35.12 & 43.84 & 3.34 & 20.20 \\
\hline NAT & 13 & 121.36 & 7.74 & 32.83 & 42.75 & 3.32 & 20.17 \\
\hline NAB & 10 & 14.19 & 1.44 & 5.90 & 6.10 & 0.68 & 3.89 \\
\hline NNK & 14 & 123.95 & 6.22 & 40.86 & 22.20 & 2.06 & 11.65 \\
\hline
\end{tabular}

Appendix 8. Within-laboratory variability $(r)$

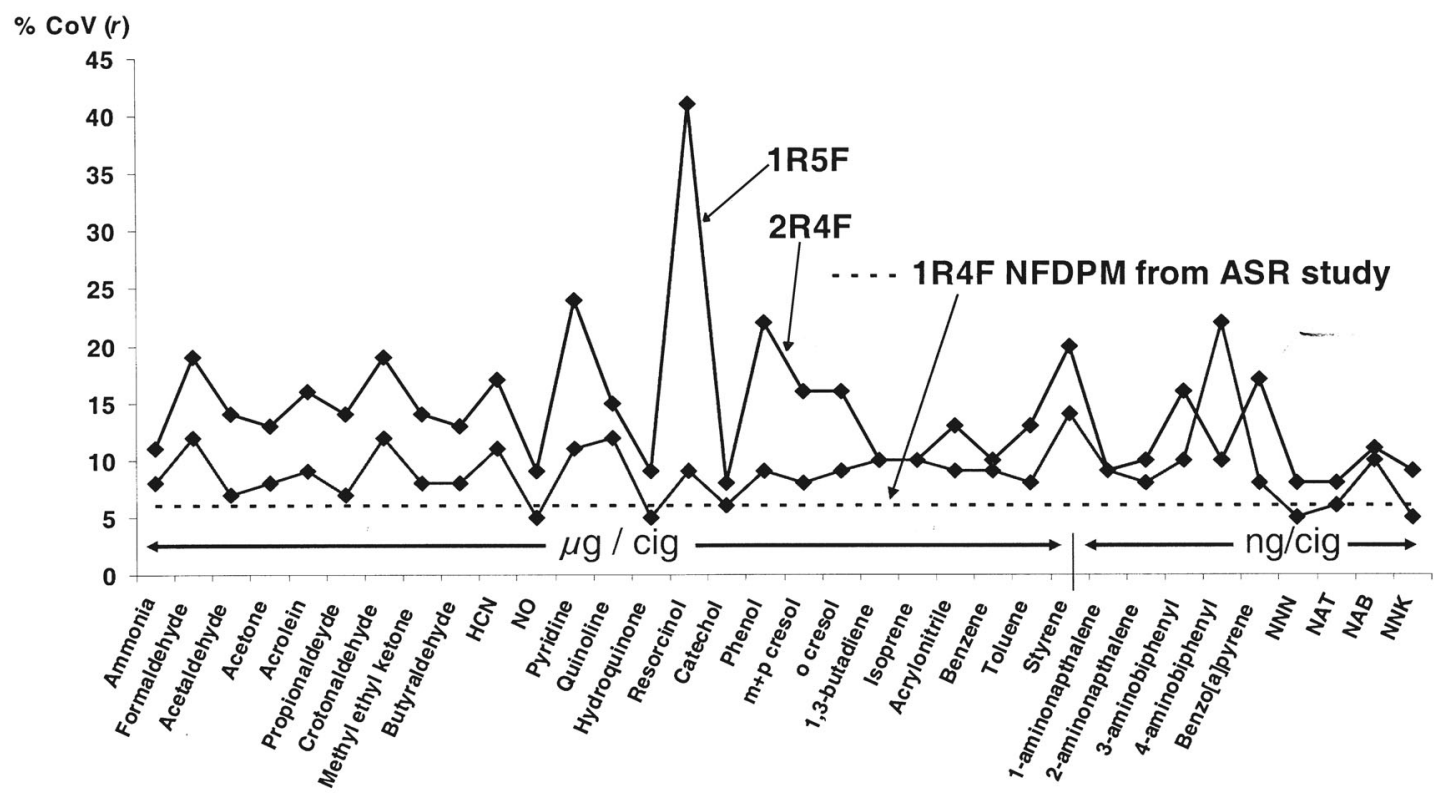

Figure A1. Within-laboratory variability $(r)$ for various analyte yields in 1R5F and 2R4F cigarettes (where ASR $=$ study on alternative smoking regimes (23); $\mathrm{CoV}=$ coefficient of variation 
Appendix 9. Among-laboratory variability $(R)$

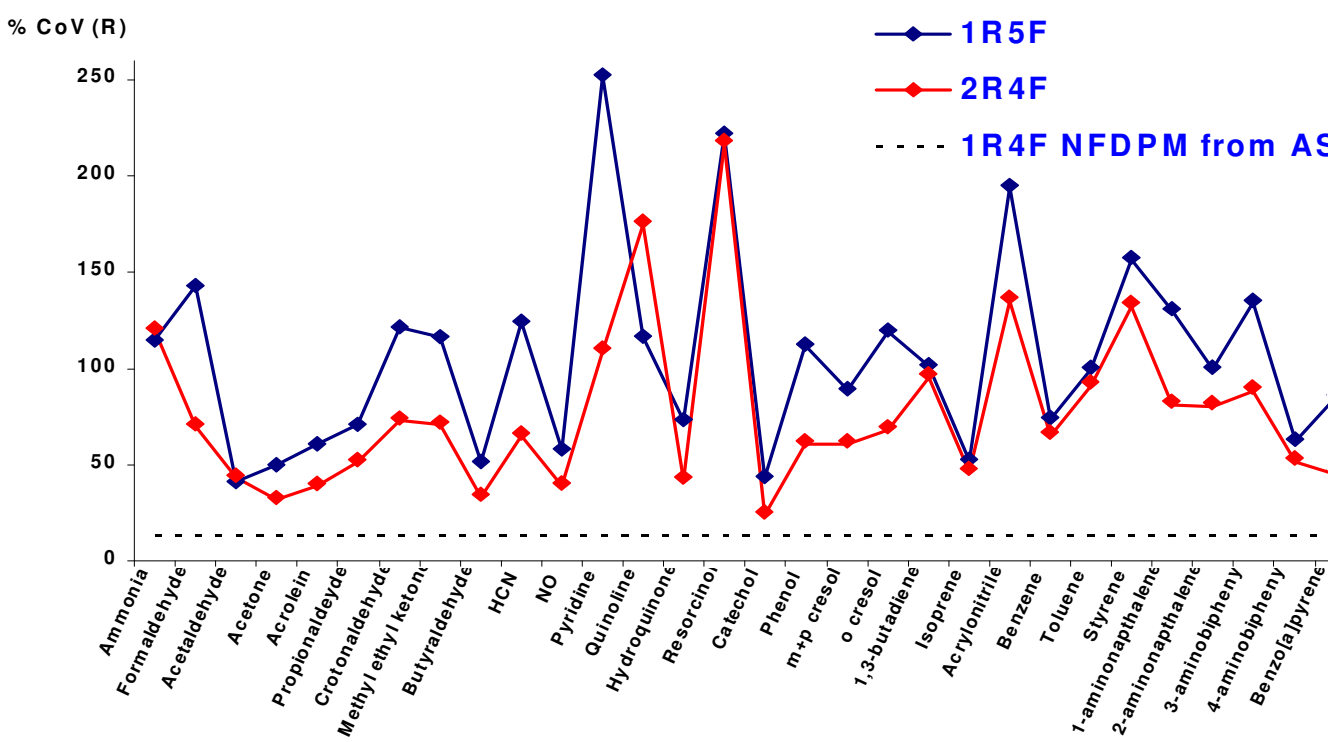

Figure A2. Among-laboratory variability $(R)$ for various analyte yields in $1 \mathrm{R} 5 \mathrm{~F}$ and $2 \mathrm{R} 4 \mathrm{~F}$ cigarettes (where $\mathrm{ASR}=$ study on alternative smoking regimes (23); $\mathrm{CoV}=$ coefficient of variation)

Appendix 10. Normalised analyte variability among laboratories

$\% \operatorname{CoV}\left(\operatorname{SD}(b)=\left\{100 \times\left\{\operatorname{SD}(L)^{2}+\left[\operatorname{SD}(r)^{2} / 5\right]\right\}^{1 / 2}\right\} /\right.$ Mean

where

- $\mathrm{D}(L)$ is the Standard Deviation among laboratories (this includes the additional variability between experiments)
- $\mathrm{SD}(r)$ is the Standard Deviation among replicates, pooled over laboratories and experiments

- Mean is the average yield of each analyte across laboratories.

- $\mathrm{SD}(b)$ can be referred to as the Standard Deviation among laboratories for the average of five replicates.

\section{-2R4F $\cdot 1 \mathrm{R} 5 \mathrm{~F} \triangle \mathrm{NFDPM}$}

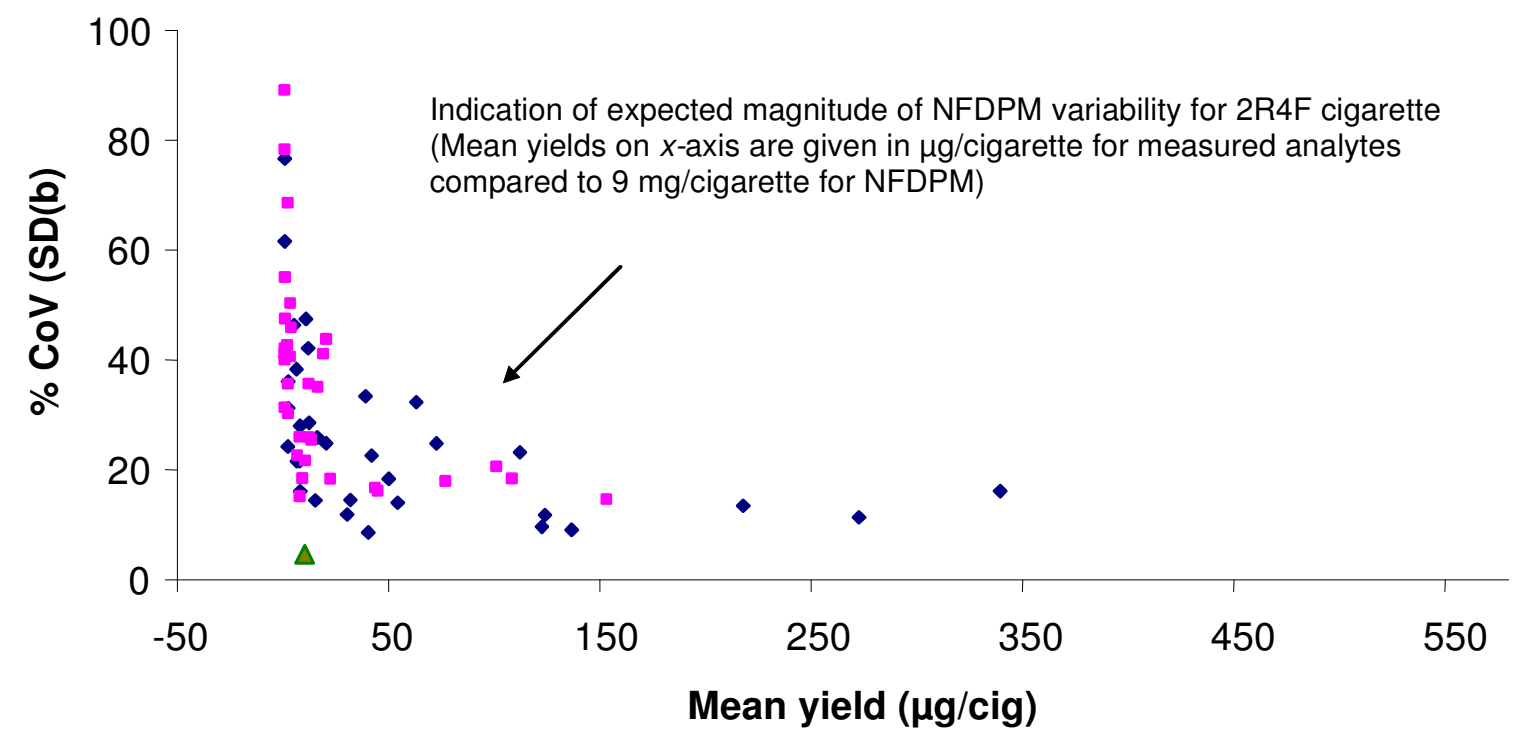

Figure A3. Normalised analyte variability among laboratories (mean yields on $x$-axis are given in $\mu \mathrm{g} / \mathrm{cig}$ for measured analytes compared to $9 \mathrm{mg} / \mathrm{cig}$ for NFDPM) 
A graphical summary of the extent to which each analyte was able to differentiate between samples A and B (2R4F and 1R5F) is given in Appendix 12. In this plot, the vertical axis defines the smallest difference between the mean yields for samples A and B that can be distinguished (with 95\% confidence) when each sample has been tested by separate laboratories. Unavoidably, in order to put the different analytes on a common scale so that they can be directly compared, the precise scale of measurement is rather complicated. For ease of understanding concerning what each point indicates in the context of method standardisation:

- Points on the vertical axis which are $\geq 100$ indicate that for the corresponding analytes it would not be possible to distinguish (with 95\% confidence) between the samples A and B. For these analytes there would appear to be the greatest need to further standardise the laboratory methods.

- Conversely, for analytes whose points on the plot are $<100$, the samples A and B would be distinguished (with 95\% confidence). However, it is suggested that further work is still needed to standardise the laboratory methods for those analytes positioned close to 100; perhaps those above 75 .

The mathematical equation below details how each value (one for each analyte) was calculated for the graphical plot in Appendix 12.

$$
\begin{gathered}
\% \operatorname{CoV}[R(\mathrm{~A}-\mathrm{B})]=100 \times R(\mathrm{~A}-\mathrm{B}) / \operatorname{Mean}(\mathrm{A}-\mathrm{B}) \text { i.e. } \\
R(\mathrm{~A}-\mathrm{B})=2\left\{\left[\operatorname{SD}\left(L_{\mathrm{A}}\right)^{2}+\operatorname{SD}\left(L_{\mathrm{B}}\right)^{2}\right]+\left[\operatorname{SD}\left(r_{\mathrm{A}}\right)^{2}+\operatorname{SD}\left(r_{\mathrm{B}}\right)^{2}\right] / 5\right\}^{1 / 2}
\end{gathered}
$$

where:

- $\mathrm{SD}\left(L_{\mathrm{A}}\right)$ and $\mathrm{SD}\left(L_{\mathrm{B}}\right)$ are the Standard Deviations among laboratories for samples $\mathrm{A}$ and $\mathrm{B}$.

- $\mathrm{SD}\left(r_{\mathrm{A}}\right)$ and $\mathrm{SD}\left(r_{\mathrm{B}}\right)$ are the Standard Deviations between replicates, pooled over laboratories and experiments.

- Mean A-B is the mean difference between samples A and B, averaged across laboratories.

Resorcinol and benzo $[a]$ pyrene have been used to further illustrate the approach to investigating the among laboratory variability. It can be seen that the yields from $2 \mathrm{R} 4 \mathrm{~F}$ (sample A) and $1 \mathrm{R} 5 \mathrm{~F}$ (sample B) do not overlap for benzo[ $a]$ pyrene between any laboratories. However, when the yields from 2R4F (sample A) and $1 \mathrm{R} 5 \mathrm{~F}$ (sample B) for resorcinol are studied, it can be seen that they do overlap between some laboratories, see Figures A4 and A5.

Another illustration is given below for $\mathrm{B}[a] \mathrm{P}$ and resorcinol that are capable of good and poor differentiation between the two reference cigarettes i.e. expressing data in terms of the mean of $(2 \mathrm{R} 4 \mathrm{~F}-1 \mathrm{R} 5 \mathrm{~F})$ and then evaluating the difference between the

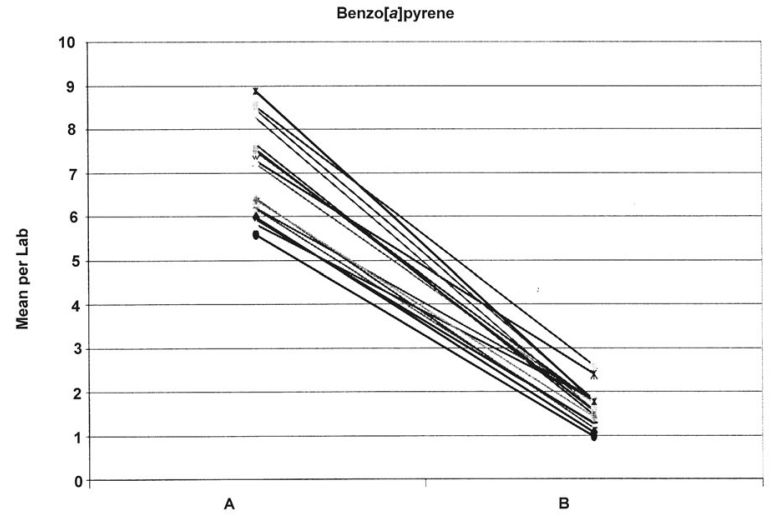

Figure A4. Statistical analysis of benzo[a]pyrene yields in 1R5F and 2R4F cigarettes

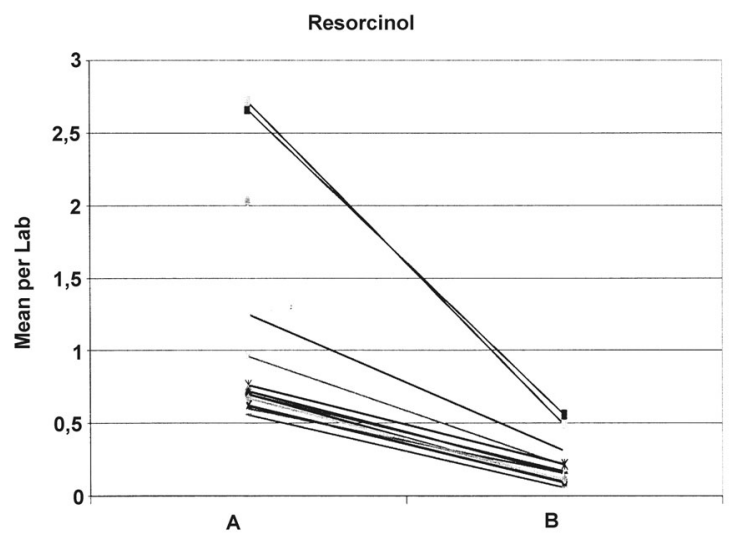

Figure A5. Statistical analysis of resorcinol yields in $1 \mathrm{R} 5 \mathrm{~F}$ and $2 \mathrm{R} 4 \mathrm{~F}$ cigarettes

highest and lowest values [indication of among laboratory variability $(R)]$ as a percentage of this mean. The $\mathrm{B}[a] \mathrm{P}$ value is less than $100 \%$ showing that the products are generally differentiated, Figure A6. For resorcinol, products were not well differentiated and give values in excess of $200 \%$, Figure A7.

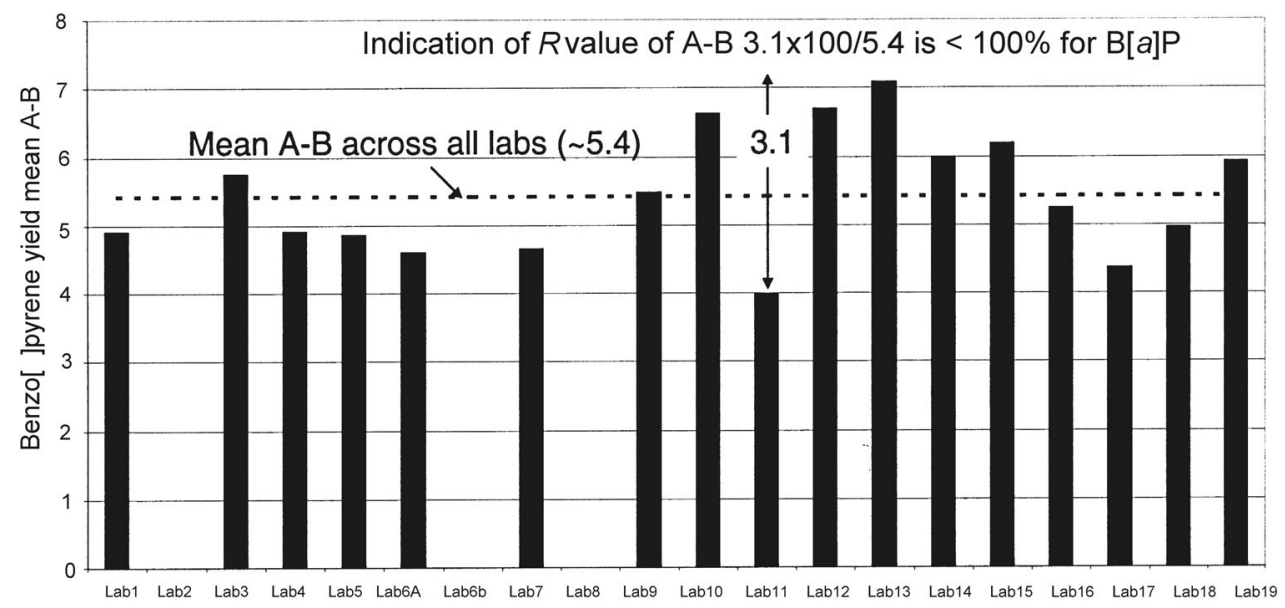

Figure A6. Statistical analysis for benzo[a]pyrene yields, differentiation of $1 \mathrm{R} 5 \mathrm{~F}(\mathrm{~A})$ and $2 \mathrm{R} 4 \mathrm{~F}(\mathrm{~B})$ cigarettes; benzo[a]pyrene $\mathrm{A}-\mathrm{B}$ : $\% \mathrm{CoV}=100 \times R(\mathrm{~A}-$ B)/(Mean A-Mean B) 


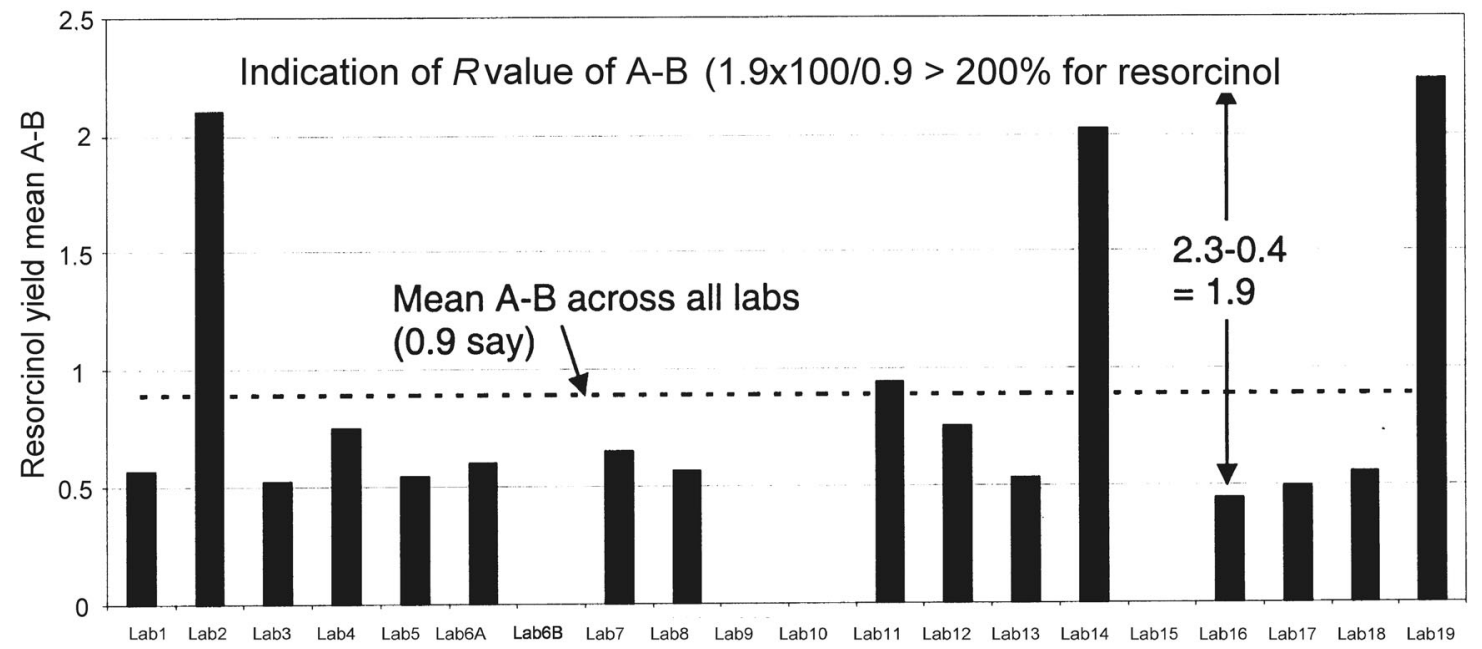

Figure A7. Statistical analysis for resorcinol yields; differentiation of $1 \mathbf{R} 5 \mathrm{~F}(\mathrm{~A})$ and $2 \mathrm{R} 4 \mathrm{~F}(\mathrm{~B})$ cigarettes; resorcinol $\mathrm{A}-\mathrm{B}$ : \%CoV $=100 \times R(\mathrm{~A}-\mathrm{B}) /(\mathrm{Mean}$ A-Mean B)

Appendix 12. Differentiation between 1R5F and 2R4F

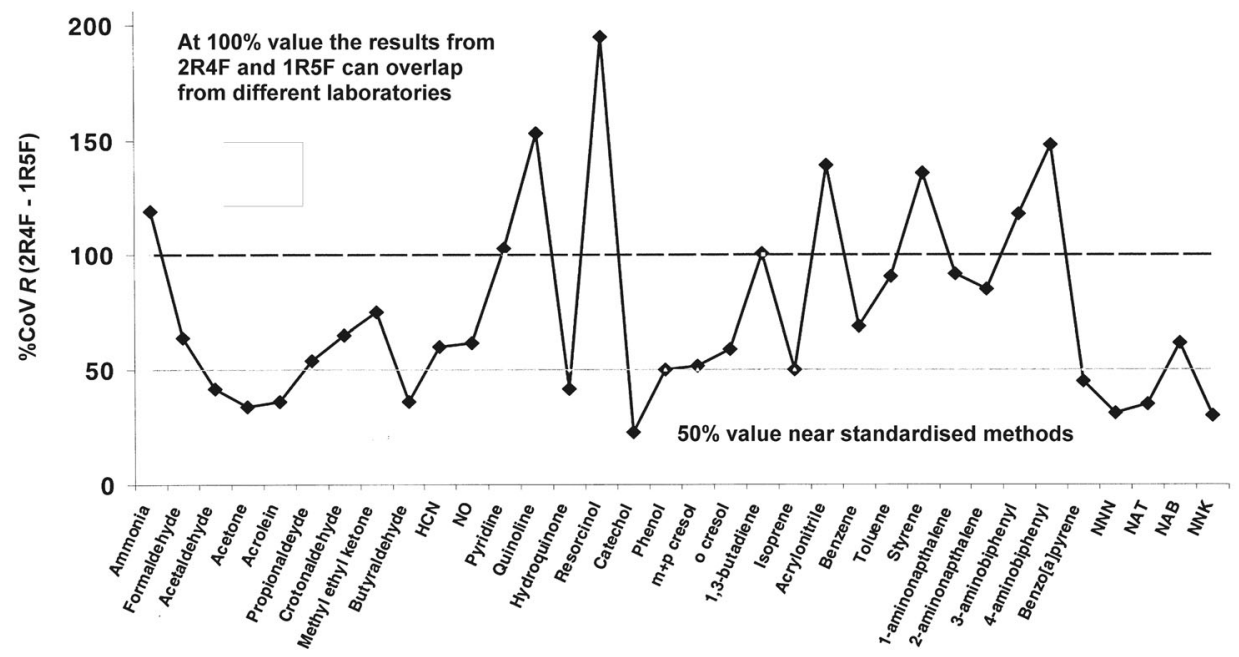

Figure A8. Differentiation between $1 \mathrm{R} 5 \mathrm{~F}$ and $2 \mathrm{R} 4 \mathrm{~F}$ cigarettes for different analytes where $R(2 \mathrm{R} 4 \mathrm{~F}-1 \mathrm{R} 5 \mathrm{~F})=$ the smallest difference between the mean yields for $2 \mathrm{R} 4 \mathrm{~F}$ and $1 \mathrm{R} 5 \mathrm{~F}$ (samples $\mathrm{A}$ and $\mathrm{B}$ ) that can be distinguished, with $95 \%$ confidence, when each sample has been tested by separate laboratories [\% CoV of $R$ (Mean $2 \mathrm{R} 4 \mathrm{~F}$ - $1 \mathrm{R} 5 \mathrm{~F}$ ) normalised as \% coefficient of variation to allow plots of all analytes on one graph], At $100 \%$ value the results from $2 \mathrm{R} 4 \mathrm{~F}$ and $1 \mathrm{R} 5 \mathrm{~F}$ can overlap from different laboratories

Appendix 13. Effects on variability of the number of cigarettes per peplicate

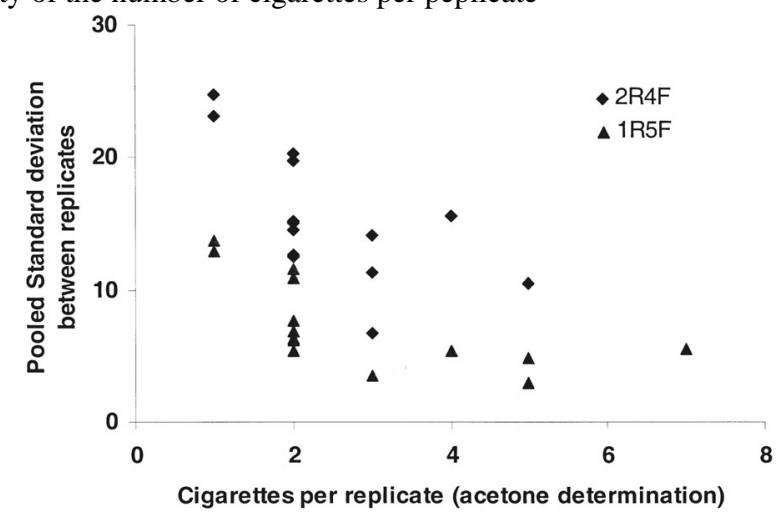

Figure A9. Effects on variability of the number of cigarettes (2R4F - 2R5F) per replicate (acetone determination) 


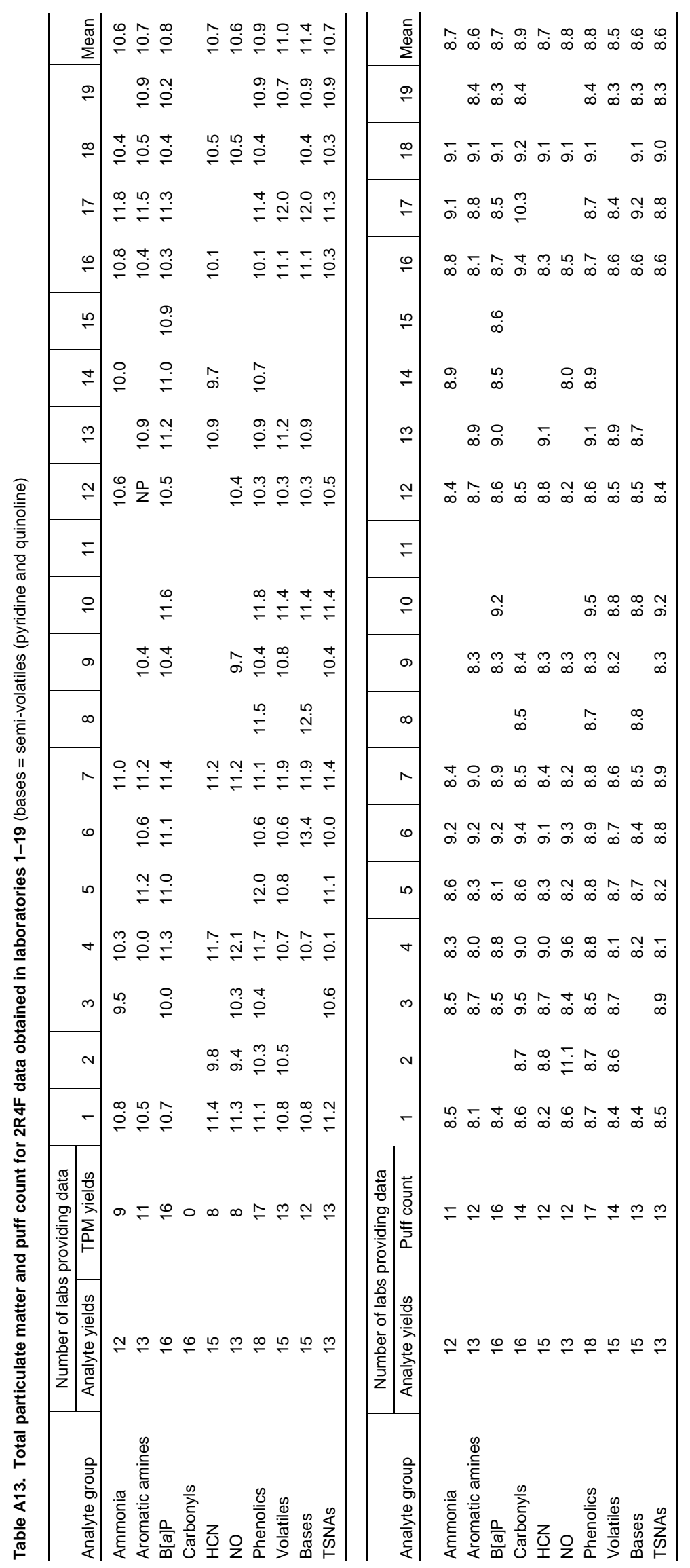




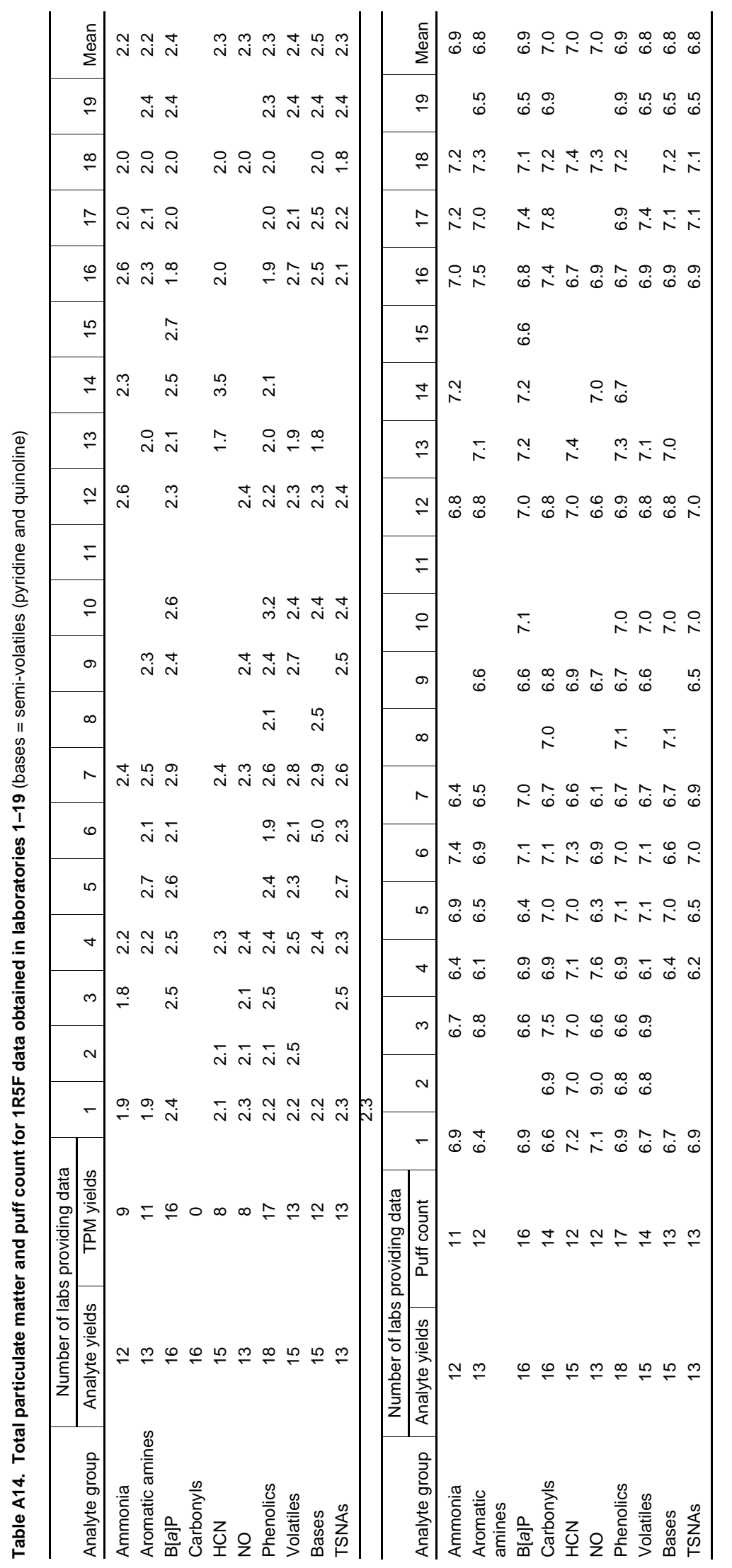


Appendix 16. Overview of ammonia methodology

Table A15. Overview of ammonia methodology in several laboratories $(\mathrm{AA}=$ auto analyser; $\mathrm{C}=$ conductivity detector; $\mathrm{CFP}=\mathrm{Cambridge}$ filter pad; $\mathrm{EP}=$ electrostatic precipitation; IC = ion chromatography; Imp = impinger; $\mathrm{SF}=$ separatory funnel; $\mathrm{P}=$ photometer)

\begin{tabular}{|c|c|c|c|c|c|c|c|c|c|c|c|c|}
\hline \multirow[b]{2}{*}{ Methodology } & \multicolumn{12}{|c|}{ Laboratory } \\
\hline & 1 & 4 & 5 & 6 & 7 & 11 & 12 & 14 & 16 & 17 & 18 & 3 \\
\hline No. cigs per replicate & 3 & 10 & 5 & 5 or 10 & 5 & 20 & 20 & 10 & 5 & $\begin{array}{l}10 \text { or } 20 \\
\quad(\mathrm{LT})\end{array}$ & 4 & 20 \\
\hline \multicolumn{13}{|l|}{ Type of smoking } \\
\hline Linear or rotary & linear & rotary & linear & linear & linear & rotary & rotary & rotary & rotary & rotary & linear & rotary \\
\hline Make & $\begin{array}{l}\text { Cerulean } \\
\text { SM450 }\end{array}$ & $\begin{array}{l}\text { Borgwaldt } \\
\text { RM20 }\end{array}$ & $\begin{array}{l}\text { Borgwaldt } \\
\text { KC20X }\end{array}$ & $\begin{array}{l}\text { Filtrona } \\
\text { SM350 }\end{array}$ & $\mathrm{KC} 10$ & $\begin{array}{l}\text { Borgwaldt } \\
\text { RM200 }\end{array}$ & $\begin{array}{l}\text { Borgwaldt } \\
\text { RM2O/ } \\
\text { RM2OH }\end{array}$ & Borgwaldt & $\begin{array}{l}\text { Borgwaldt } \\
\text { RM20CSR }\end{array}$ & $\begin{array}{l}\text { Borgwaldt } \\
\text { RM20CSR }\end{array}$ & Internal & $\begin{array}{l}\text { Borgwaldt } \\
\text { RM20 }\end{array}$ \\
\hline \multicolumn{13}{|l|}{ Trapping system } \\
\hline Filter and diameter & $\begin{array}{l}\text { CFP } \\
44 \mathrm{~mm}\end{array}$ & $\begin{array}{l}\text { CFP } \\
92 \mathrm{~mm}\end{array}$ & no & no & $\begin{array}{l}\text { CFP } \\
44 \mathrm{~mm}\end{array}$ & $\begin{array}{c}\text { CFP } \\
92 \mathrm{~mm}\end{array}$ & $\begin{array}{l}\text { CFP } \\
92 \mathrm{~mm}\end{array}$ & $\begin{array}{l}\text { CFP } \\
92 \mathrm{~mm}\end{array}$ & $\begin{array}{c}\text { CFP } \\
92 \mathrm{~mm}\end{array}$ & $\begin{array}{l}\text { CFP } \\
44 \mathrm{~mm}\end{array}$ & $\begin{array}{l}\text { CFP } \\
44 \mathrm{~mm}\end{array}$ & EP \\
\hline Trap type & $1 \mathrm{Imp}$ & $2 \mathrm{Imp}$ & $2 \mathrm{Imp}$ & $1 \mathrm{SF}$ & $2 \mathrm{Imp}$ & $1 \mathrm{Imp}$ & $3 \mathrm{Imp}$ & $1 \mathrm{Imp}$ & $2 \mathrm{Imp}$ & $\begin{array}{l}\text { solid } \\
\text { sorbent } \\
\text { tube }\end{array}$ & $1 \mathrm{Imp}$ & $1 \mathrm{Imp}$ \\
\hline Filtration step & yes & yes & no & yes & no & yes & yes & no & no & yes & yes & no \\
\hline \multicolumn{13}{|l|}{ Derivatisation } \\
\hline Reagent & no & no & no & no & no & no & no & no & no & no & no & ninhydrin \\
\hline \multicolumn{13}{|l|}{ Analytical equipment } \\
\hline Autosampler & yes & no & yes & yes & yes & no & & no & yes & & no & \\
\hline Cooling? and temperature & $10^{\circ} \mathrm{C}$ & $\mathrm{RT}$ & & $6{ }^{\circ} \mathrm{C}$ & & & & & $4{ }^{\circ} \mathrm{C}$ & & & \\
\hline $\begin{array}{l}\text { Description } \\
\text { Conditions }\end{array}$ & $\begin{array}{c}\text { IC } \\
\text { isocratic }\end{array}$ & $\begin{array}{c}\text { IC } \\
\text { isocratic }\end{array}$ & $\begin{array}{c}\text { IC } \\
\text { gradient }\end{array}$ & $\begin{array}{c}\text { IC } \\
\text { isocratic }\end{array}$ & $\begin{array}{c}\text { IC } \\
\text { isocratic }\end{array}$ & $\begin{array}{c}\text { IC } \\
\text { isocratic }\end{array}$ & $\begin{array}{c}\text { IC } \\
\text { isocratic }\end{array}$ & $\begin{array}{c}\text { IC } \\
\text { isocratic }\end{array}$ & $\begin{array}{c}\text { IC } \\
\text { gradient }\end{array}$ & $\begin{array}{c}\text { IC } \\
\text { isocratic }\end{array}$ & $\begin{array}{c}\text { IC } \\
\text { gradient }\end{array}$ & AA \\
\hline Detection & C & C & C & C & C & C & C & C & C & C & C & $\mathrm{P}$ \\
\hline Calibration curve & linear & quadratic & quadratic & quadratic & linear & linear & & linear & linear & quadratic & linear & linear \\
\hline
\end{tabular}

Appendix 17. Ammonia data

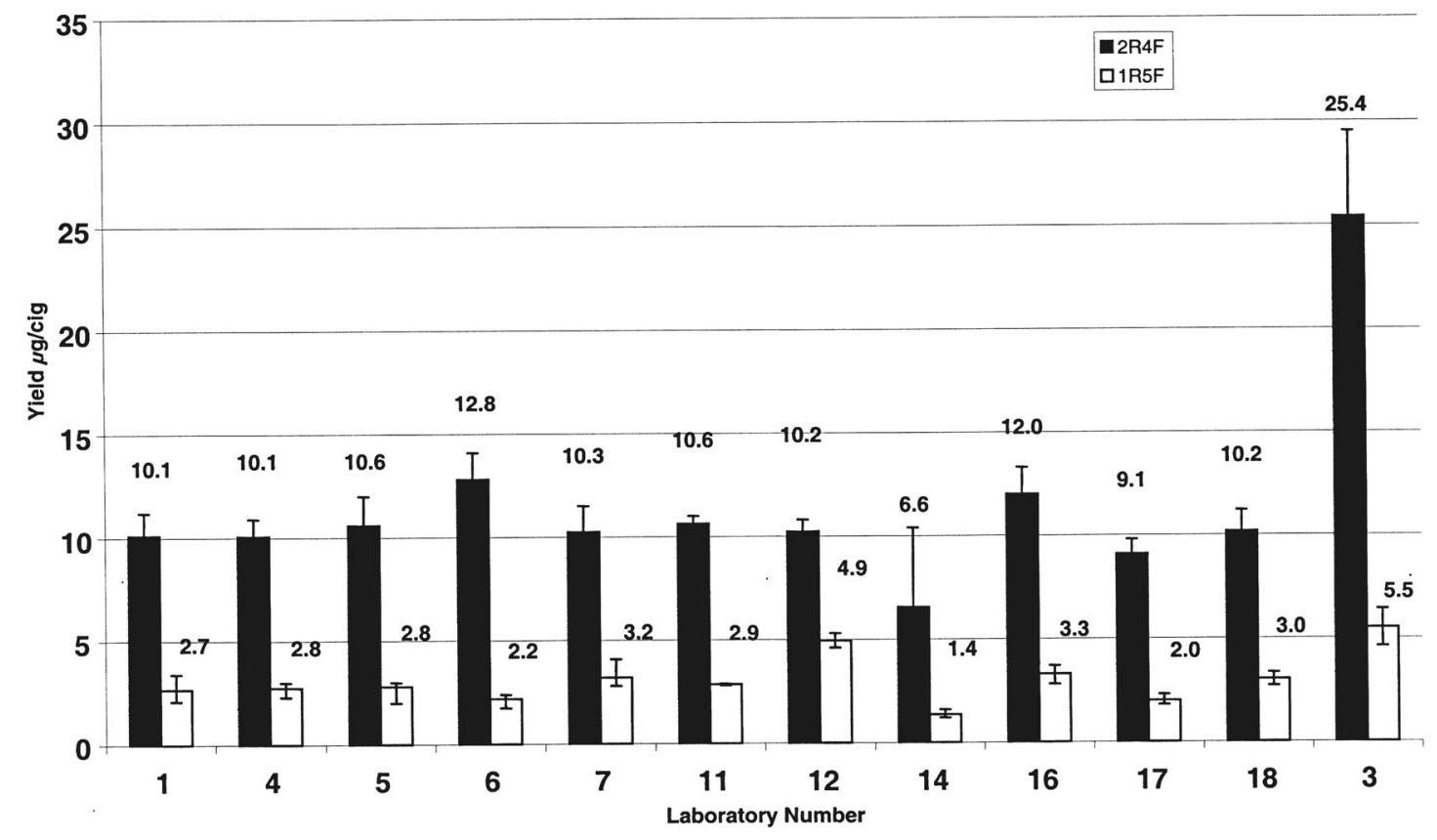

Figure A10. Ammonia yields ( $\mathrm{gg} / \mathrm{cig}$ ) obtained in different laboratories for 2R4F and 1 R5F cigarettes. Error bars indicate the maximum and minimum yields given by a laboratory 


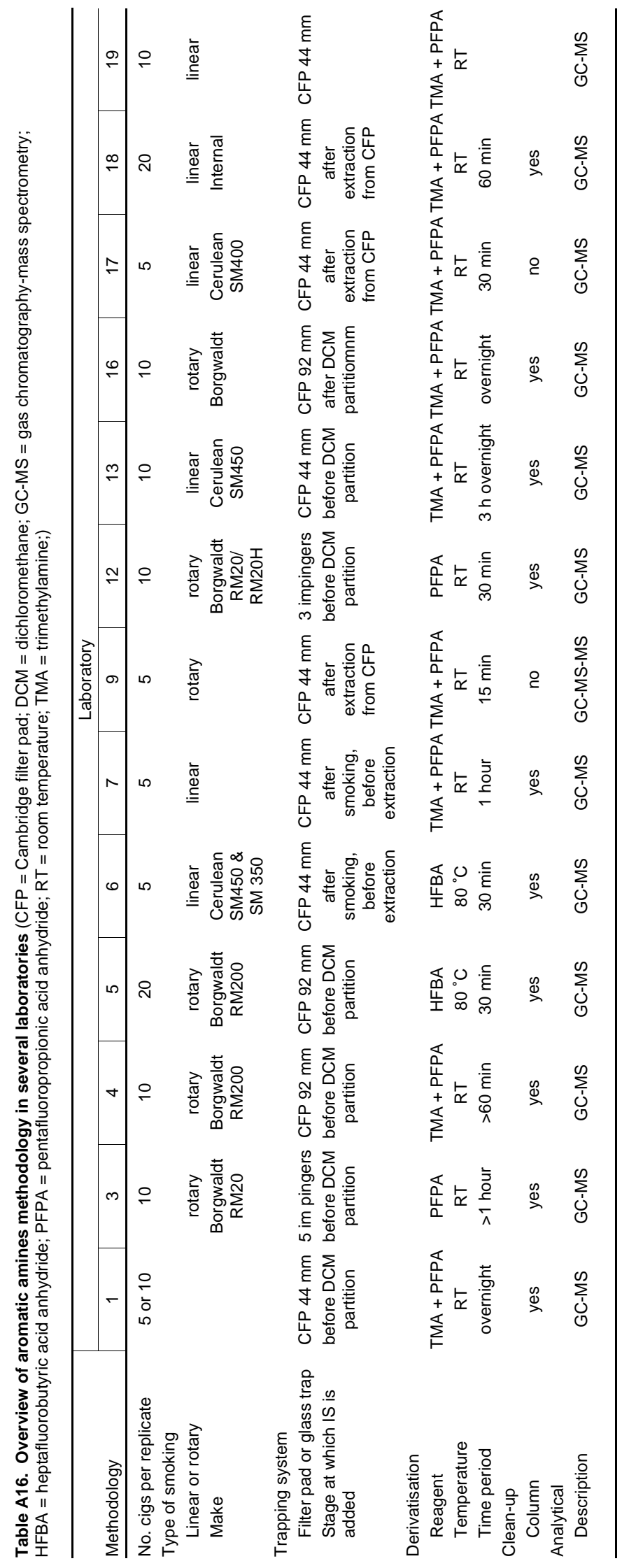


Appendix 19. Aromatic amines - yield patterns of the 4 individual amines 1-amino naphthalene (1-NA), 2-amino naphthalene (2-NA), 3amino biphenyl (3-AB), 4-amino biphenyl (4-AB)
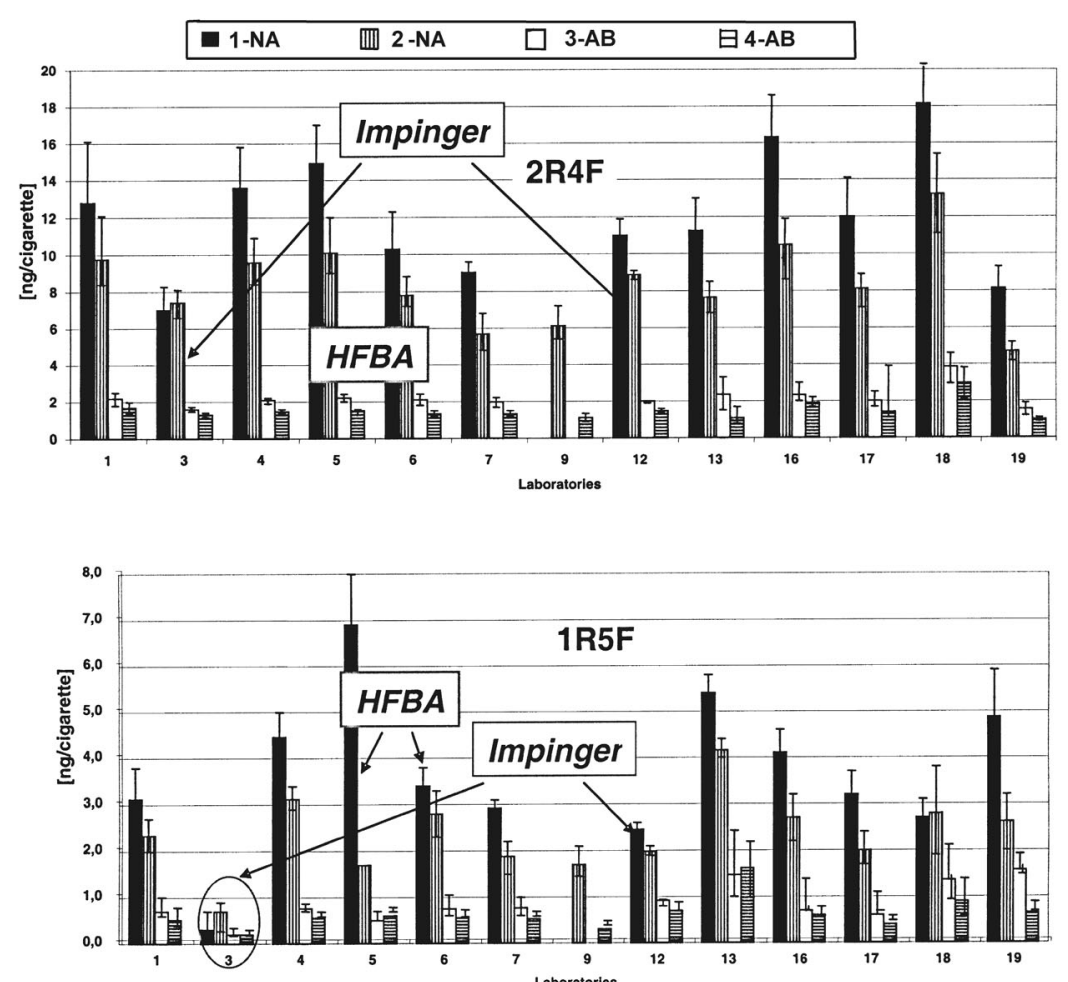

Figure A11. Aromatic amines yield patterns of the 4 individual amines 1-NA = 1-amino naphthalene, 2-NA = 2-amino naphthalene, 3-AB = 3-amino biphenyl, 4-AB = 4-amino biphenyl for 2R4F and 1R5F cigarettes. Error bars give the maximum and minimum yields given by a laboratory expressed as an average of all replicates. Major methodological differences are highlighted (Impinger = use of impinger trapping system; other laboratories trapped on Cambridge filter pads; HFBA = heptafluorobutyric acid anhydride; other methods used pentafluoropropionic acid anhydride).

Appendix 20. Aromatic amines - yield ratios of the 4 individual amines 1-amino naphthalene (1-NA), 2-amino naphthalene (2-NA), 3amino biphenyl (3-AB), 4-amino biphenyl (4-AB)

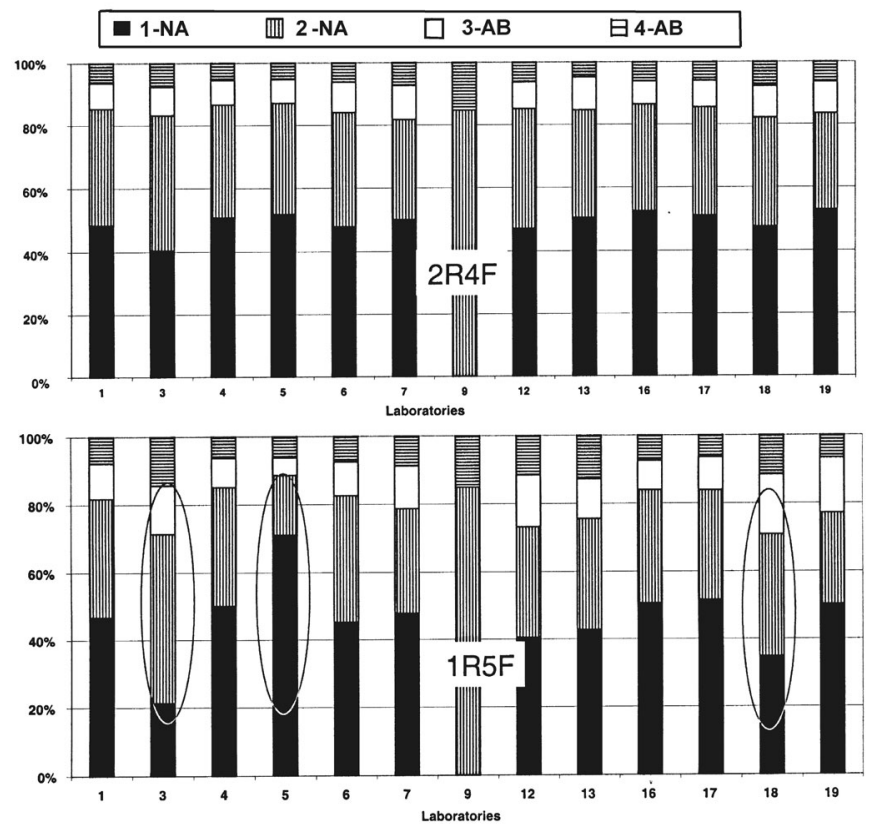

Figure A12. Aromatic amines yield ratios of the 4 individual amines 1-NA = 1-amino naphthalene, 2-NA = 2-amino naphthalene, 3-AB = 3-amino biphenyl, 4-AB = 4-amino biphenyl for 2R4F and 1R5F cigarettes. Yield ratios are the yields of the four aromatic amines summed together with individual amine yields then expressed as percentages of the total yield. The different yield ratio patterns observed are unrelated to specific methods. Note that laboratory 9 measured only 2 -amino naphthalene and 4-aminobiphenyl. 
Appendix 21. Overview of benzo[a]pyrene methodology

Table A17. Overview of benzo[a]pyrene methodology CFP = Cambridge filter pad; F = fluorescence; GC-MS = gas chromatography-mass spectrometry; $\mathrm{HPLC}=$ high performance liquid chromatography; SIM = single ion monitoring)

\begin{tabular}{|c|c|c|c|c|c|c|c|c|c|c|c|c|}
\hline \multirow[b]{2}{*}{ Methodology } & \multicolumn{12}{|c|}{ Laboratory } \\
\hline & 1 & 5 & 7 & \multicolumn{2}{|c|}{9} & \multicolumn{2}{|c|}{10} & \multicolumn{2}{|l|}{11} & 12 & 13 & 14 \\
\hline No. cigs per replicate & 5 & 20 & \multirow[t]{2}{*}{5 to 10} & \multirow{2}{*}{\multicolumn{2}{|c|}{10 or 20}} & \multicolumn{2}{|c|}{10} & \multicolumn{2}{|l|}{10} & \multirow[t]{2}{*}{10} & \multirow[t]{2}{*}{10} & \multirow[t]{2}{*}{5} \\
\hline \multicolumn{7}{|c|}{ Type of smoking machine } & & & & & & \\
\hline Linear or rotary & linear & rotary & linear & \multicolumn{2}{|c|}{ rotary } & \multicolumn{2}{|c|}{ rotary } & \multicolumn{2}{|c|}{ rotary } & rotary & linear & rotary \\
\hline Make & $\begin{array}{l}\text { Cerulean } \\
\text { SM450 }\end{array}$ & $\begin{array}{l}\text { Borgwaldt } \\
\text { RM200 }\end{array}$ & $\mathrm{n} / \mathrm{p}$ & \multicolumn{2}{|c|}{ Borgwaldt } & \multicolumn{2}{|c|}{$\begin{array}{l}\text { Borgwaldt } \\
\text { RM20 CSR }\end{array}$} & \multicolumn{2}{|c|}{$\begin{array}{l}\text { Borgwaldt } \\
\text { RM20 CSR }\end{array}$} & $\begin{array}{c}\text { Borgwaldt } \\
\text { RM20/RM20H }\end{array}$ & $\begin{array}{l}\text { Cerulean } \\
\text { SM450 }\end{array}$ & Borgwaldt \\
\hline Trapping system & & & & & & & & & & & & \\
\hline Filter and diameter & CFP 44 mm & CFP 92 mm & SFP $44 \mathrm{~mm}$ & CFP & $4 \mathrm{~mm}$ & CFP 9 & $\mathrm{~mm}$ & CFP $44 r$ & $\mathrm{~mm}$ & CFP $44 \mathrm{~mm}$ & CFP $44 \mathrm{~mm}$ & CFP $92 \mathrm{~mm}$ \\
\hline Clean-up & & & & & & & & & & & & \\
\hline Column & yes & yes & yes & & & ye & & yes & & yes & yes & yes \\
\hline Analytical equipment & & & & & & & & & & & & \\
\hline Description & GC-MS & GC-MS & GC-MS & & MS & GC- & & GC-MS & & GC-MS & GC-MS & GC-MS \\
\hline Detection & SIM & SIM & SIM & & & SII & & & & MS & SIM & SIM \\
\hline & & & & & & Labc & ratory & & & & & \\
\hline Methodology & 17 & 18 & 19 & & & 3 & & 4 & & 6 & 15 & 16 \\
\hline No. cigs per replicate & 5 & 20 & 20 & & & 20 & & 5 & & 5 & 20 & 5 \\
\hline Type of smoking mach & & & & & & & & & & & & \\
\hline Linear or rotary & linear & linear & line & & & tary & & linear & & linear & rotary & linear \\
\hline Make & $\begin{array}{l}\text { Cerulean } \\
\text { SM400 }\end{array}$ & Internal & $\mathrm{n} / \mathrm{r}$ & & $\begin{array}{r}\text { Bor } \\
\mathrm{R}\end{array}$ & $\begin{array}{l}\text { gwaldt } \\
\text { n20 }\end{array}$ & & nternal & SM4 & $\begin{array}{l}\text { Cerulean } \\
450 / \text { SM350 }\end{array}$ & $\begin{array}{l}\text { Borgwaldt } \\
\text { RM20 }\end{array}$ & Filtrona \\
\hline Trapping system & & & & & & & & & & & & \\
\hline Filter and diameter & CFP $44 \mathrm{~mm}$ & CFP $44 \mathrm{~mm}$ & CFP 4 & $4 \mathrm{~mm}$ & CFP & $92 \mathrm{~mm}$ & $\mathrm{CFF}$ & P 44 mm & & $\mathrm{FP} 44 \mathrm{~mm}$ & CFP 92 mm & CFP $44 \mathrm{~mm}$ \\
\hline Clean-up & & & & & & & & & & & & \\
\hline Column & yes & yes & yes & & & es & & yes & & $\mathrm{x}$ & yes & yes \\
\hline Analytical equipment & & & & & & & & & & & & \\
\hline Description & GC-MS & GC-MS & GC-I & & & PLC & & HPLC & & HPLC & HPLC & HPLC \\
\hline Detection & SIM & SIM & $\mathrm{MS}$ & & & $F$ & & $\mathrm{~F}$ & & $\mathrm{~F}$ & $\mathrm{~F}$ & $\mathrm{~F}$ \\
\hline
\end{tabular}

Appendix 22. Benzo[a]pyrene yields

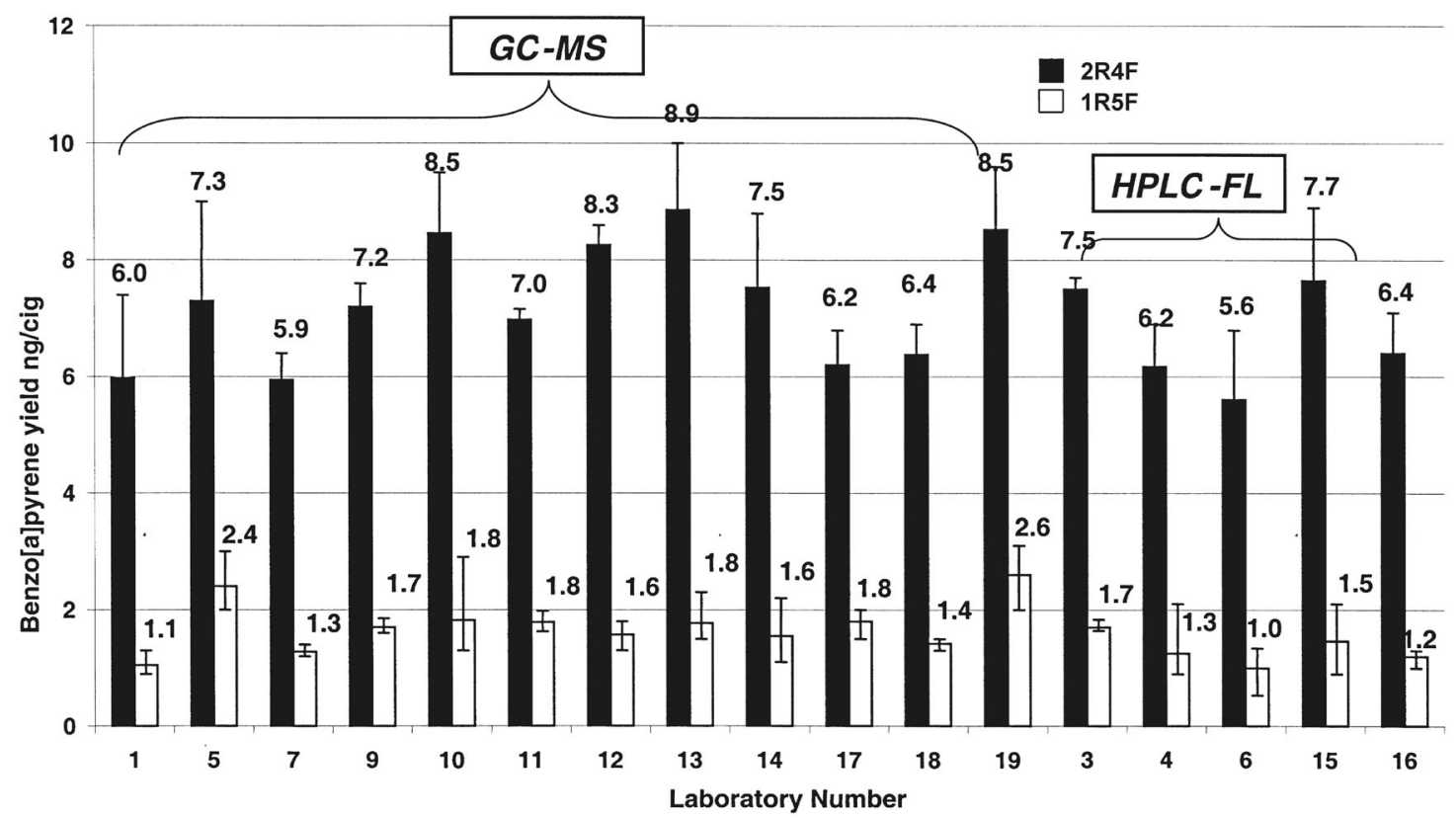

Figure A13. Benzo[a]pyrene yields (ng/cig) obtained in different laboratories for 2R4F and 1 R5F cigarettes. Error bars are maximum and minimum values given by one laboratory (GC-MS = gas chromatography - mass spectrometry; HPLC-FL = high performance liquid chromatography - fluorescence detection). 


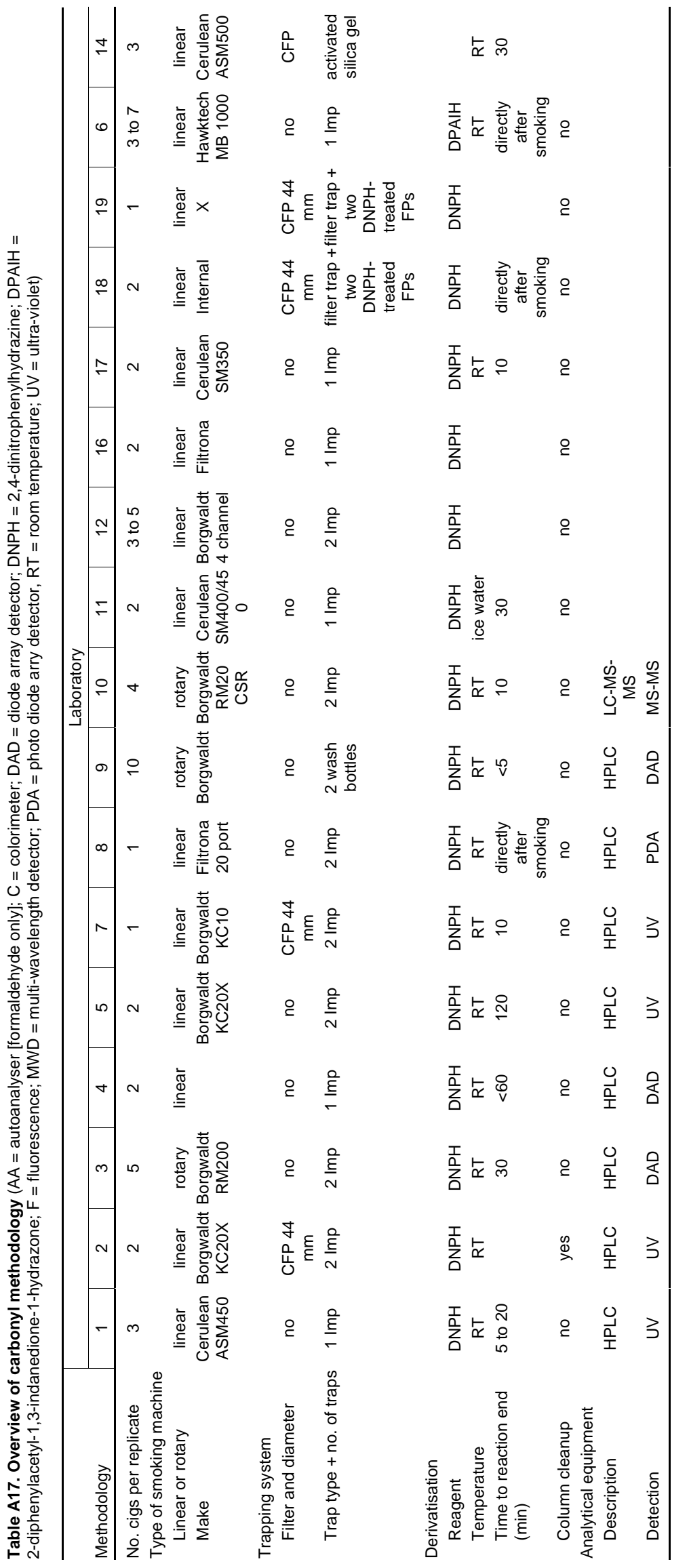


Appendix 24. Yields of the major carbonyls acetaldehyde and acetone
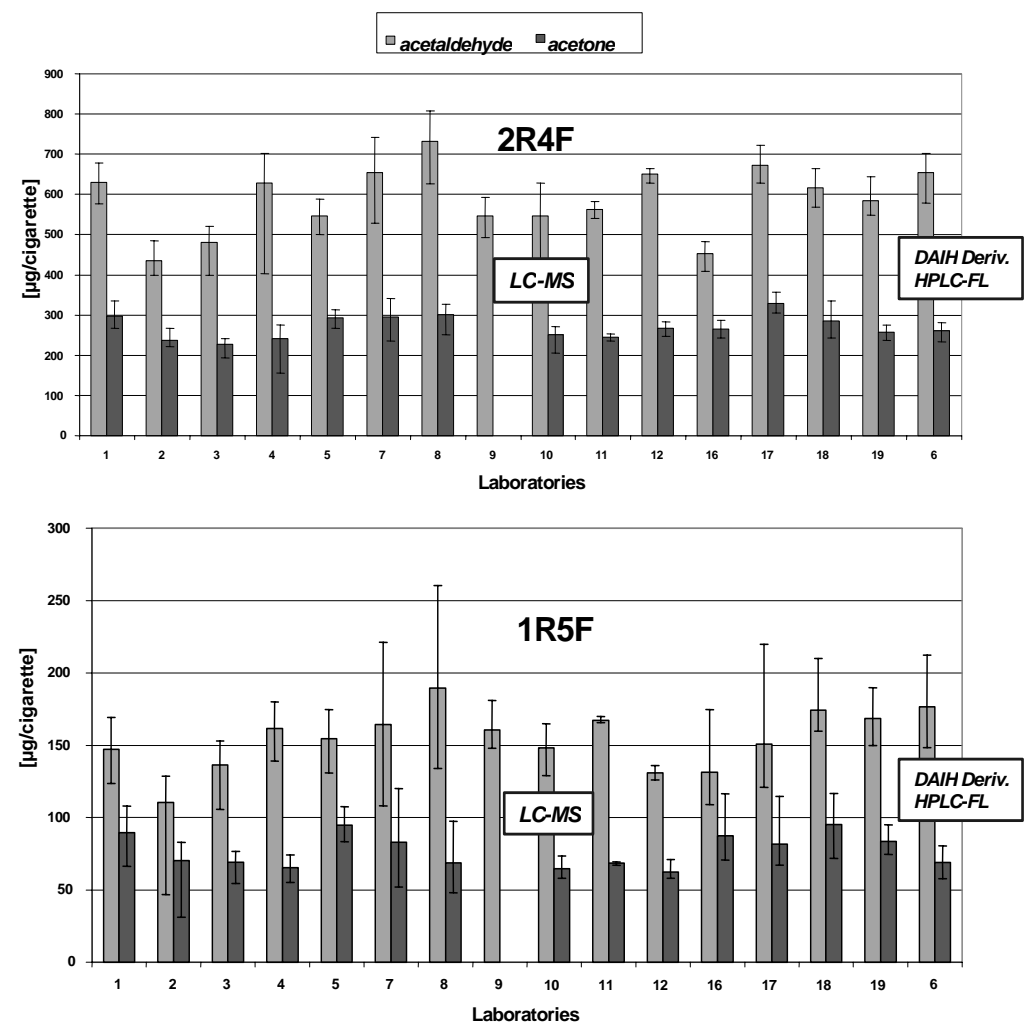

Figure A14. Yields of major carbonyls acetaldehyde and acetone obtained in different laboratories for 2R4F and 1R5F cigarettes Error bars give the maximum and minimum values for each laboratory (2-diphenylacetyl-1,3-indandione-1-hydrazone (DPAlH) derivative HPLC-FL $=$ diphenylacetylhydrazone derivative measured by high performance liquid chromatography with fluorescence detection).

Appendix 25. Yield ratios of the major carbonyls acetaldehyde and acetone
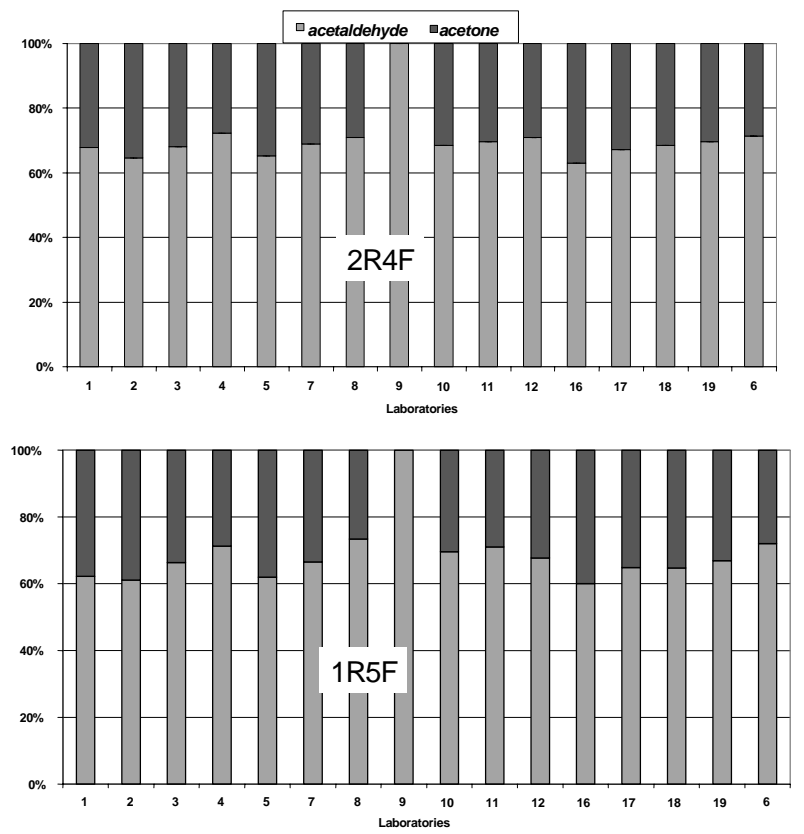

Figure A15. Yield ratios of major carbonyls acetaldehyde and acetone obtained in different laboratories for 2R4F and 1R5F cigarettes. The yields of acetaldehyde and acetone were summed together and expressed as individual percentages of the total yield. Note that Laboratory 9 did not measure acetone. 
Appendix 26. Yields of the minor carbonyls formaldehyde, acrolein, methyl ethyl ketone (MEK), propionaldehyde, butyraldehyde and crotonaldehyde
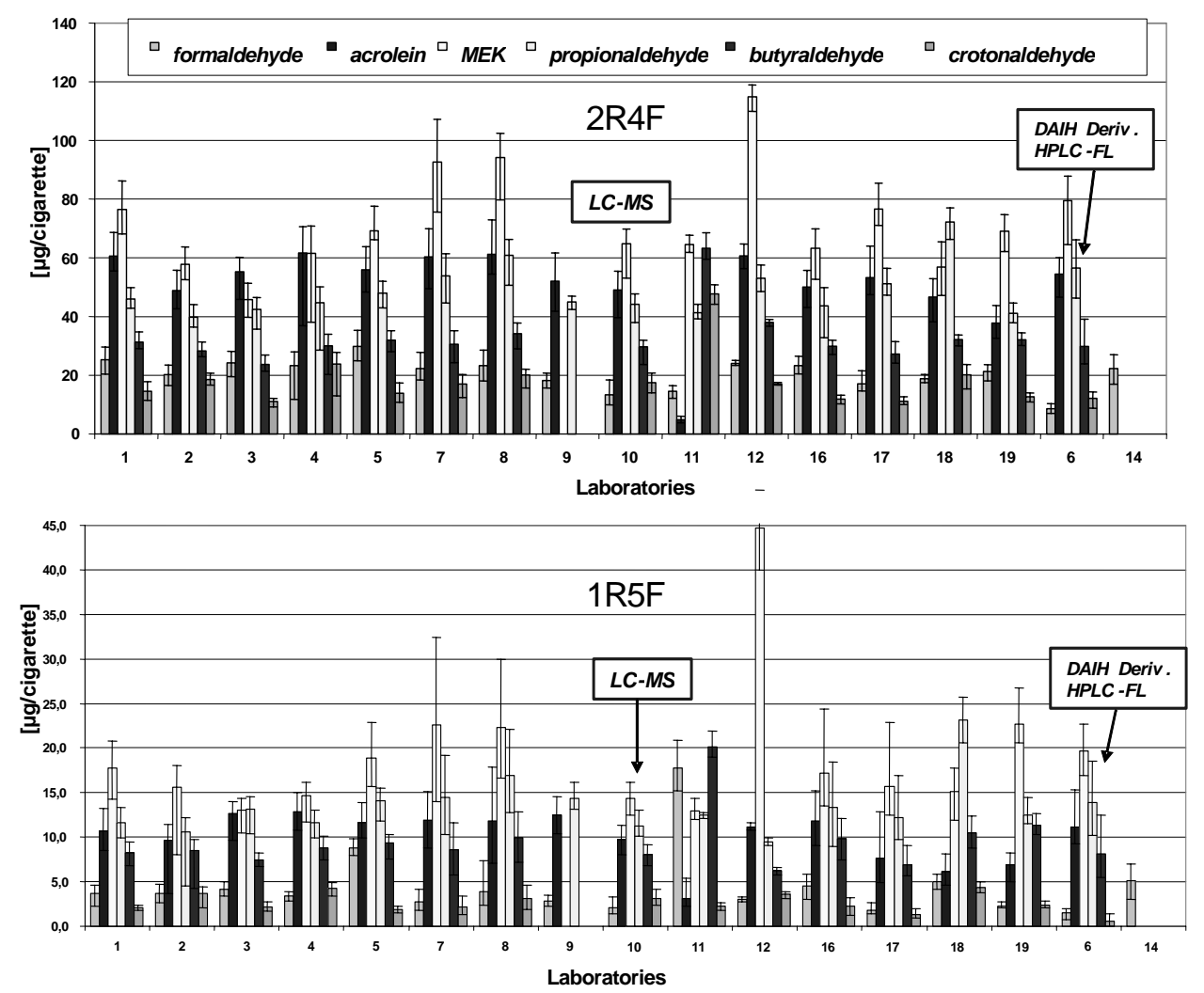

Figure A16. Yields of minor carbonyls formaldehyde, acrolein, methyl ethyl ketone (MEK), propionaldehyde, butyraldehyde and crotonaldehyde obtained in different laboratories for 2R4F and 1R5F cigarettes (LC-MS = liquid chromatography - mass spectrometry; 2-diphenylacetyl-1,3-indandione-1hydrazone (DPAIH) derivative HPLC-FL = diphenylacetylhydrazone derivative measured by high performance liquid chromatography with fluorescence detection).

Appendix 27. Yield ratios of the minor carbonyls formaldehyde, acrolein, methyl ethyl ketone (MEK), propionaldehyde, butyraldehyde and crotonaldehyde
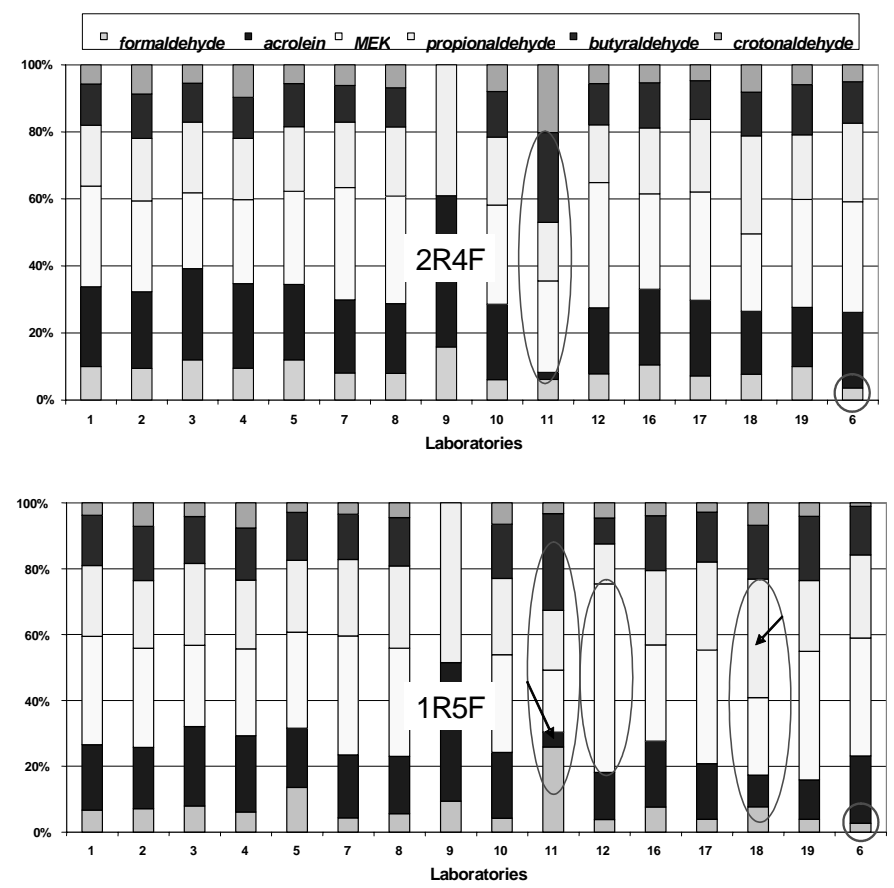

Figure A17. Yield ratios of minor carbonyls formaldehyde, acrolein, methyl ethyl ketone (MEK), propionaldehyde, butyraldehyde and crotonaldehyde. The yields of the six minor carbonyls were summed together and expressed as individual percentages of the total yield as yield ratios. The major differences are highlighted. 
Appendix 28. Overview of hydrogen cyanide methodology

Table A18. Hydrogen cyanide methodolgy (LC-MS-MS = liquid chromatography-mass spectrometry-mass spectrometry; NDA = 2,3-naphthalene dicarboxaldehyde; NPD = nitrogen phosphorous detector)

\begin{tabular}{|c|c|c|c|c|c|c|c|c|c|c|}
\hline \multirow[b]{2}{*}{ Methodology } & \multicolumn{10}{|c|}{ Laboratory } \\
\hline & \multicolumn{2}{|l|}{1} & 2 & 4 & 5 & 6 & 7 & & 13 & 14 \\
\hline No. cigs per replicate & \multicolumn{2}{|l|}{3 to 5} & \multirow[t]{2}{*}{5} & \multirow{2}{*}{\multicolumn{2}{|c|}{5}} & 5 & \multicolumn{2}{|l|}{3} & 5 to 20 & 3 \\
\hline \multicolumn{8}{|l|}{ Type of smoking machine } & & & \\
\hline Linear or rotary & \multicolumn{2}{|c|}{ linear } & \multirow{2}{*}{$\begin{array}{l}\text { linear } \\
\text { Borgwaldt } \\
\text { KC20X }\end{array}$} & linear & linear & linear & \multicolumn{2}{|c|}{ linear } & rotary & linear \\
\hline Make & \multicolumn{2}{|c|}{$\begin{array}{l}\text { Cerulean } \\
\text { ASM450 }\end{array}$} & & Internal & $\begin{array}{l}\text { Borgwaldt } \\
\text { KC20X }\end{array}$ & $\begin{array}{c}\text { Modified } \\
\text { Phipps \& Byrd }\end{array}$ & \multicolumn{2}{|c|}{$\begin{array}{l}\text { Borgwaldt } \\
\text { KC10 }\end{array}$} & $\begin{array}{l}\text { Borgwaldt } \\
\text { RM20 }\end{array}$ & $\begin{array}{l}\text { Cerulean } \\
\text { ASM500 }\end{array}$ \\
\hline \multicolumn{11}{|l|}{ Trapping system } \\
\hline Filter and diameter & \multirow{2}{*}{\multicolumn{2}{|c|}{$\begin{array}{c}\text { CFP } 44 \mathrm{~mm} \\
1 \mathrm{lmp}\end{array}$}} & \multirow{2}{*}{$\begin{array}{c}\text { CFP } 44 \mathrm{~mm} \\
1 \mathrm{Imp}\end{array}$} & CFP 44 mm & no & CFP 44 mm & \multirow{2}{*}{\multicolumn{2}{|c|}{$\begin{array}{l}\text { CFP } 44 \mathrm{~mm} \\
1 \mathrm{Imp}\end{array}$}} & \multirow{2}{*}{$\begin{array}{c}\text { CFP } 92 \mathrm{~mm} \\
1 \mathrm{Imp}\end{array}$} & CFP \\
\hline Trap type + no. of traps & & & & $1 \mathrm{Imp}$ & $2 \operatorname{Imp}$ & $\begin{array}{c}1 \text { Ascarite } \\
\text { trap }\end{array}$ & & & & $\begin{array}{l}\text { trapping unit } \\
\text { with activated } \\
\text { silicia gel }\end{array}$ \\
\hline \multicolumn{11}{|l|}{ Derivatisation } \\
\hline $\begin{array}{l}\text { Measured complex based on } \\
\text { Analytical equipment }\end{array}$ & \multicolumn{3}{|r|}{ pyrazolone } & pyrazolone & pyrazolone & \multicolumn{3}{|c|}{ barbituric acid barbituric acid } & pyrazolone & pyrazolone \\
\hline Description & \multicolumn{2}{|c|}{$\begin{array}{l}\text { UV/VIS } \\
\text { spectrophotometer }\end{array}$} & $\begin{array}{l}\text { continuous } \\
\text { flow analyser }\end{array}$ & $\begin{array}{l}\text { continuous } \\
\text { flow analyser }\end{array}$ & $\begin{array}{l}\text { continuous } \\
\text { flow analyser }\end{array}$ & $\begin{array}{l}\text { continuous } \\
\text { flow analyser }\end{array}$ & \multicolumn{2}{|c|}{$\begin{array}{l}\text { continuous } \\
\text { flow analyser }\end{array}$} & $\begin{array}{l}\text { continuous } \\
\text { flow analyser }\end{array}$ & $\begin{array}{l}\text { continuous } \\
r \text { flow analyser }\end{array}$ \\
\hline Detection & \multicolumn{2}{|c|}{ Colorimeter } & Colorimeter & r Colorimeter & Colorimeter & Colorimeter & \multicolumn{2}{|c|}{ Colorimeter } & Colorimeter & Colorimeter \\
\hline Wavelenght & 518 & & 540 & 630 & 540 & 570 & 575 & & 540 & 540 \\
\hline & & & & & Laborator & & & & & \\
\hline Methodology & 16 & & 18 & 10 & 11 & 12 & & & 3 & 9 \\
\hline No. cigs per replicate & 5 & & $3-5$ & 10 & 20 & 6 & & & 20 & 10 \\
\hline Type of smoking machine & & & & & & & & & & \\
\hline Linear or rotary & linear & & linear & rotary & rotary & linear & & & rotary & rotary \\
\hline Make & Filtrona & & Internal & $\begin{array}{l}\text { Borgwaldt } \\
\text { RM20CSR }\end{array}$ & $\begin{array}{l}\text { Borgwaldt } \\
\text { RM200 }\end{array}$ & $\begin{array}{l}\text { Borgwal } \\
4 \text { chann }\end{array}$ & & & $\begin{array}{l}\text { orgwaldt } \\
\text { RM20 }\end{array}$ & Borgwaldt \\
\hline Trapping system & & & & & & & & & & \\
\hline Filter and diameter & CFP $44 \mathrm{~mm}$ & & $\mathrm{P} 44 \mathrm{~mm}$ & $\mathrm{x}$ & CFP 92 mm & $\mathrm{x}$ & & & no & $\mathrm{X}$ \\
\hline Trap type + no. of traps & $1 \operatorname{Imp}$ & & $1 \mathrm{Imp}$ & $2 \operatorname{Imp}$ & $1 \operatorname{Imp}$ & $\begin{array}{l}1 \text { glass tube fill } \\
\mathrm{NaOH} \text { on su }\end{array}$ & $\begin{array}{l}\text { lled with } \\
\text { upport }\end{array}$ & $\begin{array}{l}\text { glass } \\
\text { indivi } \\
\text { being }\end{array}$ & $\begin{array}{l}\text { ss syringe, } \\
\text { idual puffs } \\
\text { g sampled }\end{array}$ & $2 \operatorname{Imp}$ \\
\hline Derivatisation & & & & & & & & & & \\
\hline Measured complex based on & pyrazolone & bark & bituric acid & NDA \& taurine & no & no & & & no & $\begin{array}{l}\text { addition of } \\
\text { ohosphoric acid }\end{array}$ \\
\hline Analytical equipment & & & & & & & & & & \\
\hline Description & $\begin{array}{l}\text { continuous } \\
\text { flow analyser }\end{array}$ & spectr & $\begin{array}{l}\text { JV/VIS } \\
\text { ophotometer }\end{array}$ & LC-MS-MS & IC & ion sensitive el & lectrode & & GC & headspace GC \\
\hline $\begin{array}{l}\text { Detection } \\
\text { Wavelenght }\end{array}$ & $\begin{array}{l}\text { Colorimeter } \\
\quad 540\end{array}$ & & $\begin{array}{l}\text { lorimeter } \\
600\end{array}$ & MS-MS & Conductivity & ion sensitive el & lectrode & & FID & NPD \\
\hline
\end{tabular}

Appendix 29. Hydrogen cyanide yields

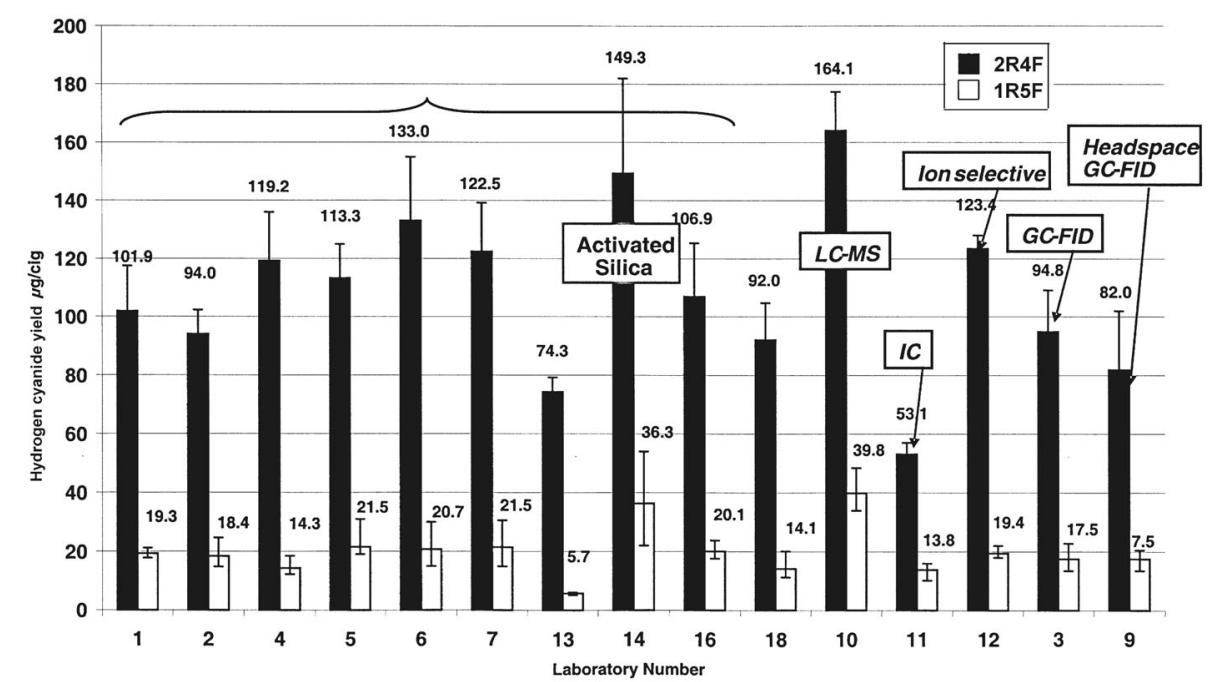

Figure A18. Hydrogen cyanide yields ( $\mu \mathrm{g} / \mathrm{cig}$ ) obtained in different laboratories for 2R4F and $1 \mathrm{R} 5 \mathrm{~F}$ cigarettes. Error bars give the maximum and minimum yields given by a laboratory expressed as an average. Chloramine T, reaction with pyrazolone or barbituric acid. Detection and quantification by continuous flow analysis or photometer. 
Appendix 30. Overview of nitric oxide methodology

Table A19. Nitric oxide methodology

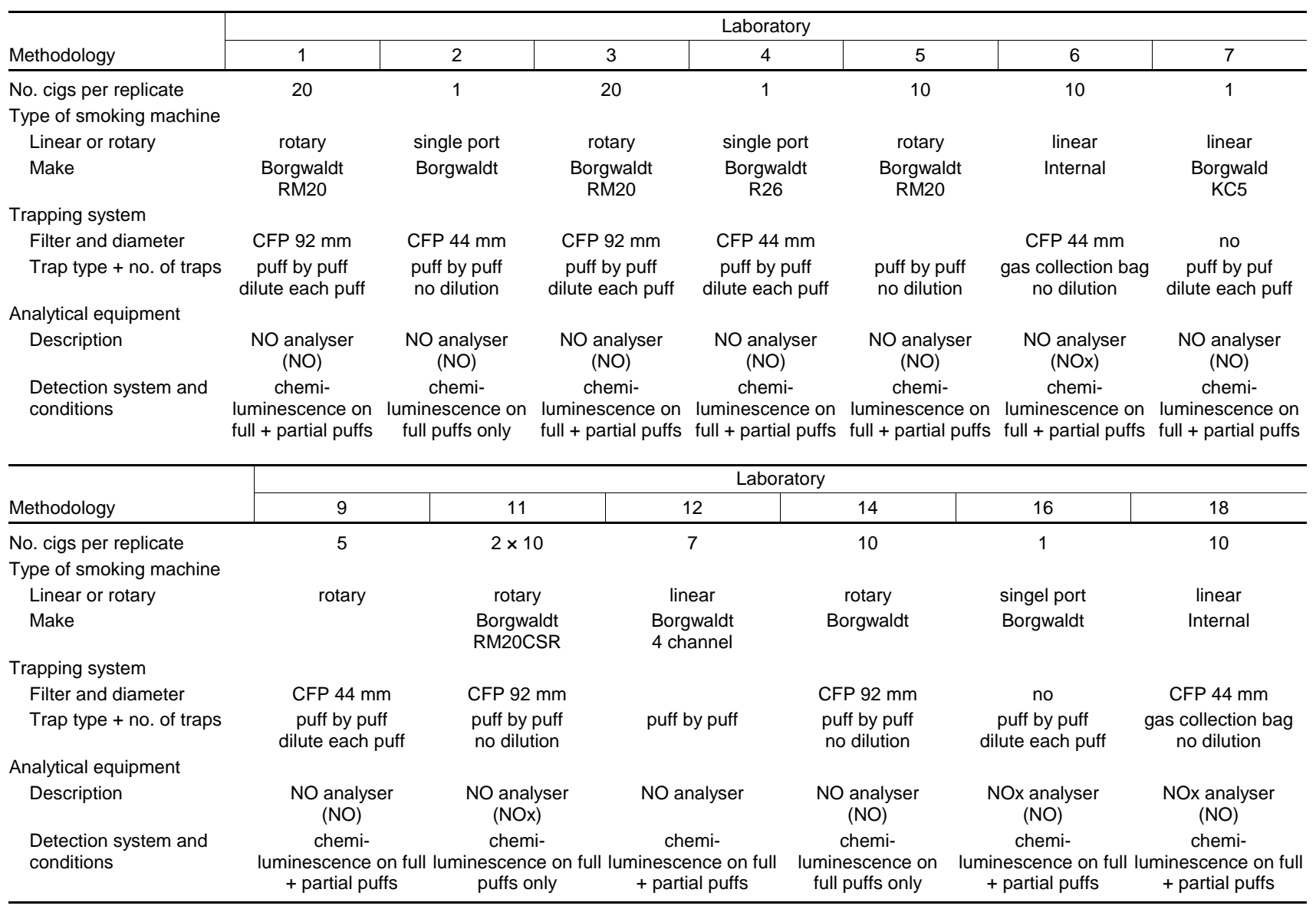

Appendix 31. Nitric oxide yields

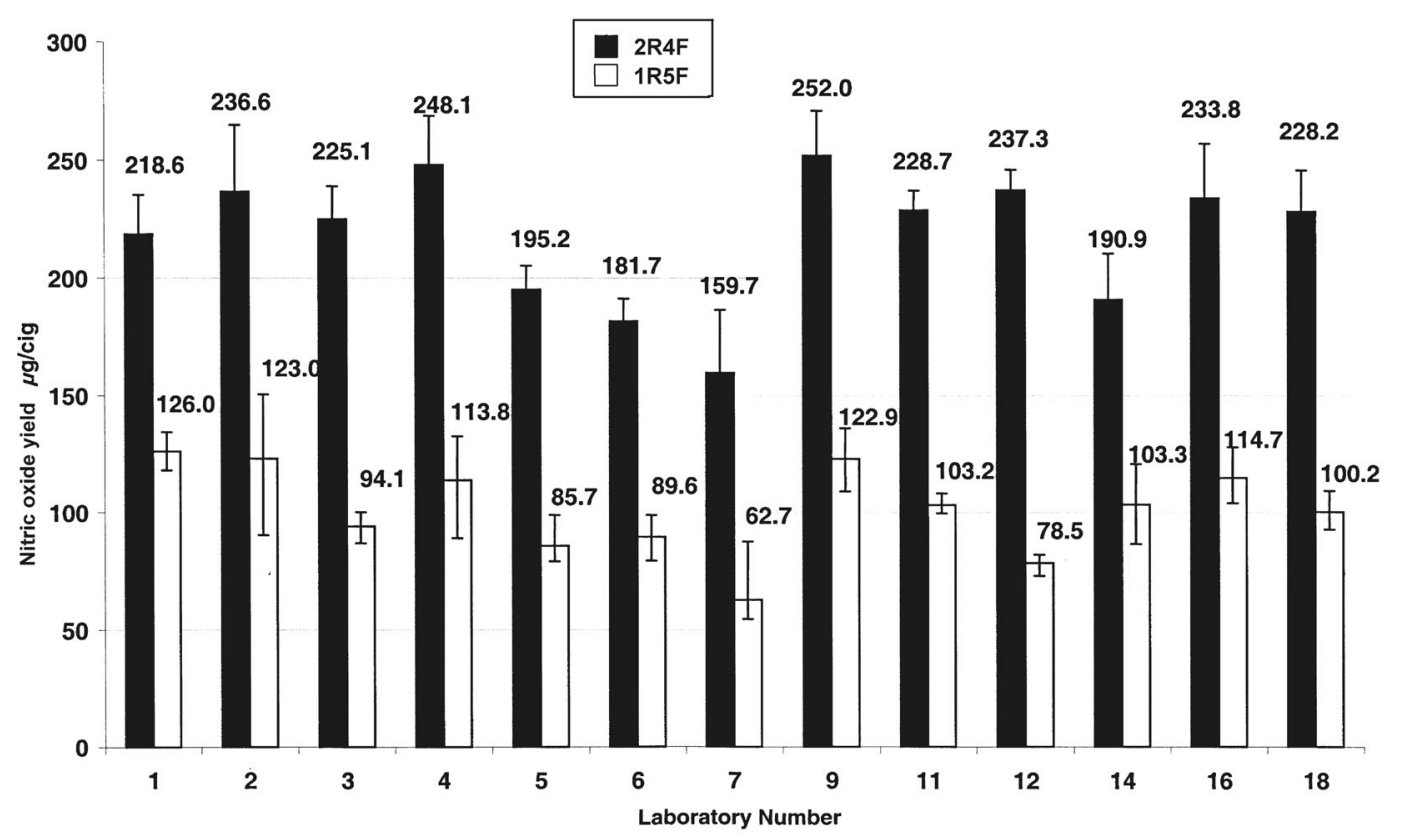

Figure A19. Nitric oxide yields ( $\mu \mathrm{g} / \mathrm{cig}$ ) obtained in different laboratories for 2R4F and 1R5F cigarettes. Error bars give the maximum and minimum yields given by a laboratory expressed as an average of all replicates. 
Appendix 32. Overview of phenolics methodology

Table A19. Phenolics methodology (BSTFA = bis(trimethylsilyl)trifluoroacetamide; TMCS = trimethylchlorosilane; PDA = photo diode array; HPLC = high performance liquid chromatography; GC-MS = gas chromatography-mass spectrometry; SIM = single ion monitoring)

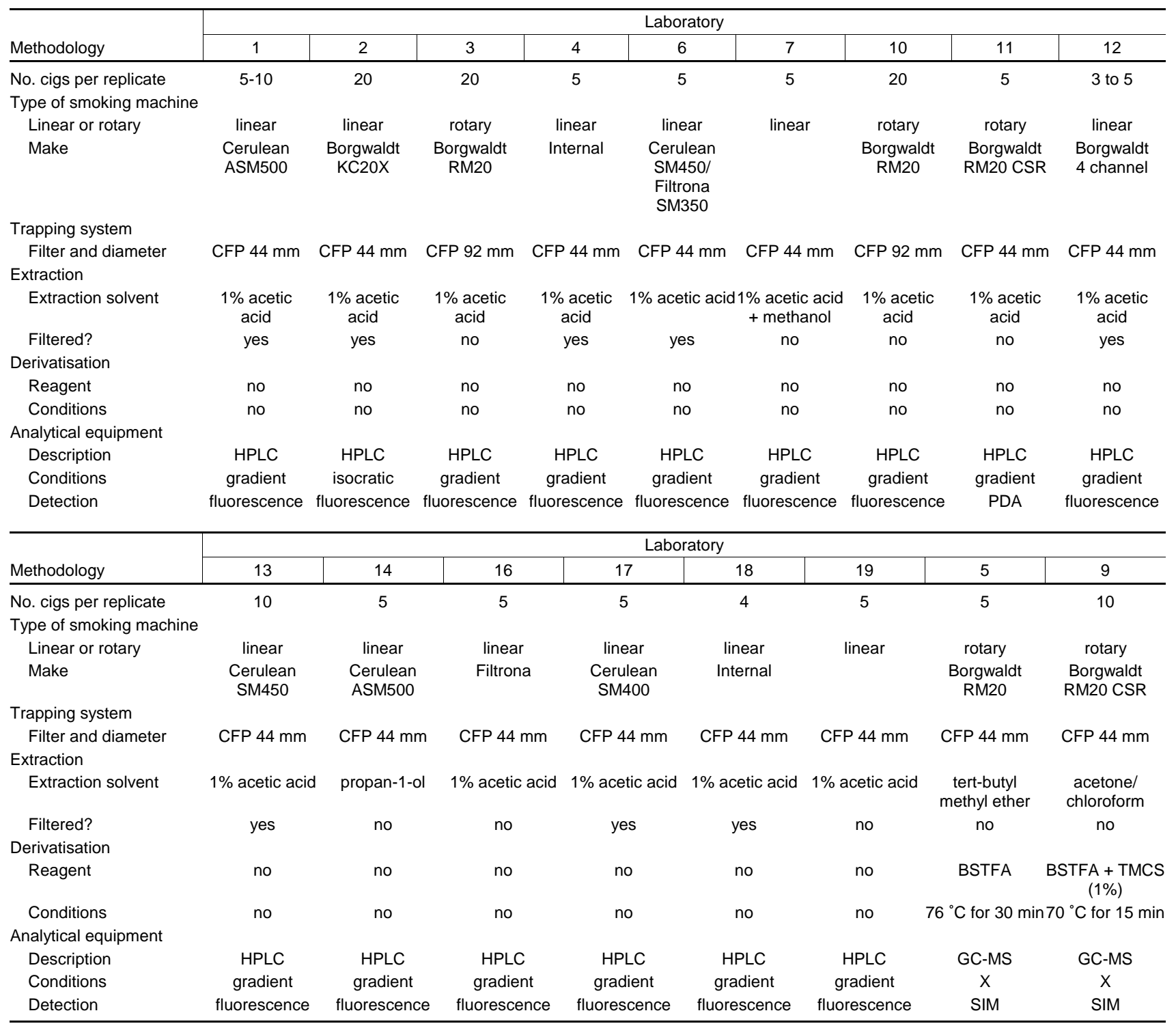


Appendix 33. Yields of phenolics
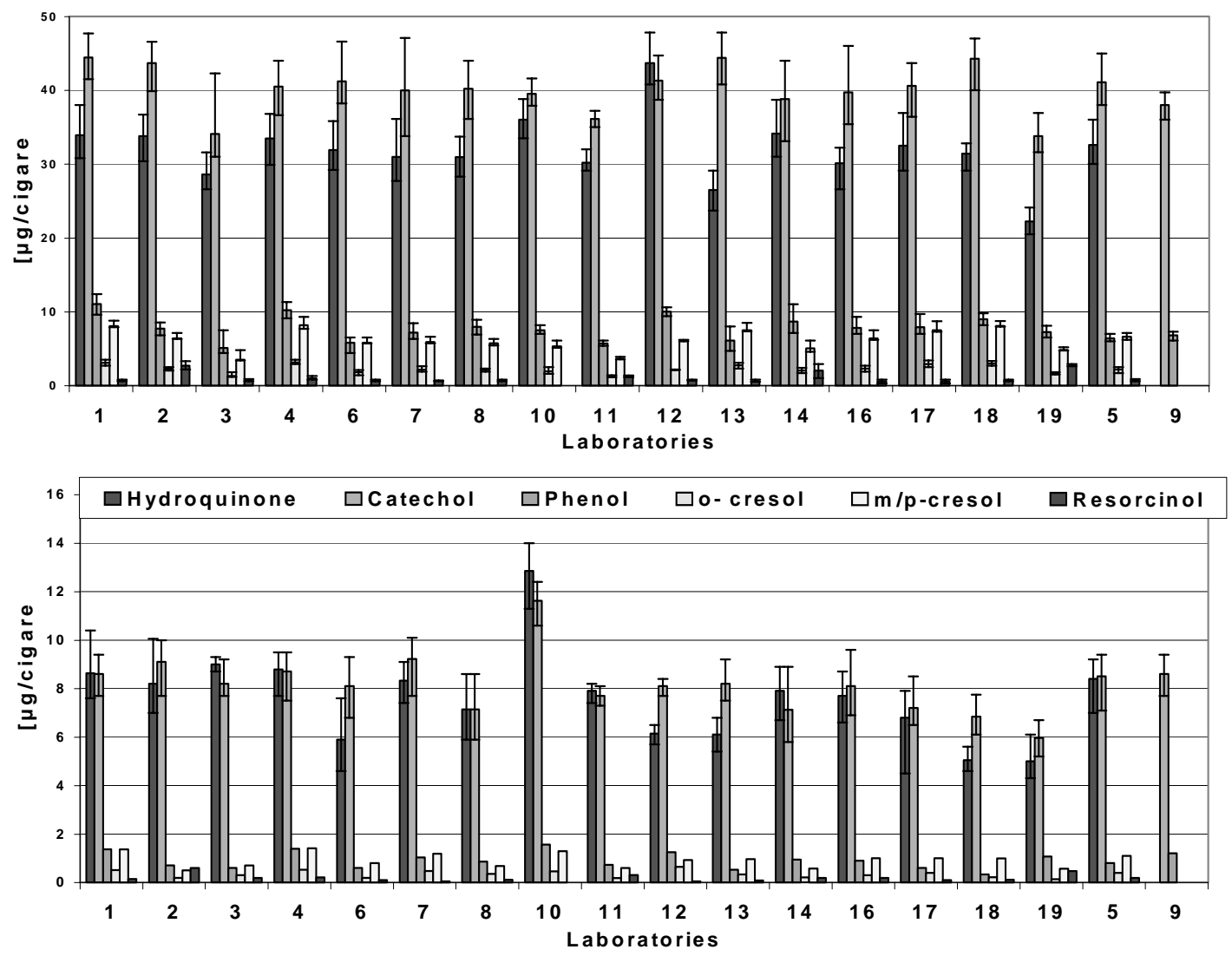

Figure A20. Phenolics yields (hydroquinone, catechol, phenol, o-cresol, $\mathrm{m} / \mathrm{p}$-cresol, resorcinol) obtained in different laboratories for $2 \mathrm{R} 4 \mathrm{~F}$ and $1 \mathrm{R} 5 \mathrm{~F}$ cigarettes. Laboratories 5 and 9 carried out BSTFA derivatisation. Error bars give the maximum and minimum yields given by a laboratory expressed as an average of all replicates

Appendix 34. Ratio patterns of phenolics

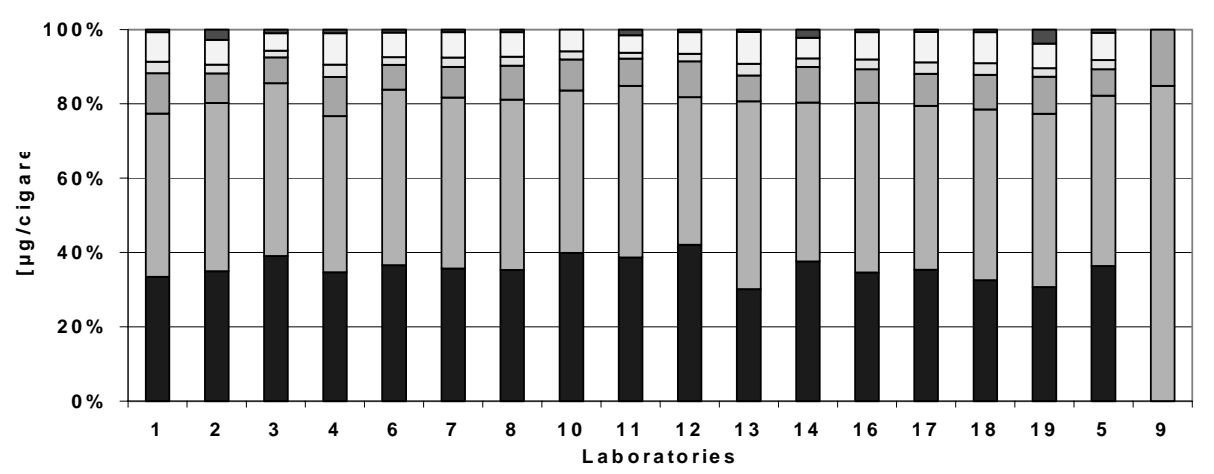

2R4F

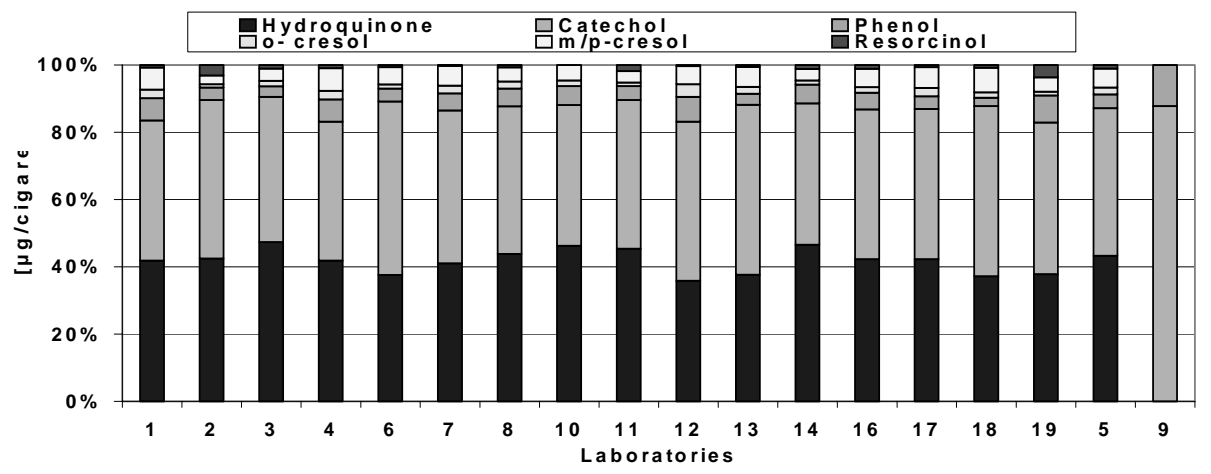

1R5F

Figure A21. Ratio patterns of phenolics (hydroquinone, catechol, phenol, $o$-cresol, $m / p$-cresol, resorcinol) obtained in different laboratories for $2 \mathrm{R} 4 \mathrm{~F}$ and 1 R5F cigarettes. The yields of the six phenolics were summed together and expressed as individual percentages of the total yield as yield ratios. 
Appendix 35. Minor phenolic yields

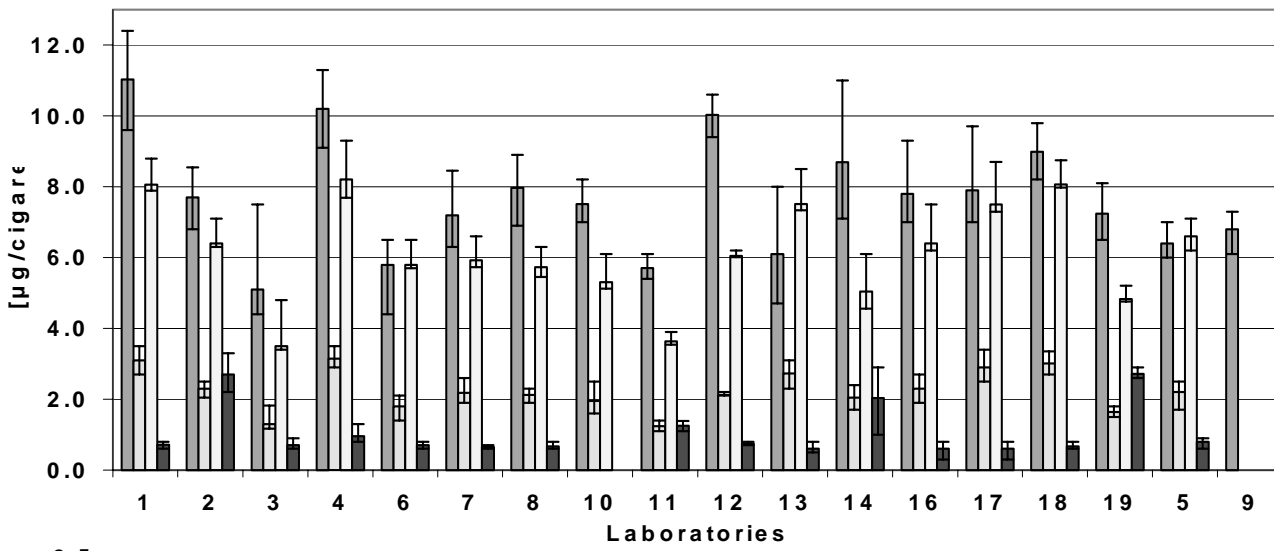

2R4F

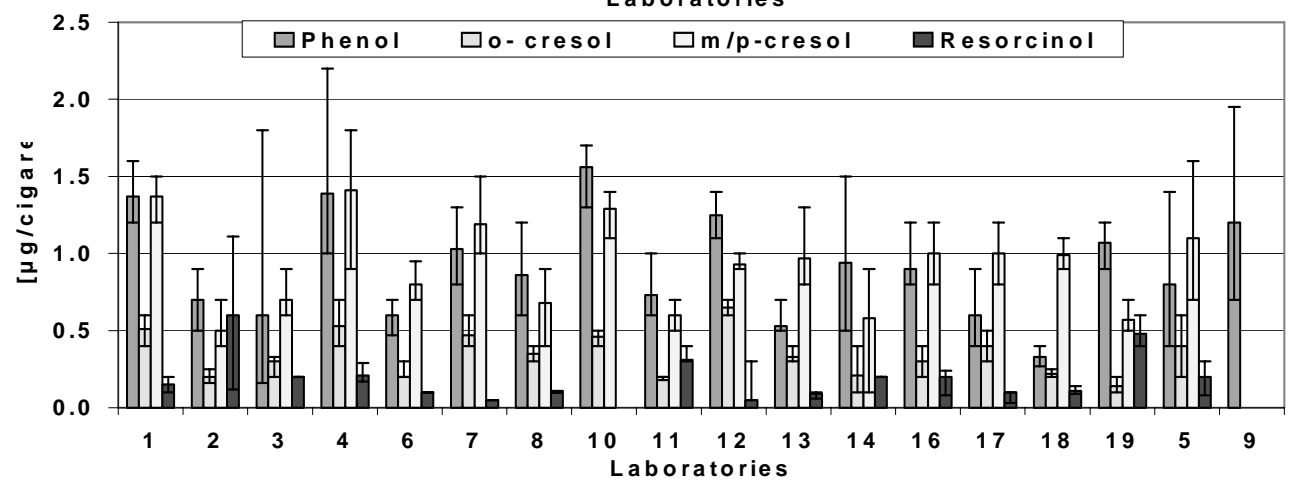

$1 R 5 F$

Figure A22. Minor phenolic yields (phenol, $o$-cresol, $m / p$-cresol, resorcinol) obtained in different laboratories for 2R4F and 1 R5F cigarettes. Error bars indicate the maximum and minimum yields given by a laboratory expressed as an average of all replicates.

Appendix 36 - Ratio patterns of minor phenolics

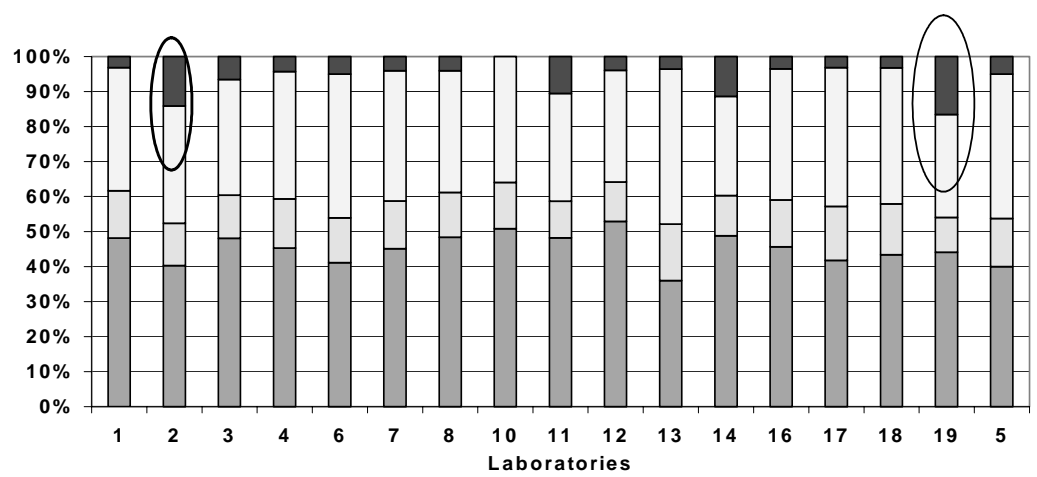

2R4F

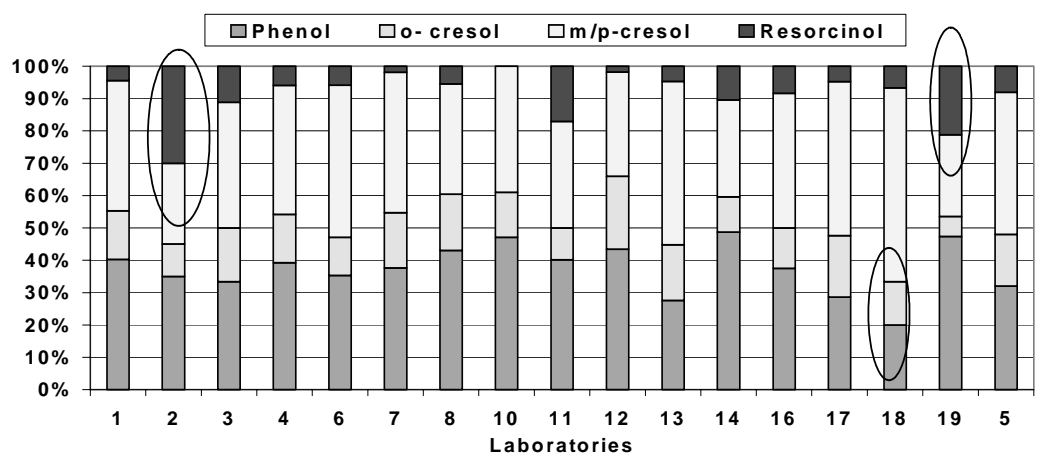

1R5F

Figure A23. Ratio patterns of minor phenolics (phenol, o-cresol, $m / p$-cresol, resorcinol) for $2 \mathrm{R} 4 \mathrm{~F}$ and $1 \mathrm{R} 5 \mathrm{~F}$ cigarettes. The yields of the four minor phenolics were summed together and expressed as individual percentages of the total yield as yield ratios. Some differences in patterns between $2 \mathrm{R} 4 \mathrm{~F}$ and $1 \mathrm{R} 5 \mathrm{~F}$, see laboratories 2, 18 and 19 . 
Appendix 37. Overview of methodology for selected volatiles

Table A20. Methodology for selected volatiles ( $\mathrm{EI}=$ electron ionization; FID = flame ionization detection; $\mathrm{SIM}=$ single ion monitoring)

\begin{tabular}{|c|c|c|c|c|c|c|c|c|c|c|c|}
\hline \multirow[b]{2}{*}{ Methodology } & \multicolumn{11}{|c|}{ Laboratory } \\
\hline & 1 & 11 & 1 & \multicolumn{2}{|c|}{2} & \multicolumn{2}{|c|}{4} & 5 & $6 \mathrm{~A}$ & $6 \mathrm{~B}$ & 7 \\
\hline & 20 & 20 & $5-10$ & 1 & & 10 & & 5 & & 20 & 5 \\
\hline \multicolumn{12}{|l|}{ Type of smoking machine } \\
\hline Linear or rotary & rotary & rotary & rotary & \multicolumn{2}{|c|}{ linear } & \multicolumn{2}{|c|}{ rotary } & rotary & rotary & linear & \multirow[t]{2}{*}{ linear } \\
\hline Make & $\begin{array}{l}\text { Borgwaldt } \\
\text { RM20 }\end{array}$ & $\begin{array}{l}\text { Borgwaldt } \\
\text { RM200 }\end{array}$ & $\begin{array}{l}\text { Borgwaldt } \\
\text { RM20 }\end{array}$ & \multicolumn{2}{|c|}{$\begin{array}{l}\text { Borgwaldt } \\
\text { KC20X }\end{array}$} & \multicolumn{2}{|c|}{$\begin{array}{l}\text { Borgwaldt } \\
\text { RM20 }\end{array}$} & $\begin{array}{l}\text { Borgwaldt } \\
\text { RM20 }\end{array}$ & $\begin{array}{l}\text { Borgwaldt } \\
\text { RM20CSR }\end{array}$ & $\begin{array}{l}\text { Borgwaldt } \\
\text { RM20 CSR }\end{array}$ & \\
\hline \multicolumn{12}{|l|}{ Trapping system } \\
\hline Filter and diameter & $x \quad 0$ & CFP 92 mm & CFP 92 mm & \multicolumn{2}{|c|}{ CFP 92 mm } & \multicolumn{2}{|c|}{ CFP 92 mm } & CFP 44 mm & CFP $92 \mathrm{~mm}$ & CFP 92 mm & CFP $44 \mathrm{~mm}$ \\
\hline Trapping & $\begin{array}{c}\text { glass syringe } \\
\text { individual puffs } \\
\text { RT }\end{array}$ & $1 \mathrm{Imp}$ & $\begin{array}{l}1 \mathrm{Imp} \\
70^{\circ} \mathrm{C}\end{array}$ & $\begin{array}{r}2 \mathrm{Ir} \\
-70\end{array}$ & & $\begin{array}{l}2 \operatorname{In} \\
-70\end{array}$ & & $\begin{array}{c}1 \text { Tedlar } k \\
\text { RT }\end{array}$ & $4 \operatorname{Imp}$ & $\begin{array}{c}\text { Tedlar bag } \\
\text { RT }\end{array}$ & $\begin{array}{l}1 \mathrm{Imp} \\
-70^{\circ} \mathrm{C}\end{array}$ \\
\hline Trapping solvent & no & methanol & ethanol & meth & anol & meth & & no & methanol & methanol & methanol \\
\hline Extraction & & & & & & & & & & & \\
\hline Filtration step & no & no & no & $\mathrm{n}$ & & nc & & no & no & no & no \\
\hline Clean-up & & & & & & & & & & & \\
\hline Column clean-up step & no & no & no & ye & & nc & & no & no & no & no \\
\hline Analytical equipment & & & & & & & & & & & \\
\hline Description & GC & GC & C-MS & GC- & MS & GC-1 & & GC-MS & & C-MS & GC-MS \\
\hline Detection system & FID & FID & SIM & $\mathrm{M}$ & & SII & & SIM & & SIM & MS-EI \\
\hline & & & & & & Labc & atory & & & & \\
\hline Methodology & 9 & 10 & 12 & & & 13 & & 16 & 17 & 18 & 19 \\
\hline No. cigs per replicate & 10 & 10 & 10 & & & 10 & & 10 & 10 or 20 & 5 & 10 \\
\hline Type of smoking machine & & & & & & & & & & & \\
\hline Linear or rotary & rotary & rotary & rota & & & tary & & rotary & rotary & linear & linear \\
\hline Make & $\begin{array}{c}\text { Borgwaldt } \\
20 \text {-port }\end{array}$ & $\begin{array}{l}\text { Borgwaldt } \\
\text { RM20CSR }\end{array}$ & $\begin{array}{r}\text { Borgn } \\
\mathrm{RM} 20 / \mathrm{R}\end{array}$ & $\begin{array}{l}\text { aldt } \\
\mathrm{M} 2 \mathrm{OH}\end{array}$ & $\begin{array}{r}\text { Borg } \\
\text { R }\end{array}$ & $\begin{array}{l}\text { ywaldt } \\
\text { M20 }\end{array}$ & & $\begin{array}{l}\text { rgwaldt } \\
\text { M20CS }\end{array}$ & $\begin{array}{l}\text { Borgwaldt } \\
\text { RM20CSR }\end{array}$ & & $\begin{array}{l}\text { Borgwaldt } \\
\text { KC } 5 \text { port }\end{array}$ \\
\hline Trapping system & & & & & & & & & & & \\
\hline Filter and diameter & CFP $44 \mathrm{~mm}$ & CFP $92 \mathrm{~mm}$ & CFP 4 & $\mathrm{~mm}$ & CFP & $92 \mathrm{~mm}$ & CFP & 92 mm & CFP $92 \mathrm{~mm}$ & CFP $44 \mathrm{~mm}$ & CFP $44 \mathrm{~mm}$ \\
\hline Traping & $\begin{array}{c}3 \operatorname{Imp} \\
-78^{\circ} \mathrm{C}\end{array}$ & $\begin{array}{c}2 \operatorname{Imp} \\
0^{\circ} \mathrm{C} ;-70^{\circ} \mathrm{C}\end{array}$ & $3 \mathrm{Im}$ & & & $\begin{array}{l}\operatorname{lmp} \\
0{ }^{\circ} \mathrm{C}\end{array}$ & & $\begin{array}{l}1 \mathrm{Imp} \\
70^{\circ} \mathrm{C}\end{array}$ & $\begin{array}{l}1 \mathrm{Imp} \\
-70^{\circ} \mathrm{C}\end{array}$ & $1 \operatorname{Imp}$ & $\begin{array}{c}1 \mathrm{Imp} \\
-70^{\circ} \mathrm{C}\end{array}$ \\
\hline Trapping solvent & methanol & methanol & methe & anol & metl & hanol & & ethanol & ethanol & methanol & methanol \\
\hline Extraction & & & & & & & & & & & \\
\hline Filtration step & no & no & yes & & & רo & & no & no & no & no \\
\hline Clean-up & & & & & & & & & & & \\
\hline Column clean-up step & no & no & no & & & רo & & no & no & no & no \\
\hline Analytical equipment & & & & & & & & & & & \\
\hline Description & GC & GC-MS & GC-I & & GC & -MS & & C-MS & GC-FID & GC-MS & GC-MS \\
\hline Detection system & MS & SIM & MS & & & $\mathrm{IM}$ & $\begin{array}{l}\text { MS } \\
\text { pos }\end{array}$ & $\begin{array}{l}\text { ion trap } \\
\text { sitive El }\end{array}$ & FID & SIM & MS \\
\hline
\end{tabular}


Appendix 38. Overview of selected volatiles yields (1,3-butadiene, isoprene, acrylonitrile, benzene, toluene)
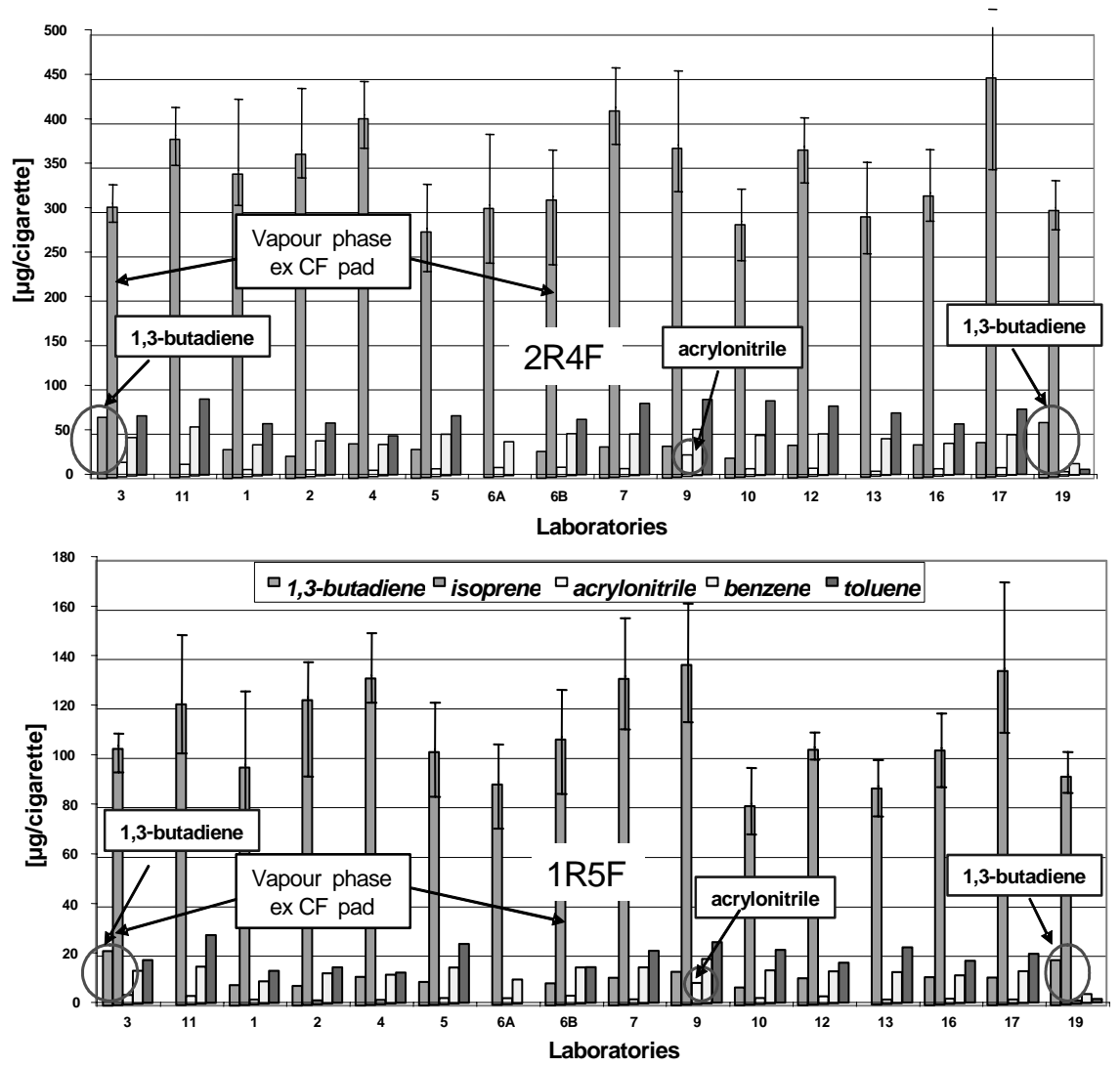

Figure A24. Selected volatiles yields ( $\mu \mathrm{g} / \mathrm{cig}$ ) (1,3-butadiene, isoprene, acrylonitrile, benzene, toluene) for 2R4F and 1R5F cigarettes. Error bars give the maximum and minimum yields given by a laboratory expressed as an average of all replicates.

Appendix 39. Ratio of patterns of selected volatiles (1,3-butadiene, isoprene, acrylonitrile, benzene, toluene)

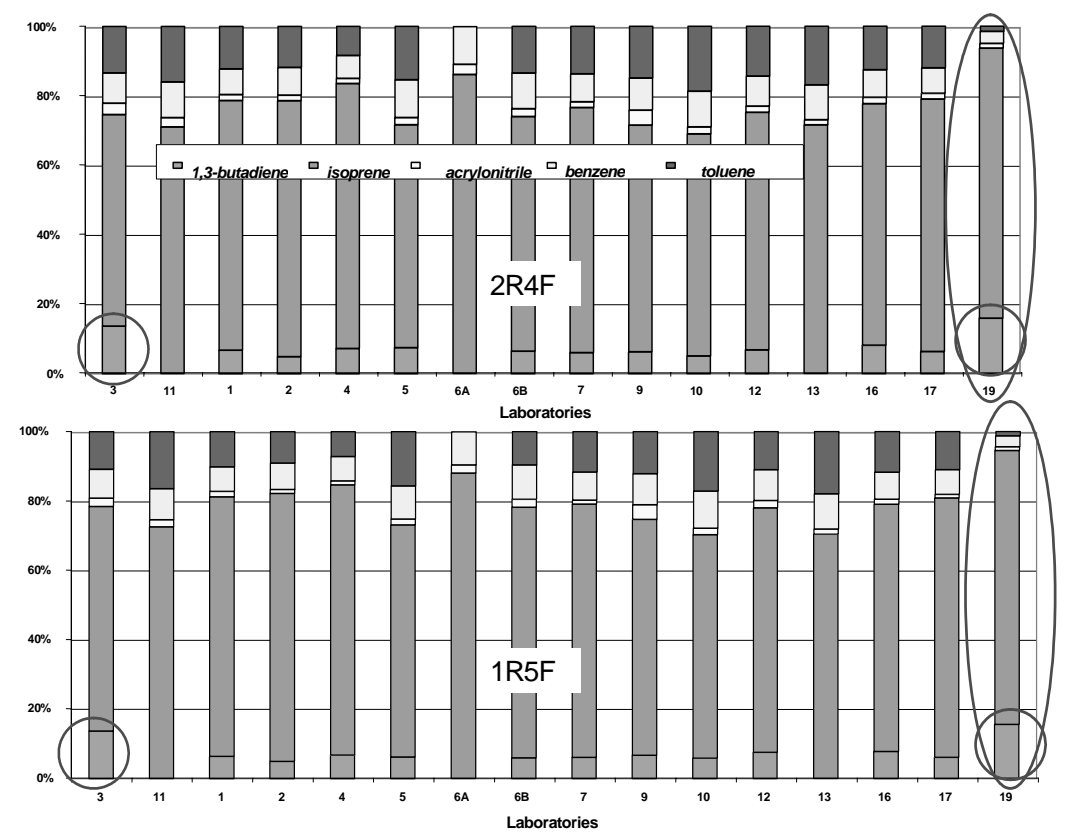

Figure A25. Ratio of patterns of selected volatiles (1,3-butadiene, isoprene, acrylonitrile, benzene, toluene) for 2R4F and 1R5F cigarettes. The yields of the five selected volatiles were summed together and expressed as individual percentages of the total yield as yield ratios. Major differences are highlighted. 
Appendix 40. Overview of styrene methodology

Table A21. Styrene methodology $(\mathrm{EI}=$ electron ionization; FID = flame ionization detection; GC-MS = gas chromatography-mass spectrometry; SIM = single ion monitoring)

\begin{tabular}{|c|c|c|c|c|c|c|c|c|c|}
\hline \multirow[b]{2}{*}{ Methodology } & \multicolumn{9}{|c|}{ Laboratory } \\
\hline & 3 & 5 & 1 & \multicolumn{2}{|l|}{4} & 7 & 9 & 10 & 11 \\
\hline No. cigs per replicate & 20 & 20 & $5-10$ & \multicolumn{2}{|l|}{20} & 5 & 10 & 20 & \multirow[t]{2}{*}{20} \\
\hline \multicolumn{9}{|l|}{ Type of smoking machine } & \\
\hline Linear or rotary & rotary & rotary & rotary & \multicolumn{2}{|c|}{ linear } & linear & rotary & rotary & rotary \\
\hline Make & $\begin{array}{l}\text { Borgwaldt } \\
\text { RM20 }\end{array}$ & $\begin{array}{l}\text { Borgwaldt } \\
\text { RM200 }\end{array}$ & $\begin{array}{l}\text { Borgwaldt } \\
\text { RM20 }\end{array}$ & \multicolumn{2}{|c|}{$\begin{array}{l}\text { Borgwaldt } \\
\text { RM20 }\end{array}$} & & $\begin{array}{l}\text { Borgwaldt } \\
20 \text {-port }\end{array}$ & $\begin{array}{l}\text { Borgwaldt } \\
\text { RM20CSR }\end{array}$ & $\begin{array}{l}\text { Borgwaldt } \\
\text { RM200 }\end{array}$ \\
\hline \multicolumn{10}{|l|}{ Trapping system } \\
\hline Filter and diameter & CFP 92 mm & CFP $44 \mathrm{~mm} \mathrm{CF}$ & CFP $92 \mathrm{~mm}$ & \multicolumn{2}{|c|}{ CFP 92 mm } & CFP $44 \mathrm{~mm}$ & \multirow{2}{*}{$\begin{array}{l}\text { CFP } 44 \mathrm{~mm} \\
\quad 3 \mathrm{Imp}\end{array}$} & CFP $92 \mathrm{~mm}$ & CFP $92 \mathrm{~mm}$ \\
\hline Trapping & glass syringe & $\begin{array}{l}1 \mathrm{XAD}-4 \\
\text { sorbent tube }\end{array}$ & $1 \operatorname{Imp}$ & \multicolumn{2}{|c|}{$2 \operatorname{Imp}$} & $1 \mathrm{Imp}$ & & 2 Imp & $1 \mathrm{Imp}$ \\
\hline Trapping solvent & $\begin{array}{l}\text { styrene not } \\
\text { extraxted from CFP }\end{array}$ & methanol & methanol & metha & & methanol & methanol & methanol & methanol \\
\hline Extraction & & & & & & & & & \\
\hline Filtration step & no & no & no & no & & no & no & no & no \\
\hline Clean-up & & & & & & & & & \\
\hline Column clean-up step & no & no & no & no & & no & no & no & no \\
\hline Analytical equipment & & & & & & & & & \\
\hline Description & $\mathrm{GC}$ & GC-MS & GC-MS & GC-N & & GC-MS & $\mathrm{GC}$ & GC-MS & GC \\
\hline Detection system & FID & SIM & SIM & SIN & & MS-EI & MS & SIM & FID \\
\hline & & & & & Lab & oratory & & & \\
\hline Methodology & 12 & 13 & & 4 & & 16 & 17 & 18 & 19 \\
\hline No. cigs per replicate & 10 & 20 & & 5 & & 20 & 10 or 20 & 5 & 10 \\
\hline Type of smoking machine & & & & & & & & & \\
\hline Linear or rotary & rotary & rotary & & ear & & otary & rotary & linear & linear \\
\hline Make & $\begin{array}{c}\text { Borgwaldt } \\
\text { RM20/RM20H }\end{array}$ & $\begin{array}{l}\text { Borgwaldt } \\
\text { RM20 }\end{array}$ & $\begin{array}{r}\text { KC Aut } \\
5-p\end{array}$ & $\begin{array}{l}\text { omation } \\
\text { oort }\end{array}$ & Bor & rgwaldt & $\begin{array}{l}\text { Borgwaldt } \\
\text { RM20CSR }\end{array}$ & Internal & $\begin{array}{l}\text { Borgwaldt } \\
\text { RM200 }\end{array}$ \\
\hline Trapping system & & & & & & & & & \\
\hline Filter and diameter & CFP 44 mm & CFP $92 \mathrm{~mm}$ & CFP & $44 \mathrm{~mm}$ & CFP & $92 \mathrm{~mm}$ & CFP $92 \mathrm{~mm}$ & CFP $44 \mathrm{~mm}$ & CFP $44 \mathrm{~mm}$ \\
\hline Trapping & 3 liquid impingers & 2 Imp & & $\mathrm{mp}$ & & Imp & $1 \mathrm{Imp}$ & $1 \mathrm{Imp}$ & no \\
\hline Trapping solvent & methanol & methanol & meth & nanol & me & thanol & methanol & methanol & methanol \\
\hline Extraction & & & & & & & & & \\
\hline Filtration step & yes & no & $\mathrm{n}$ & 10 & & yes & yes & no & no \\
\hline Clean-up & & & & & & & & & \\
\hline Column clean-up step & no & no & $\mathrm{n}$ & 10 & & no & no & no & no \\
\hline Analytical equipment & & & & & & & & & \\
\hline Description & GC-MS & GC-MS & $\mathrm{GC}$ & -MS & & C-MS & GC-FID & GC-MS & GC-MS \\
\hline Detection system & MS & SIM & $\mathrm{S}$ & IM & $\begin{array}{c}\text { MS } \\
\text { pos }\end{array}$ & $\begin{array}{l}\text { ion trap } \\
\text { itive El }\end{array}$ & FID & SIM & MS \\
\hline
\end{tabular}

Appendix 41. Styrene yields

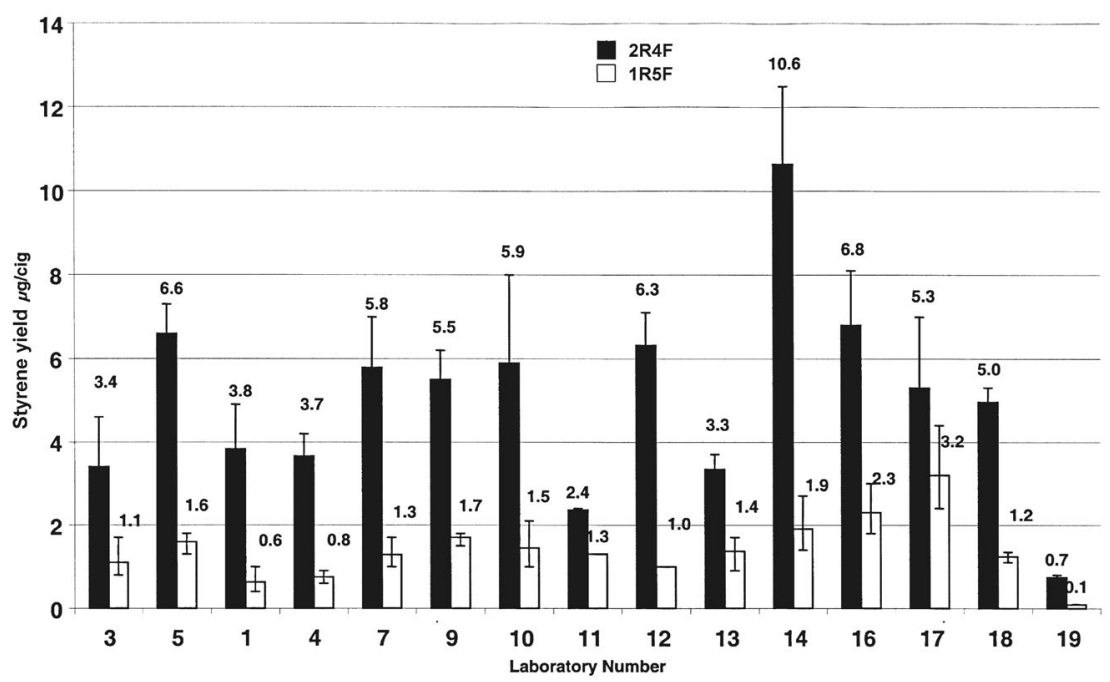

Figure A26. Styrene yields ( $\mu \mathrm{g} / \mathrm{cig}$ ) for $2 \mathrm{R} 4 \mathrm{~F}$ and $1 \mathrm{R} 5 \mathrm{~F}$ cigarettes. Error bars give the maximum and minimum yields given by a laboratory expressed as an average of all replicates. Data at limit of quantification/detection (LOQ/LOD) was set at LOQ/2 just for this graphical analysis. 
Appendix 42. Overview of semi-volatiles methodology

Table A22. Overview of semi-volatiles methodology $(E I=$ electron ionization; FID = flame ionization detection; $M S=$ mass spectrometry; SIM = single ion monitoring)

\begin{tabular}{|c|c|c|c|c|c|c|c|c|}
\hline \multirow[b]{2}{*}{ Methodology } & \multicolumn{8}{|c|}{ Laboratory } \\
\hline & 8 & 10 & 11 & 12 & 13 & 16 & 17 & 19 \\
\hline No. cigs per replicate & 20 & 10 & 20 & 10 & 20 & 20 & 10 or 20 & 20 \\
\hline \multicolumn{9}{|c|}{ Type of smoking machine } \\
\hline Linear or rotary & linear & rotary & rotary & rotary & rotary & rotary & rotary & linear \\
\hline Make & $\begin{array}{c}\text { Filtrona } \\
20 \text {-prt }\end{array}$ & $\begin{array}{l}\text { Borgwaldt } \\
\text { RM20CSR }\end{array}$ & $\begin{array}{l}\text { Borgwaldt } \\
\text { RM200 }\end{array}$ & $\begin{array}{c}\text { Borgwaldt } \\
\text { RM20/RM20H }\end{array}$ & $\begin{array}{l}\text { Borgwaldt } \\
\text { RM20 }\end{array}$ & Borgwaldt & $\begin{array}{l}\text { Borgwaldt } \\
\text { RM20CSR }\end{array}$ & $n / p$ \\
\hline \multicolumn{9}{|l|}{ Trapping system } \\
\hline Filter and diameter & CFP 44 mm & CFP 92 mm & CFP 92 mm & CFP $44 \mathrm{~mm}$ & CFP $92 \mathrm{~mm}$ & CFP 92 mm & CFP $92 \mathrm{~mm}$ & CFP $44 \mathrm{~mm}$ \\
\hline Trapping & $1 \mathrm{Imp}$ & $2 \operatorname{Imp}$ & \multirow{2}{*}{$\begin{array}{c}1 \text { Imp } \\
\text { methanol }\end{array}$} & \multirow{2}{*}{$\begin{array}{c}3 \text { Imp } \\
\text { methanol }\end{array}$} & \multirow{2}{*}{$\begin{array}{c}2 \text { Imp } \\
\text { methanol }\end{array}$} & \multirow{2}{*}{$\begin{array}{c}2 \text { Imp } \\
\text { methanol }\end{array}$} & $1 \operatorname{Imp}$ & $2 \operatorname{Imp}$ \\
\hline Solvent & $\begin{array}{l}\text { methanol/ } \\
\text { triethyl amine }\end{array}$ & methanol & & & & & methanol & methanol \\
\hline Additional filtration & no & no & \multirow[t]{2}{*}{ no } & \multirow[t]{2}{*}{ yes } & no & yes & yes & yes \\
\hline Analytical equipment & & & & & & & & \\
\hline Detection system & $n / p$ & SIM & FID & MS & SIM & MS (ion trap) & FID & MS \\
\hline & & & & & boratory & & & \\
\hline Methodology & 5 & 14 & & 18 & 1 & 4 & 6 & 7 \\
\hline No. cigs per replicate & 5 & 5 & & 5 & $5-10$ & 20 & 10 & 5 \\
\hline Type of smoking mach & & & & & & & & \\
\hline Linear or rotary & rotary & linear & & linear & linear & rotary & rotary & linear \\
\hline Make & $\begin{array}{l}\text { Borgwaldt } \\
\text { RM20 }\end{array}$ & $\begin{array}{l}\text { Cerulean } \\
\text { ASM500 }\end{array}$ & & Internal & $\begin{array}{l}\text { Cerulean } \\
\text { SM450 }\end{array}$ & $\begin{array}{l}\text { Borgwaldt } \\
\text { RM20 }\end{array}$ & $\begin{array}{l}\text { Borgwaldt } \\
\text { RM20CSR }\end{array}$ & KC10 \\
\hline Trapping system & & & & & & & & \\
\hline Filter and diameter & CFP $44 \mathrm{~mm}$ & CFP $44 \mathrm{~mm}$ & & $\mathrm{P} 44 \mathrm{~mm}$ & CFP $44 \mathrm{~mm}$ & CFP 92 mm & CFP 44 mm & CFP $44 \mathrm{~mm}$ \\
\hline Trapping & $\begin{array}{c}1 \mathrm{XAD}-4 \\
\text { sorbent tuibe }\end{array}$ & $\begin{array}{c}1 \mathrm{XAD}-4 \\
\text { connected to } \mathrm{CP}\end{array}$ & F unit connec & $\begin{array}{l}\text { XAD-4 } \\
\text { ted to CF unit }\end{array}$ & $1 \mathrm{Imp}$ & $2 \operatorname{Imp}$ & $\begin{array}{c}2 \text { CFPs; } \\
\text { acid pretreated }\end{array}$ & $1 \operatorname{Imp}$ \\
\hline Solvent & methanol & $\begin{array}{c}\text { methanol/hexa } \\
\text { trimethyl amir }\end{array}$ & $\begin{array}{l}\text { ane/ } \\
\text { ne }\end{array}$ & nethanol & methanol & methanol & methanol & $\begin{array}{c}\text { methanol/ } \\
\text { triethyl amine }\end{array}$ \\
\hline Additional filtration & no & no & & no & no & no & no & no \\
\hline Analytical equipment & & & & & & & & \\
\hline Detection system & SIM & SIM & & SIM & SIM & SIM & SIM & MS-EI \\
\hline
\end{tabular}

Appendix 43. Yields of semi-volatiles (pyridine, quinoline and styrene)
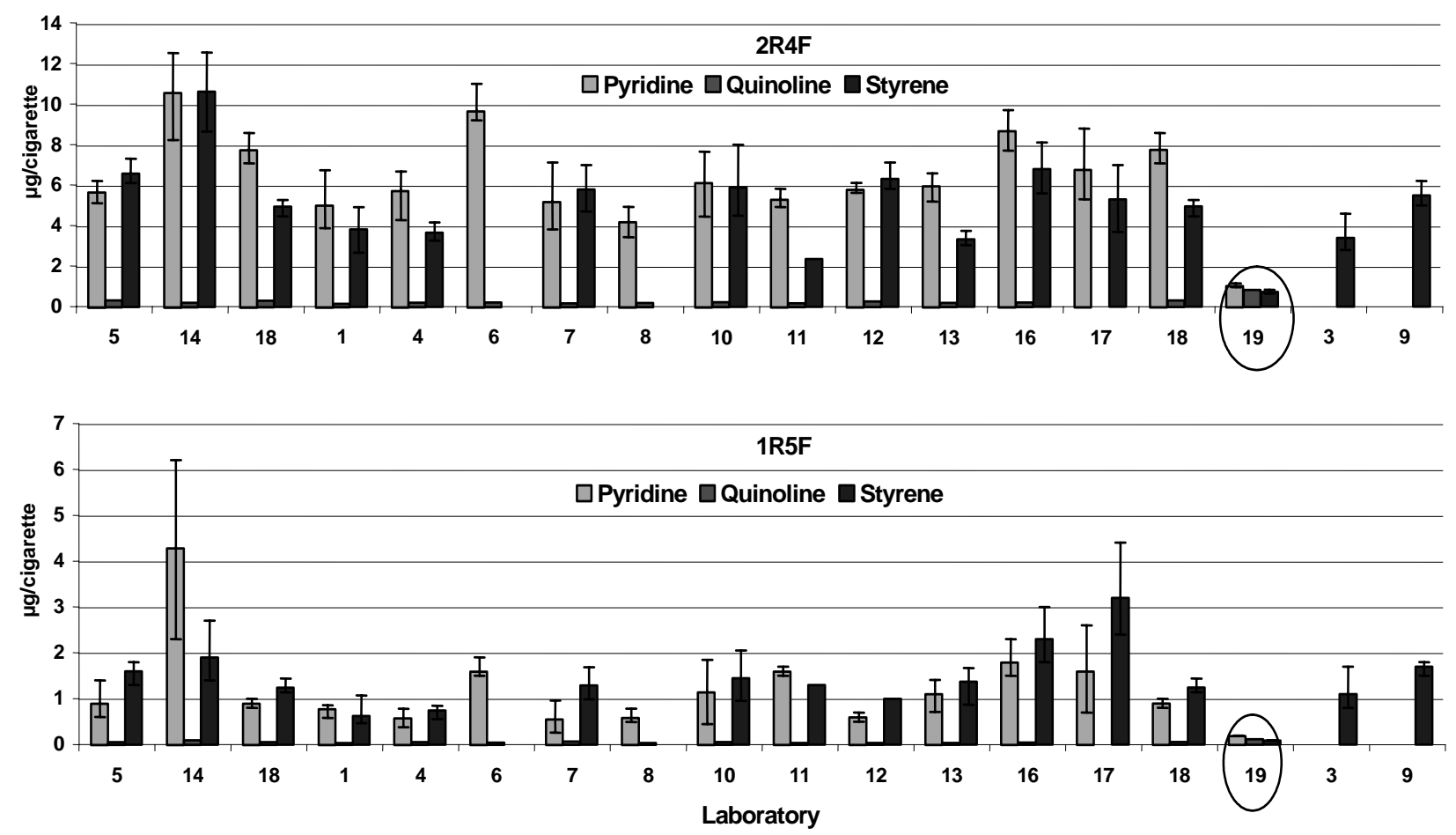

Figure A27. Yields of semi-volatiles ( $\mu \mathrm{g} / \mathrm{cig}$ ) (pyridine, quinoline and styrene) for 2R4F and 1R5F cigarettes. Error bars indicate the maximum and minimum yields given by a laboratory expressed as an average of all replicates 
Appendix 44. Overview of TSNA methodology

Table A23. TSNA methodology (GC-TEA = gas chromatography-thermal energy analyser; $M S$ = mass spectrometry)

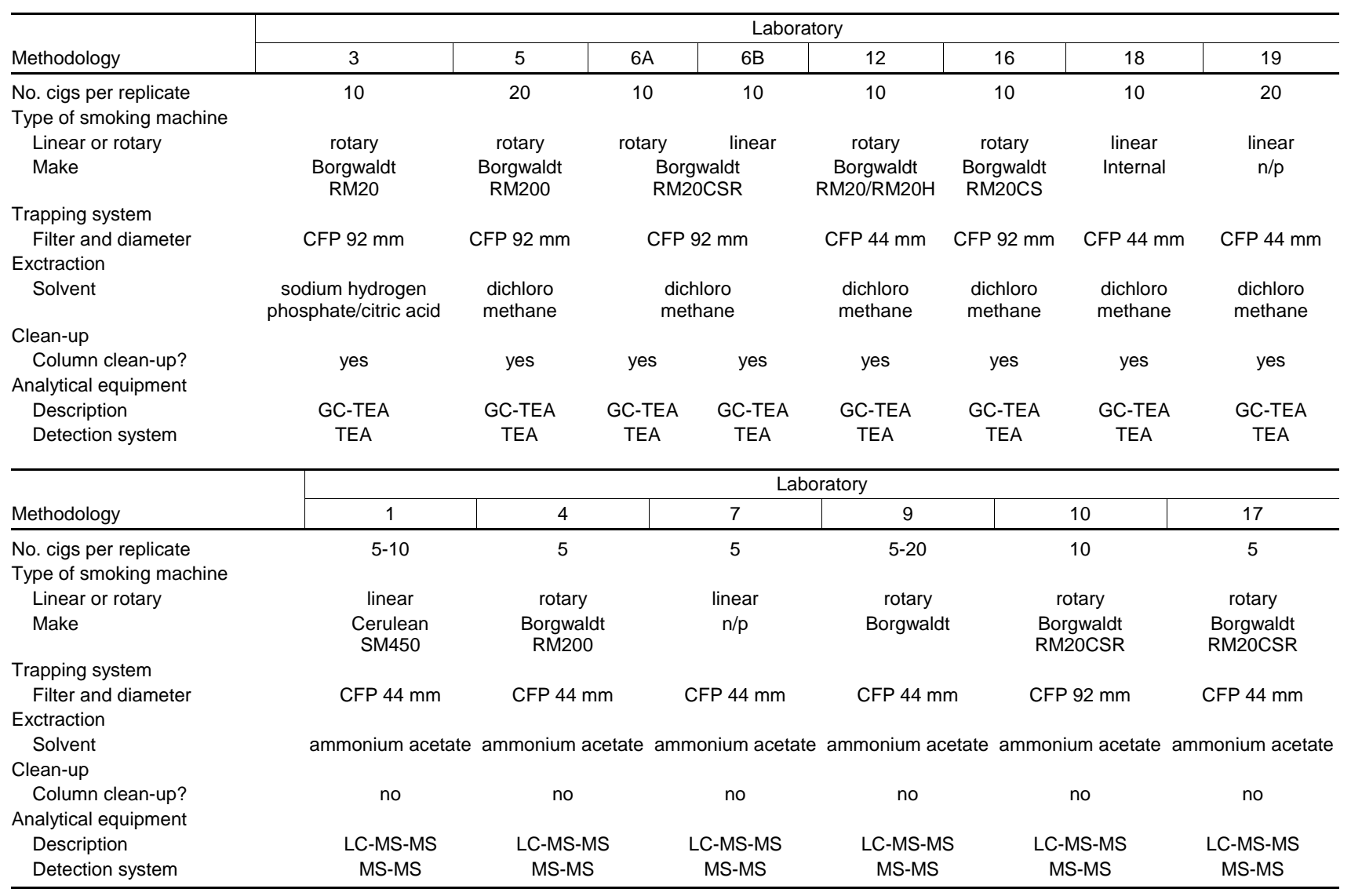

Appendix 45. Overview of TSNA yields (NNN $=N$-nitroso-nornicotine, $\mathrm{NNK}=$
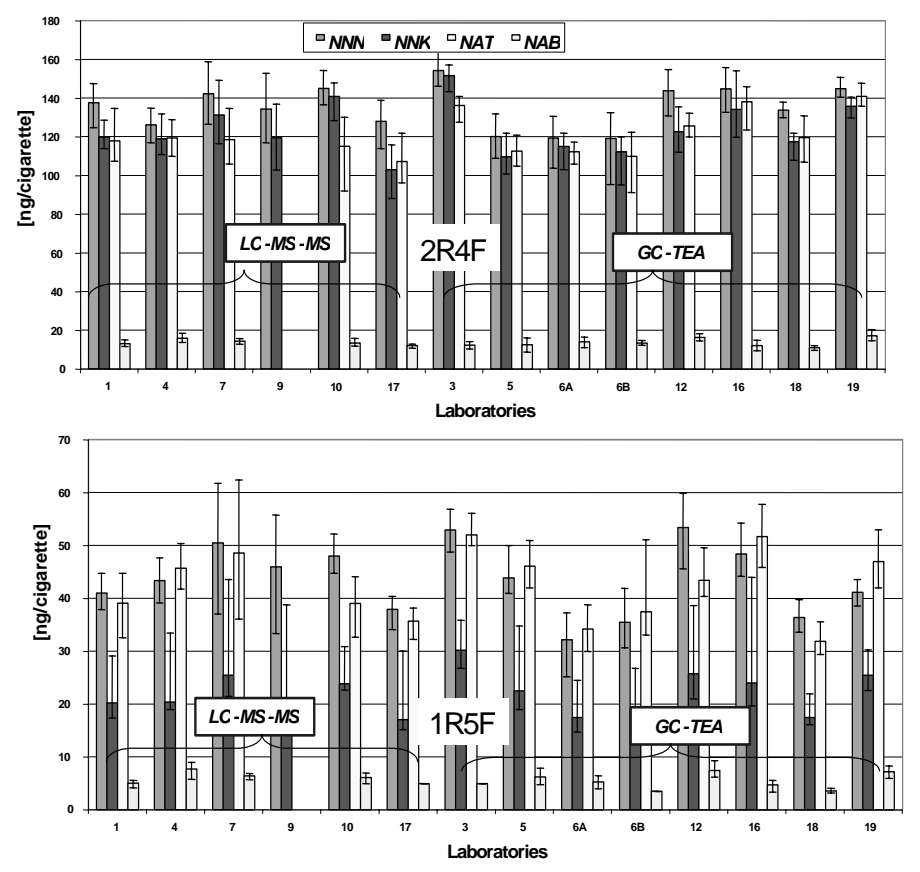

Figure A28. TSNA yields (ng/cig) (NNN, NNK, NAT, NAB) for 2R4F and 1R5F cigarettes. Error bars indicate the maximum and minimum yields given by a laboratory expressed as an average of all replicates (LC-MS-MS = liquid chromatography-mass spectrometry-mass spectrometry; GC-TEA = gas chromatography-thermal energy analyser). 